\title{
Function analysis of Xenopus NumbL in the context of primary neurogenesis
}

\author{
Dissertation \\ for the award of the degree \\ "Doctor rerum naturalium" \\ Division of Mathematics and Natural Sciences \\ of the Georg August University Göttingen \\ submitted by \\ Frank Nieber \\ from Celle, Germany \\ Göttingen 2010
}


Dr. Kristine A. Henningfeld

Department of Developmental Biochemistry, University of Göttingen

Prof. Dr. Ernst A. Wimmer

Department of Developmental Biology, University of Göttingen

Prof. Dr. Andreas Wodarz (Reviewer)

Department of Stem Cell Biology, University of Göttingen

Prof. Dr. Tomas Pieler (Reviewer)

Department of Developmental Biochemistry, University of Göttingen

Date of the oral examination: 


\section{Affidavit}

Herewith I declare that I prepared the PhD thesis "Function analysis of Xenopus NumbL in the context of primary neurogenesis" on my own and with no other sources and aids than quoted.

29.10.2010

Frank Nieber

Submission Date 


\section{List of Publications}

1. Frank Nieber, Tomas Pieler, Olaf Jahn, and Kristine A. Henningfeld. NumbL is essential for Xenopus primary neurogenesis and functions independent of Notch signaling. In preparation

2. Frank Nieber, Tomas Pieler, and Kristine A. Henningfeld. Comparative Expression Analysis of the Neurogenins in Xenopus tropicalis and Xenopus laevis. Dev Dyn. 2009 238:451-458 


\section{Table of Contents}

Table of Contents

I

Acknowledgements $\quad$ IV

List of Figures $\quad \mathrm{V}$

Abbreviations $\quad$ VII

1. Introduction

1.1 Neural Induction 1

1.2 Neuroectoderm maturation 4

1.3 Neuronal Differentiation 6

1.4 Lateral Inhibition 9

1.5 Numb as cell fate determinant in neurogenesis 11

1.6 Numb acts as scaffold protein 13

1.7 Numb and Numblike isoforms 14

1.8 Multiple functions of Numb 16

1.9 Regulation of Numb 16

1.10 Xenopus Numb and Numblike 17

$\begin{array}{ll}1.11 \text { Aims } & 18\end{array}$

2. Materials and Methods

a. Organisms

2.1.1 Xenopus laevis and Xenopus tropicalis 19

$\begin{array}{ll}\text { 2.1.2 Escherichia coli } & 19\end{array}$

2.2 Oligonucleotides

$\begin{array}{ll}\text { 2.2.1 RT-PCR oligonucleotides } & 19\end{array}$

$\begin{array}{ll}\text { 2.2.2 General oligonucleotides } & 21\end{array}$

$\begin{array}{ll}\text { 2.2.3 Morpholino oligonucleotides } & 21\end{array}$

2.3 Constructs

2.3.1 Overexpression $\quad 22$

2.3.2 Markers for whole mount in situ hybridization $\quad 27$ 
2.4 Total RNA extraction and cDNA synthesis

2.5 RT-PCR analysis

2.6 In vitro synthesis of RNA

2.6.1 Capped sense RNA

30

2.6.2 Antisense RNA

30

2.7 $\mathrm{T}_{\mathrm{N}} \mathrm{T}$ in vitro translation 30

2.8 Embryo culture and microinjections 31

2.9 X-Gal staining 32

2.10 Whole mount in situ hybridization 33

2.11 Phosphorylated Histone $3(\mathrm{pH} 3)$ staining 35

$\begin{array}{ll}2.12 \text { Sections } & 35\end{array}$

2.13 Fluorescent labeling of animal caps 36

2.14 Tandem affinity purification (TAP) 37

3. Results

3.1 Xenopus Numb isoforms switch during neural development 39

3.2 NumbL is expressed in the territories of primary neurogenesis 40

3.3 NumbL is positively regulated by Neurogenin 1-3 43

3.4 NumbL gain-of-function leads to an increase in neural tube size

3.5 NumbL knockdown does not activate the Notch pathway 46

3.6 Notch inhibition does not rescue NumbL knockdown

3.7 A knockdown of NumbL leads to an increase in neural progenitors

3.8 NumbL knockdown increases the number of mitotically active cells in the ectoderm at early gastrula stages

3.9 NumbL knockdown promotes neural crest formation at tailbud stages

3.10 Ngn expression patterns are disturbed in NumbL

morphants 
3.11 NumbL knockdown leads to an increase in early neural gene expression

3.12 Zic expression is increased in a Notch independent manner upon NumbL knockdown

3.13 Xenopus Numb and NumbL are located in the cytoplasm

3.14 NumbL interacts with the AP-2 complex

3.15 Interaction with the AP-2 complex is essential for NumbL function

4. Discussion

4.1 NumbL has a dual function during Xenopus primary neurogenesis

4.2 NumbL function during Xenopus primary neurogenesis is independent of Notch signaling

4.3 NumbL is localized in the cytoplasm and interacts with the AP-2 complex

6. Bibliography

7. Appendix 


\section{Acknowledgements}

I would like to thanks Prof. Pieler for providing me the opportunity to perform my PhD thesis in his laboratory. In addition, I would like to thank Prof. Wimmer and Prof. Wodarz for helpful discussion during my thesis committee meetings. I also thank Prof. Doenecke, Prof. Bucher and Dr. Stoykova, who kindly agreed to be part of my extended thesis committee.

Especially, I thank my supervisor Dr. Kristine Henningfeld for her all-time support. I appreciate her enormous personal effort in guiding and teaching me during my thesis. So Kris, thank you a lot for discussion, ideas and help with any kind of problems!

Further, I thank the members of the department and particular the members of the Neuro-Group, Barbara, Katja, Marie and Patrick for the motivating and inspiring working atmosphere in the laboratory.

I express my gratitude to Dr. Olaf Jahn and Dr. Ivan Manzini who supported me in different aspects of my project and the Göttingen Graduate School for Neurosciences and Molecular Biosciences for funding of my thesis. 


\section{List of Figures}

Figure 1: Organizing centres during neural induction

Figure 2: Overview of excreted signaling inhibitors expressed by the Spemann organizer and the pathways inhibited

Figure 3: Neural Induction

4

Figure 4: Neuroectoderm maturation 6

Figure 5: Domains of primary neurogenesis $\quad 7$

Figure 6: Neuronal differentiation $\quad 8$

Figure 7: Lateral inhibition by the Delta Notch signaling pathway 10

Figure 8: Lateral inhibition defines the number of neurons in the neuroectoderm

Figure 9: Numb as cell fate determinant in Drosophila SOP

Figure 10: Protein-protein interaction domains of Numb

Figure 11: Numb isoforms

Figure 12: NumbL knockdown inhibits proneural factors downstream of Ngn

Figure 13: Temporal expression analysis of X.tropicalis Numb and NumbL isoforms

Figure 14: Comparison of spatiotemporal expression of $X$. laevis Numb and NumbL

Figure 15: NumbL is positively regulated by the neurogenins

Figure 16: NumbL overexpression promotes neurogenesis and enlarges the neural tube

Figure 17: NumbL knockdown does not cause an increase of the Notch signaling pathway in the open neural plate

Figure 18: Notch signaling does not rescue NumbL knockdown

Figure 19: NumbL knockdown leads to an increase in early neural gene 
expression

Figure 20: NumbL knockdown leads to increased proliferation during gastrula stages and loss of cell cycle regulators

Figure 21: NumbL knockdown promotes neural crest fate at tailbud stages

Figure 22: NumbL knockdown influences Neurogenin expression

Figure 23: NumbL knockdown leads to an increase in Zic gene expression

Figure 24: Zic genes are activated by Notch but Notch inhibition does not rescue the NumbL knockdown phenotype

Figure 25: Subcellular localization of mouse MT-Numb1, X.laevis MT-NumbL and X.tropicalis MT-Numb3

Figure 26: Subcellular localization of $X$. laevis NumbL and $X$. tropicalis Numb under wildtype and neuralized conditions

Figure 27: NumbL interacts with components of the AP-2 complex

Figure 28: Interaction with the AP-2 complex is crucial for NumbL function

Figure 29: Scheme of NumbL dual function during primary neurogenesis

Appendix Figure 1: Genomic structure of X. tropicalis Numb and identified insert sequences

Appendix Figure 2: Tandem affinity purification of NumbL(DLA)-CTap 


\section{Abbreviations}

\begin{tabular}{|c|c|}
\hline AP & alkaline phosphatase \\
\hline ATP & adenosine triphosphate \\
\hline $\mathrm{BCIP}$ & 5-bromo-4-chloro-3-indolyl phosphate \\
\hline $\mathrm{BMB}$ & Bohringer Mannheim blocking reagent \\
\hline BMP & bone morphogenetic protein \\
\hline bp & base pairs \\
\hline BSA & bovine serum albinum \\
\hline${ }^{\circ} \mathrm{C}$ & Celsius degree \\
\hline CIAP & calf intestine alkaline phosphatise \\
\hline Dig & dioxigenine \\
\hline DNA & deoxyribonucleic acid \\
\hline DTT & dithiothreitol \\
\hline EDTA & ethylendiaminetetraacetic acid \\
\hline EGTA & $\begin{array}{l}\text { ethylenglycole-bis(2-aminoethylether)-N,N- } \\
\text { tetraacetate }\end{array}$ \\
\hline et al. & et alii \\
\hline g & gramm \\
\hline $\mathrm{h}$ & hours \\
\hline HCG & human chorionic gonadotropin \\
\hline $\mathrm{kb}$ & kilobase \\
\hline I & liter \\
\hline LB & Luria-Bertani \\
\hline$\mu$ & micro \\
\hline $\mathrm{m}$ & milli \\
\hline M & molar \\
\hline MAB & maleic acid buffer \\
\hline MEM & MOPS-EGTA-MgSO ${ }_{4}$ buffer \\
\hline MEMFA & MOPS-EGTA-MgSO ${ }_{4}$ formaldehyde buffer \\
\hline
\end{tabular}




\begin{tabular}{|c|c|}
\hline $\min$ & minutes \\
\hline $\mathrm{mm} \mathrm{MO}$ & mismatch $\mathrm{MO}$ \\
\hline MO & morpholino oligonucleotide \\
\hline mRNA & messenger RNA \\
\hline $\mathrm{n}$ & nano \\
\hline $\mathrm{NaAc}$ & sodium acetate \\
\hline NBT & nitro-blue tetratzolium \\
\hline Ngn & neurogenin \\
\hline Ngnr & neurogenin related \\
\hline PAGE & polyacrylamid gel electrophoresis \\
\hline PBS & phosphate buffered saline \\
\hline PCR & polymerase chain reaction \\
\hline $\mathrm{pH}$ & $\begin{array}{l}\text { negative decade logarithm of hydrogen ion } \\
\text { concentration }\end{array}$ \\
\hline РTB & phosphor-tyrosine-binding \\
\hline PRR & proline rich repeat \\
\hline RNA & ribonucleic acid \\
\hline rpm & rounds per minute \\
\hline RT & room temperature, reverse transcriptase \\
\hline RT-PCR & reverse transcriptase PCR \\
\hline sec & second \\
\hline SSC & standard saline citrate buffer \\
\hline Taq & Thermus aquaticus \\
\hline TAP & Tandem affinity purification \\
\hline$T_{m}$ & melting temperature \\
\hline U & units \\
\hline Vol. & volume \\
\hline X-Gal & 5-bromo-4-chloro-3-indolyl-ß-D-galactoside \\
\hline X. laevis & Xenopus laevis \\
\hline
\end{tabular}


X. tropicalis Xenopus tropicalis

\section{Abbreviations of Deoxynucleic Acids}
A Adenine
C Cytosine
G Guanine
T Thymine

\section{Abbreviations of Amino Acids}

$\begin{array}{llll}\text { A } & \text { Alanine } & \text { C } & \text { Cystein } \\ \text { D } & \text { Aspartate } & \text { E } & \text { Glutamate } \\ \text { F } & \text { Phenylalanine } & \text { G } & \text { Glycine } \\ \text { H } & \text { Histidine } & \text { I } & \text { Isoleucine } \\ \text { K } & \text { Lysine } & \text { L } & \text { Leucine } \\ \text { M } & \text { Methionine } & \text { N } & \text { Asparagine } \\ \text { P } & \text { Proline } & \text { Q } & \text { Glutamine } \\ \text { R } & \text { Arginine } & \text { S } & \text { Serine } \\ \text { T } & \text { Threonine } & \text { V } & \text { Valine } \\ \text { W } & \text { Tryptophane } & \text { Y } & \text { Tyrosine }\end{array}$




\section{Introduction}

\subsection{Neural Induction}

In Xenopus, the majority of neurons are born in two main waves. In the first wave, called primary neurogenesis, the early nervous system required for movements and responses of the larvae is established (Hartenstein, 1989). In the second wave, which begins at the onset of metamorphosis, the majority of primary neurons are replaced with secondary neurons to generate the nervous system of the adult animal (Wullimann et al., 2005). The molecular mechanisms of both phases of neurogenesis may be conserved, as genes involved in the process of primary neurogenesis are also active during secondary neurogenesis (Wullimann et al., 2005).

During gastrulation, the dorsal ectoderm acquires the competence for a neural fate in a process called neural induction. Cells of the dorsal ectoderm receive inducing signals from the mesoderm and adopt a neural fate at the expense of an epidermal fate (De Robertis and Kuroda, 2004). Prior to the onset of gastrulation at blastula stages the combined activity of two signaling centers predisposes the prospective neuroectoderm to neural induction (Kuroda et al., 2004) (Figure 1). One is the blastula Chordin and Noggin expressing centre (BCNE), which is located in dorsal animal cells and expresses the BMP antagonists Chordin and Noggin, as well as Xnr3 and the homeobox gene Siamois (Kuroda et al., 2004). The other is the Nieuwkoop center, which is localized in dorsal vegetal cells and expresses Cerberus, an inhibitor of Wnt, BMP and Nodal signaling (Piccolo et al., 1999) and the Nodal-related endomesodermal inducers $X n r 1, X n r 2, X n r 4, X n r 5$ and $X n r 6$ that induce the Spemann organizer in overlying mesodermal cells (Nieuwkoop, 1969; Agius et al., 2000; Takahashi et al., 2000; Shivdasani, 2002; Kimelman, 2006). 


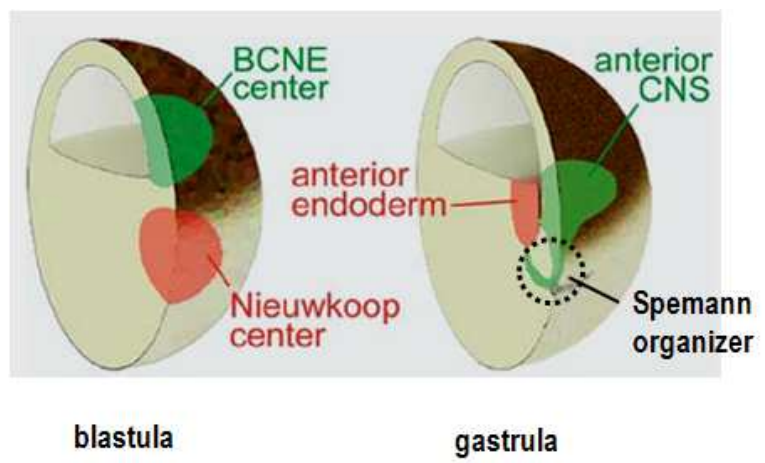

Figure 1: Organizing centers during neural induction. During gastrula stages, the Nieuwkoop center is found in the dorsal vegetal region while the blastula Chordin/Noggin expressing cells (BCNE) are located in the animal region. Both centers induce the Spemann organizer during gastrula stages and give rise to the anterior-most endoderm or the ectodermal anterior CNS, respectively (after Kuroda et al., 2004, modified).

During gastrulation, the Spemann organizer expresses and secretes several organizer-specific proteins such as the Wnt inhibitors Frzb-1, Dickkopf-1, Crescent (Leyns et al., 1997; Glinka et al., 1998; Pera et al., 2000; Piccolo et al., 1999), the TGF/Nodal inhibitors Lefty and Antivin (Meno et al., 1996; Thisse et al., 1999), the BMP antagonists Chordin, Noggin and Follistatin (Piccolo et al, 1996; Zimmerman et al., 1996; lemura et al., 1998) and Cerberus, which inhibits Nodal, Wnt and BMP signals (Piccolo et al., 1999) (Figure 2).

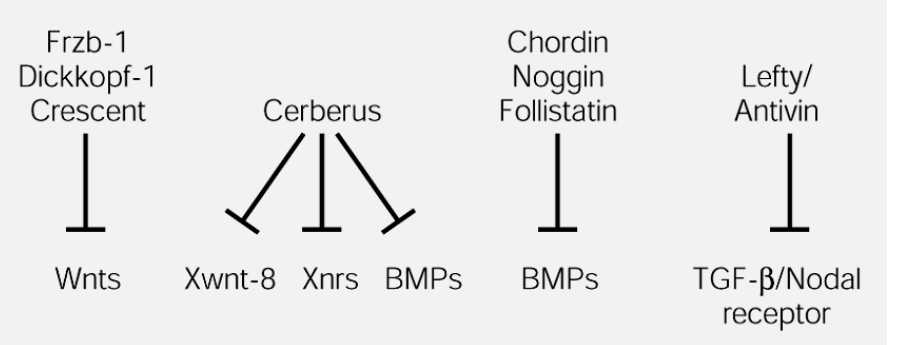

Figure 2: Overview of excreted signaling inhibitors expressed by the Spemann organizer and the pathways inhibited. The secreted factors of the Spemann organizer antagonize an epidermal fate in ectodermal cells and therefore enable a neural induction of the ectoderm (De Robertis et al., 2000).

The Spemann organizer is not a homogeneous structure and can be separated in three subregions that possess different inducing potentials: the head organizer, the trunk/tail organizer and the deep yolky endoderm (Spemann and Mangold, 1921; Spemann, 1931; Nieuwkoop et al., 1952; Saxen et al., 1962; 
Gerhart, 2001). With the onset of gastrulation, the first tissue to invaginate through the early blastopore lip contains cells of the vegetal marginal zone (ventral band), which form the yolky endoderm subregion of the organizer (Sasai et al., 1995). These cells express Dickkopf and Cerberus and induce the most anterior neural structures and the cement gland. The head organizer originates in the ventral marginal zone and gives rise to mesodermal tissue of the organizer (Harland and Gerhardt, 1997; Kodjabachian, 1998). The head organizer expresses anti-BMPs, such as Chordin, Noggin and Follistatin, as well as the Wnt-inhibitor Frzb-1 and Crescent, and induces the anterior neural plate that will give rise to the forebrain and midbrain. The trunk/tail organizer originates in the dorsal band of the marginal zone (Gerhardt, 2001) and induces the posterior neural plate through Chordin, Noggin and Follistatin expression. FGF signaling was also found to be essential for establishment and maintenance of the trunk/tail organizer (Mitchel and Sheets, 2001; Delaune et al., 2005; Fletcher and Harland, 2008).

For the induction of a neural fate in the ectoderm, bone morphogenetic protein (BMP) signaling levels have to be lowered, as BMPs induces genes like the zinc-finger transcription factor GATA-1 drive ectodermal tissue to an epidermal fate (Shibata et al., 1998; Gawantka et al., 1995). The secreted BMP antagonists expressed by the Spemann organizer inhibit BMP signaling by binding BMPs and preventing their interaction with BMP-receptors (Chordin and Noggin) or by blocking activation of the receptor (Follistatin). Another inhibitor of BMP signaling is Derriere (or GDF3), which like BMP belongs to the TGF- $\beta$ family of ligands (Levine at al., 2006; Levine et al., 2009), and is expressed already before gastrulation in the BCNE. However, BMP inhibition alone is not sufficient to induce a neural fate in the ectoderm; it has been shown that low levels of FGF signaling are also required (Delaune et al., 2005). FGF inhibits BMP signaling by downregulating the activity of Smads, intracellular transducers of the BMP pathway via the Ras/MAPK pathway (Pera et al., 2003; Kuroda et al., 2005). Although an inhibition of BMP is sufficient to induce early neural markers like Zic1, FGF4 activity was found to be essential for the induction of early neural genes like Zic3 and FoxD5a that were not induced by BMP inhibition alone (Marchal et al., 2009). Recently, the necessity of simultaneous BMP inhibition 
and FGF signals for stable induction of neural genes was demonstrated. FGF activation could induce the neural markers Sox 2 and Sox3 in Xenopus ectodermal explants, but BMP signals were able to revert the tissue to an epidermal fate (Wills et al., 2010). In addition to BMP inhibition and FGF signaling, inhibition of Wnt signaling is needed to allow the establishment of the neural ectoderm. Wnt inhibition strongly increases the neuroectoderm size and activation of the canonical Wnt pathway impairs the expression of neural markers (Heeg-Truesdell et al., 2006).

\subsection{Neuroectoderm maturation}

The process of neural induction results in the expression of a large number of genes that coordinately promote a neural fate, limit the size of the neural plate and regulate the onset of neuronal differentiation (Sasai et al., 1996; Moody et al., 2002). Although the transcriptional regulation of most panneural genes has not been characterized to date, FGF4-mediated calcium influxes via DHP-sensitive $\mathrm{Ca}^{+}$channels in the cells of the presumptive neural ectoderm were shown to be essential and sufficient for the induction of early neural genes (Moreau et al., 2008; Lee et al., 2009) (Figure 3).

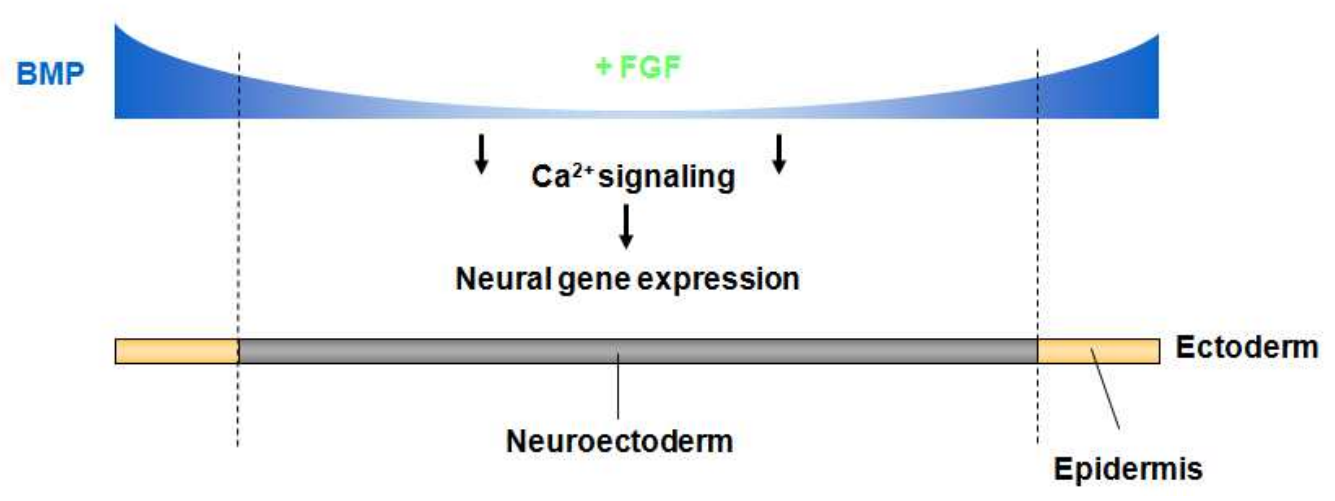

Figure 3: Neural Induction. Absence of BMP signaling together with low levels of FGF signaling lead to a calcium dependent induction of neural genes in the ectoderm. High levels of BMP inhibit a neural fate and promote an epidermal fate. 
The genes induced during neural induction include the forkhead transcription factor FoxD5 (Sölter et al., 1999), coiled-coil domain containing DNA replication inhibitor Geminin (Kroll et al., 1998), the HMG-box genes Sox2, Sox3, SoxD and Sox11 (Uwanogho et al., 1995; Mizuseki et al., 1998a; Kishi et al., 2000; Wegner and Stolt, 2005; Dee et al., 2008), the zinc finger transcription factors Zic1, Zic2 and Zic3 (Nakata et al., 1997; Brewster et al., 1998; Mizuseki et al., 1998b) and the Iroquois genes Xiro1, Xiro2 and Xiro3 (Bellefroid et al., 1998). While BMP antagonism alone is sufficient to induce Zic1, which like Zic3 promotes expression of downstream neural genes, activation of FoxD5 and Zic3 and their downstream targets Geminin and Sox11 requires FGF4 activity (Marchal et al., 2009). The activation of Zic2, downstream of FoxD5, was in turn found to be dependent on Notch signaling (Yan et al., 2009a). Sox11, Geminin and Zic2 were found to be sufficient to induce the downstream targets Sox2 and Sox3 (Yan et al., 2009b). Upon maturation of the neuroectoderm, additional panneural markers like the neural cell adhesion molecule (NCAM) and SoxD are expressed (Kintner et al., 1987; Mizuseki et al., 1998b). In contrast to Sox2 and Sox3, which enhance the sensitivity of ectodermal cells to inducing signals, SoxD has been shown to induce neuronal differentiation through the activation of Ngn2 (Mizuseki et al., 1998b, Hardcastle et al., 2000) (Figure 4).

Nodal related genes as targets of $W n t-8, V e g T$ and $V g 1$ are proposed to restrict a neural fate at the borders of the neural plate and thereby define the size of the neuroectoderm (Heeg-Tuesdell et al., 2006). 


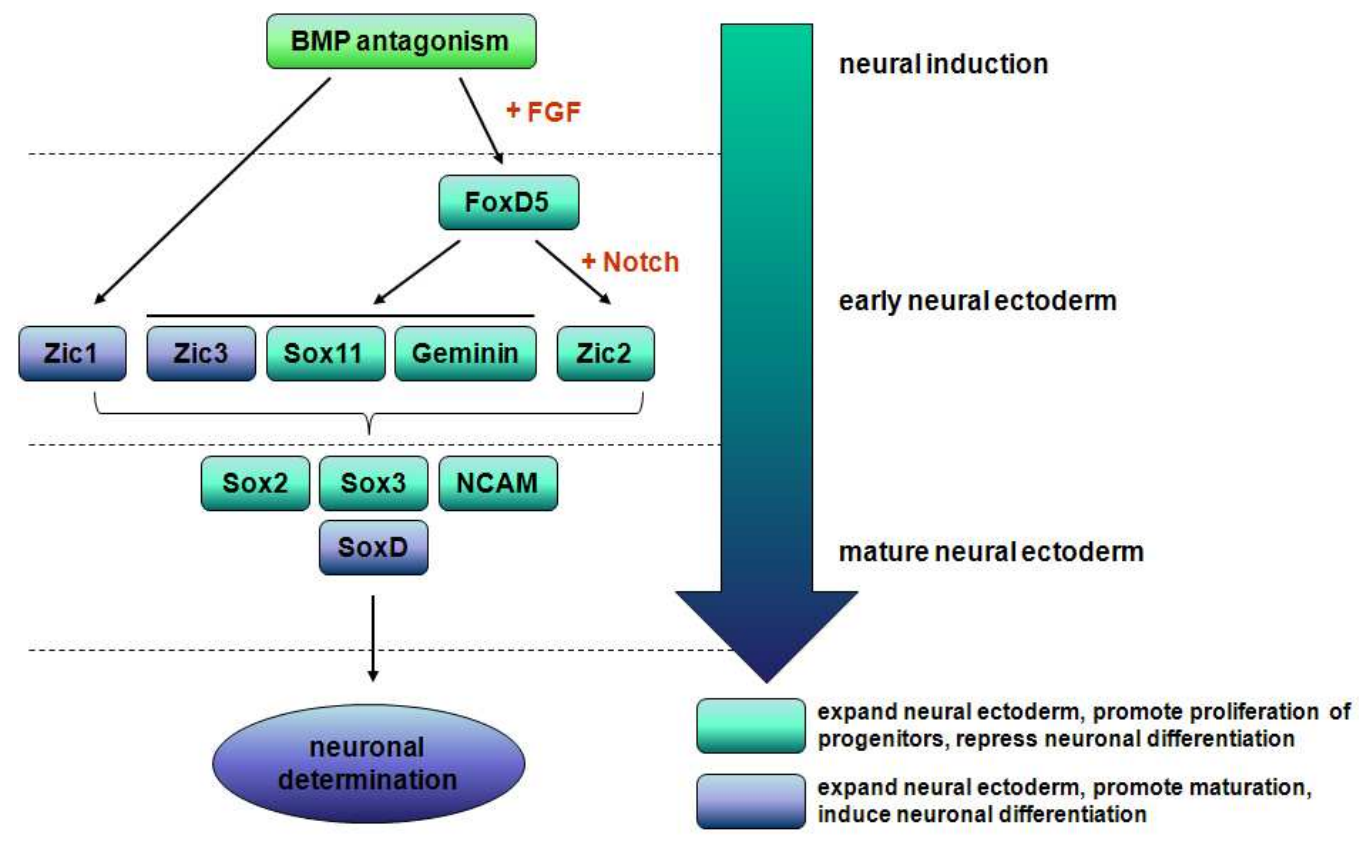

Figure 4: Neuroectoderm maturation. Upon BMP inhibition and low levels of FGF signaling, the forkhead transcription factor FoxD5 is induced. Zic1 is induced independently of FGF signalling. FoxD5 induces Notch dependent and independent further downstream neural genes like Zic3, Sox11, Geminin or Zic2. Upon maturation of the neuroectoderm, the neural markers Sox2, Sox3, NCAM and SoxD are expressed. Zic1, Zic3 and SoxD promote single cells in the mature neuroectoderm to express neuronal determination factors and undergo differentiation.

\subsection{Neuronal Differentiation}

The primary neurons are born in three bilateral longitudinal domains in the posterior neural plate and can be visualized by the expression of neural specific type II $\beta$-tubulin ( $N$-tubulin) (Oschwald et al., 1991). With the exception of the trigeminal placodes, neurogenesis in the anterior neural plate is delayed until late neurula stages (Papalopulu and Kintner, 1996). The neuroectoderm at the open neural plate stage is bilayered. While the primary neurons mainly arise from the deeper sensorial layer, the cells in the superficial epidermal layer stay in a proliferative state and undergo differentiation in a later phase of development (Chalmers et al., 2002; Hartenstein, 1989) (Figure 5). As the neural plate folds and forms the neural tube, the medial, intermediate and lateral stripe will give rise to motor neurons, interneurons and sensory neurons, respectively (Chitnis et al., 1995; Hartenstein, 1989) (Figure 5). 
A

B

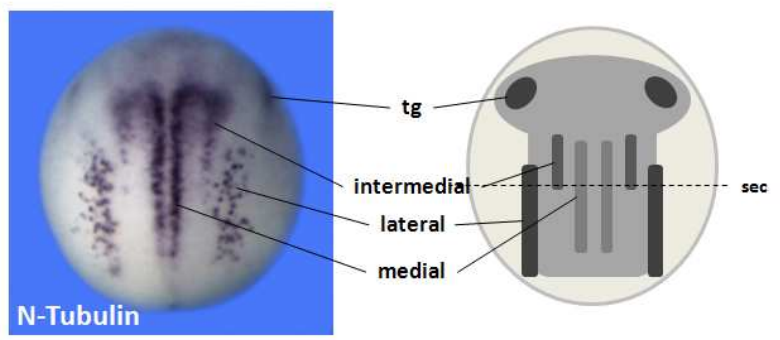

\section{C}

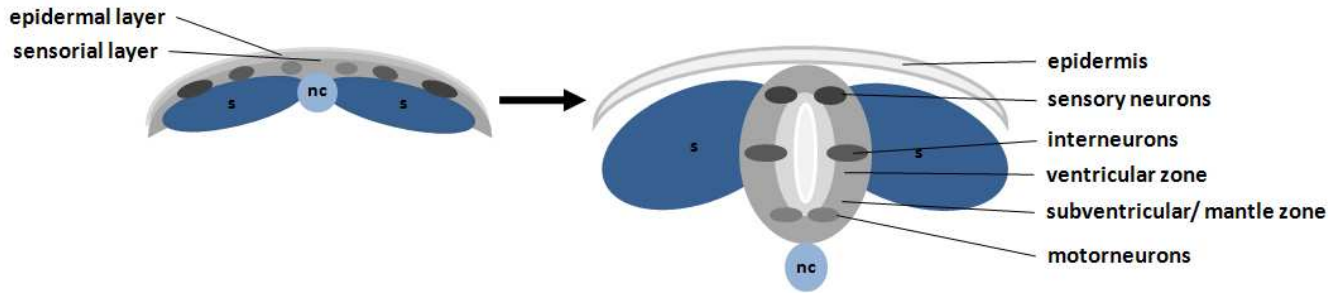

Figure 5: Domains of primary neurogenesis. (A) Stage 15 embryo stained for $N$-tubulin by whole mount in situ hybridization to mark postmitotic neurons. The embryo is shown in a dorsal view, anterior up. (B) Schematic representation of the domains of primary neurogenesis at the open neural plate stage (light grey). The characteristic domains are depicted in the three longitudinal domains on both sides of the midline and the trigeminal placodes. (C) Schematic representation of a transversal section of the open neural plate of the embryo as indicated with the dashed line $(\mathrm{sec})$ in (B). The neuroectoderm consists of a superficial and a deep cell layer. Primary neurons are located in the deep layer. (D) Schematic representation of a transversal section of a stage 30 posterior neural tube. The neural plate has folded up to form the neural tube, the medial, intermediate and lateral stripe of primary neurons give rise to motorneurons, interneurons and sensory neurons, respectively. While proliferating progenitor cells are located in the ventricular zone, differentiating neurons are located in the subventricular and mantle layer. $\mathrm{tg}$, trigeminal placodes; s, somite; nc, notochord; sec, plane of section.

The first proneural genes expressed in the areas of primary neurogenesis belong to the neurogenin family of bHLH transcription factors (Ngn), Ngn1, Ngn2 (originally referred to as $\mathrm{Ngnr}-1$ ) and $\mathrm{Ngn3}$, which are distantly related to the Drosophila proneural transcription factor Atonal (Jarman et al., 1993; Ma et al., 1996, Nieber et al., 2009). Neurogenins are proposed to act as neuronal determination factors (Sommer et al., 1996; Ma et al., 1996; Mizuseki et al., 1998b) and several panneural genes like Zic1, Zic3 and SoxD have been shown to induce Ngn2 expression. Zic2 is instead expressed in between the stripes of Ngn1 and Ngn2 and inhibits Ngn expression and function (Brewster et al., 1998), thereby refining the territories of neurogenesis. Ngn2 instructs neural as non- 
neural ectoderm to undergo neuronal differentiation by activating a network of downstream differentiation factors, such as NeuroD, Coe2, Xebf3, Mxi1 and MyT1 (Bellefroid et al., 1996; Ma et al., 1996; Dubios et al., 1998; Klisch et al., 2006; Pozolli et al., 2001). In addition, Ngn2 induces the cell cycle inhibitors p21 activated kinase 3 (Pak3) and the growth arrest and DNA damage induced gene gamma (Gadd45-y) to enable cell cycle exit and differentiation of progenitor cells (Souopgui et al., 2002; De la Calle-Mustienes et al., 2002). An additional cell cycle regulator, the Cip/Kip cyclin dependent kinase inhibitor $p 27^{\text {Xic1 }}$ is also highly expressed in neuronally determined cells and was found to be required for activation of downstream differentiation factors (Vernon et al., 2005; Carruthers et al., 2003) and stabilization of Ngn2 by presumably preventing its phosphorylation by CDK and subsequent degradation (Vosper et al., 2009 and Philpott, unpublished data) (Figure 6). Ngn2 was additionally described to activate transcription of genes that encode proteins involved in chromatin remodeling like Brg1 and the proneural RNA binding protein Seb4R, which are essential for neuronal differentiation (Seo et al., 2005; Boy et al., 2004). More recently, it has been shown that Ngn2 also induces genes encoding a variety of other transport proteins, signal pathway components and transcription factors; the underlying functionalities of the mainly uncharacterized genes remain to be elucidated (Seo et al., 2007).

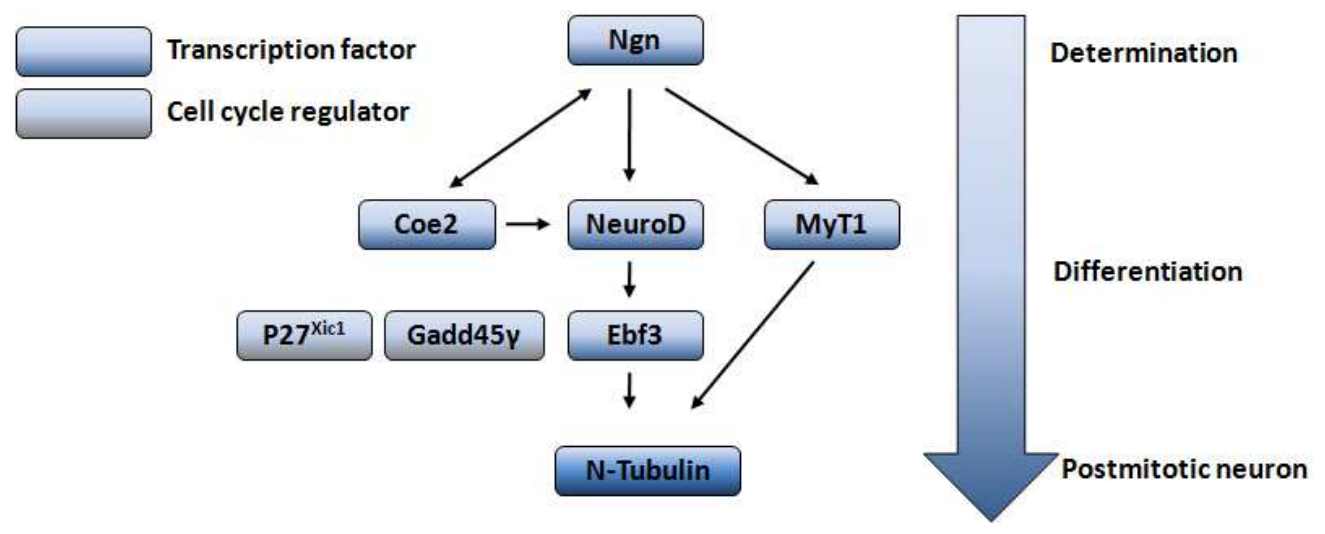

Figure 6: Neuronal differentiation. Schematic representation of genes that are activated by Ngn2. Color code for transcription factors and cell cycle regulators is indicated on the left. Ngns define neuronal determined cells and activate a network of downstream transcription factors like Coe2, NeuroD, MyT1 and Ebf3, which finally leads to the expression of N-tubulin in postmitotic neurons. The cell cycle regulators $\mathrm{p} 27^{\mathrm{xic} 1}$ and Gadd $45 \mathrm{p}$ are also necessary for differentiation. 


\subsection{Lateral Inhibition}

Neurogenins not only induce downstream differentiation factors, they also activate the Notch pathway, which inhibits neurogenesis in a process called lateral inhibition (Figure 7). This is achieved by induction of Delta-1, a single pass membrane ligand for the Notch receptor (Chitnis et al., 1995). Delta-2 and Serrate- 1 are additional Notch ligands that were shown to function in Xenopus primary neurogenesis (Peres et al., 2006; Kiyota et al., 2004). Upon Delta-1 binding the Notch receptor of a neighboring cell, a series of proteolytic cleavages occurs that releases the intracellular domain of the Notch receptor (NICD) into the cytoplasm (Louvi et al., 2006). NICD translocates into the nucleus, were it replaces a co-repressor at the suppressor of hairless $(\mathrm{Su}(\mathrm{H}))$ transcription factor, acts as a co-activator and drives expression of target genes (Louvi et al., 2006; Wettstein et al., 1997). Some of the best-characterized Notch target genes are the bHLH repressors of the enhancer of split-related (ESR) and Hairy family. The ESR proteins inhibit Ngn2 expression and function. Thus, the signal-receiving cell is prevented from undergoing neuronal differentiation (Chitnis et al., 1996, Dawson et al., 1995) and a salt and pepper like pattern of primary neurons is created (Figure $8 A-D$ ). If Notch signaling is artificially activated by expression of NICD, neuronal differentiation is blocked in every cell of the neuroepithelium, resulting in a loss of postmitotic neurons (Figure 8E,F). Vice versa, if Notch activity is blocked by expression of a dominant negative $\mathrm{Su}(\mathrm{H})$, lateral inhibition is blocked and all cells in the territories of primary neurogenesis undergo neuronal differentiation (Figure $8 \mathrm{G}, \mathrm{H}$ ). 


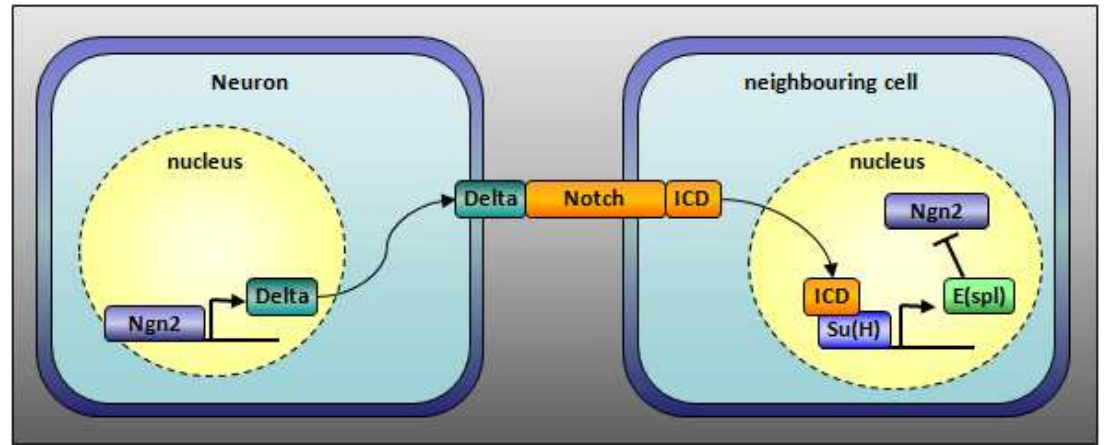

Figure 7: Lateral inhibition by the Delta Notch signaling pathway. Expression of Ngn2 in the cell fated to become a neuron activates Delta, a ligand of the Notch receptor. Upon Delta binding to the Notch receptors of the neighbouring cell, a series of proteolytic cleavages releases the intracellular domain of the receptor (NICD) which translocates to the nucleus and acts as a coactivator in inducing expression of Enhancer of split related genes (ESR). The ESRs inhibit Ngn2 expression and function in the signal-receiving cell and prevent it from undergoing neuronal differentiation.

How a single cell within the territories of primary neurogenesis can escape lateral inhibition, enter neuronal differentiation and inhibit all surrounding cells from differentiating remains unclear. It has been proposed, that once a cell activates the transcription of downstream proneural genes through elevated levels of Ngn, it becomes refractory to lateral inhibition in a process that requires MyT1 (Van Doren et al., 1992; Bellefroid et al., 1996). This is supported by the finding that ectopic neurogenesis induced by Ngn overexpression can be blocked by Notch activation (Ma et al., 1996), while the neuroectoderm of embryos injected with Ngn2 and MyT1 mRNA becomes resistant to lateral inhibition by Notch (Bellefroid et al., 1996). 
A

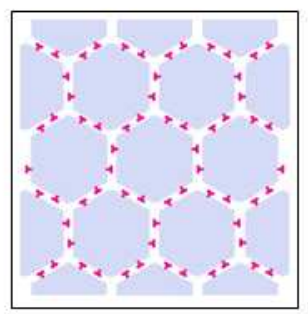

E

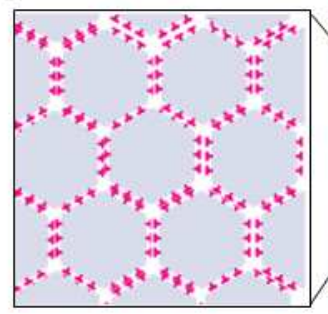

B

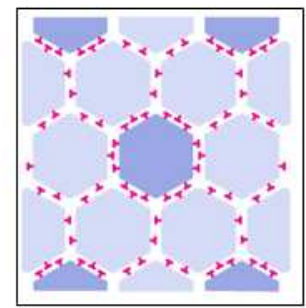

F

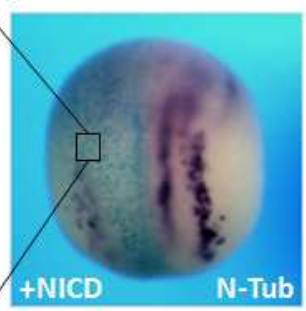

C

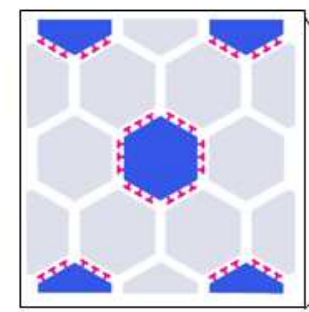

G

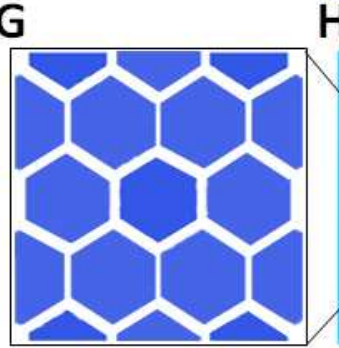

D

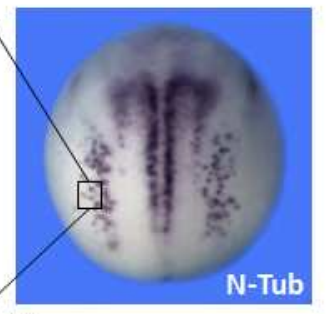

H

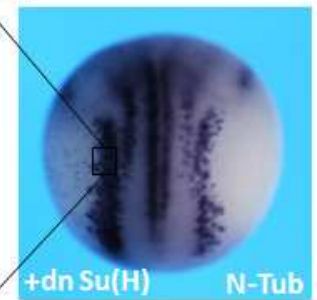

Figure 8: Lateral inhibition defines the number of neurons in the neuroectoderm. (A) Upon initial induction of neuronal determination factors like Ngn, the cells in the neuroectoderm express Delta-1 and mutually inhibit each other from undergoing differentiation. (B) Some cells express higher levels of Delta or become refractory to inhibitory signals. (C) Neuronal determined cells suppress differentiation in neighbouring cell and undergo neuronal differentiation. (D) Salt and pepper like pattern of primary neurons in a stage 15 embryo (E, F) Ectopic activation of Notch signaling by the constitutively active NICD. All cells inhibit each other from undergoing differentiation. $(\mathbf{G}, \mathbf{H})$ Inhibition of Notch signaling by $\mathrm{Su}(\mathrm{H})^{\mathrm{DBM}}$, a dominant negative form of $\mathrm{Su}(\mathrm{H})$. Lateral inhibition does not occur, all cells in the territories of primary neurogenesis undergo neuronal differentiation (modified from Molecular Biology of the Cell, 2005).

\subsection{Numb as cell fate determinant in neurogenesis}

Numb was originally identified as a cell fate determinant in dividing Drosophila sensory organ precursor cells (SOPs) (Uemura et al., 1989). In the development of a sensory hair in Drosophila, a single SOP undergoes two subsequent divisions, giving rise to four cells of different types: a hair cell, two outer supporting cells and a neuron. While a loss of Numb generated four outer supporting cells, Numb overexpression generated four neurons (Rhyu et al., 1994) (Figure 9). Numb was found to be asymmetrically distributed to one daughter cell upon cell division and inhibit Notch signaling in this cell, thereby determining different cell fates in the daughters (Wang et al., 1997). 


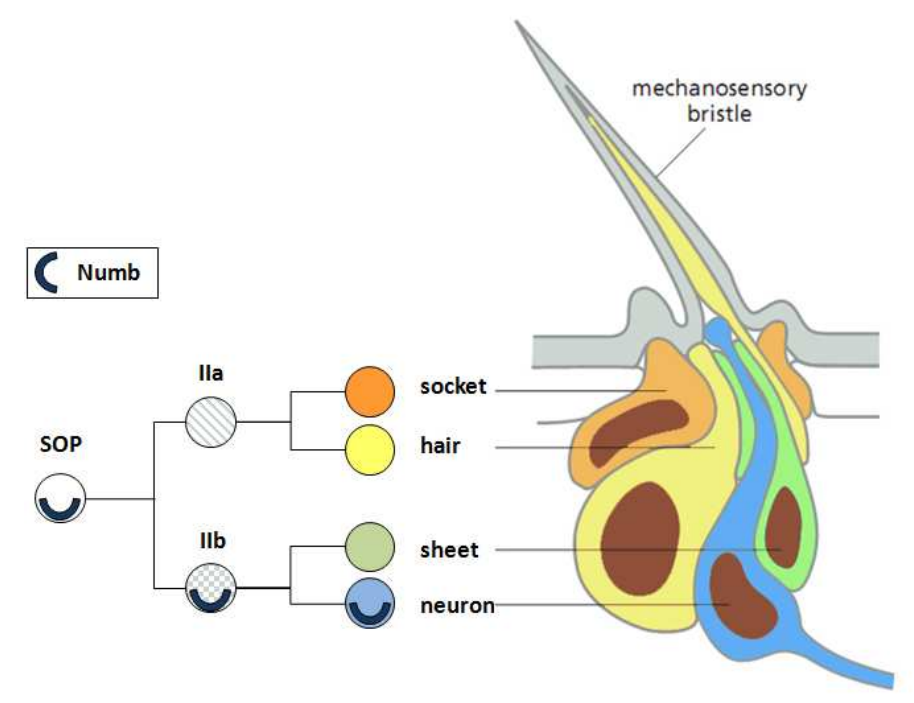

Figure 9: Numb as cell fate determinant in Drosophila SOP. Numb is asymmetrically distributed upon division of the SOP and the subsequent division of the Ilb cell, acting as intrinsic cell fate determinant to inhibit Notch signaling and enable neuronal differentiation (modified from Rhyu et al., 1994).

The Numb proteins are highly conserved in their sequence throughout species. In contrast to Drosophila, which has only one Numb gene, two closely related Numb genes have been identified in vertebrates, Numb and Numblike (NumbL) (Verdi et al., 1996; Zhong et al., 1996). The murine and the human Numb homologues, mNumb and hNumb can substitute dNumb function and similarly induce ectopic neuron formation when overexpressed in Drosophila (Verdi et al., 1996; Toriya et al., 2006) suggesting Numb function is conserved through evolution.

In mice, Numb and NumbL were also shown to function in vertebrate neurogenesis, as a loss of both results in an overall loss of differentiated neurons (Petersen et al., 2002; Li et al., 2003; Petersen et al., 2004). Numb and NumbL were found to act in a partially redundant manner and to be essential for neural development in the mouse. While a homozygous knockout of NumbL in mouse causes no severe phenotype (Petersen et al., 2002), Numb depleted mice showed defects in cranial neural tube closure and die around E11.5 (Zhong et al., 2000). Conditional Numb knockout mice are viable and exhibited a loss of differentiated neurons in the forebrain, an effect that could be enhanced in a NumbL null background (Petersen et al., 2002; Li et al., 2003). Contradictory 
results were obtained with respect to the mechanism of the loss of differentiated neurons. A double knockout of Numb and NumbL, using nestin-Cre mediated excision at E8.5 prior to the onset of neurogenesis, resulted in a depletion of neural progenitors and reduced number of differentiated neurons, suggesting a function in progenitor cell maintenance at this early stage (Petersen et al., 2002). Vice versa, a knockout of both genes, using Emx-Cre at E9.5 - E12.5, was found to cause hyperproliferation of neural progenitors in the forebrain, impairing differentiation (Li et al., 2003). Knockout of Numb at E10.5 in a NumbL deficient background, using D6-Cre, similarly resulted in depletion of neural progenitors (Petersen et al., 2004). Thus, Numb was shown to be essential for neurogenesis, but playing two distinct roles, one in maintaining the proliferative state of progenitors and a second in enabling differentiation of these cells.

\subsection{Numb acts as scaffold protein}

Numb contains several protein-protein interaction domains and correspondingly, has been shown to interact with a wide variety of different proteins. A highly conserved phosphotyrosine binding domain (PTB) is localized in the $\mathrm{N}$-terminus and a proline-rich repeat domain (PRR) more C-terminally. The Numb PTB domain was shown not only to bind proteins containing phosphotyrosine residues (Blaikie et al., 1994), but also mediate interaction with PDZ-domain containing proteins like LNX or even more distinct peptide ligands like putative serine/threonine kinase NAK (Chien et al., 1998). The PRR was found to interact with a wide variety of proteins containing $\mathrm{SH} 3$ interaction domains (Verdi et al., 1996). Located in the most distal C-terminus are DPF AP-2 and NPF Eps-15 interaction motifs, which mediate interactions with the endocytotic machinery (Santolini et al., 2000) (Figure 10). 
mNumb 1

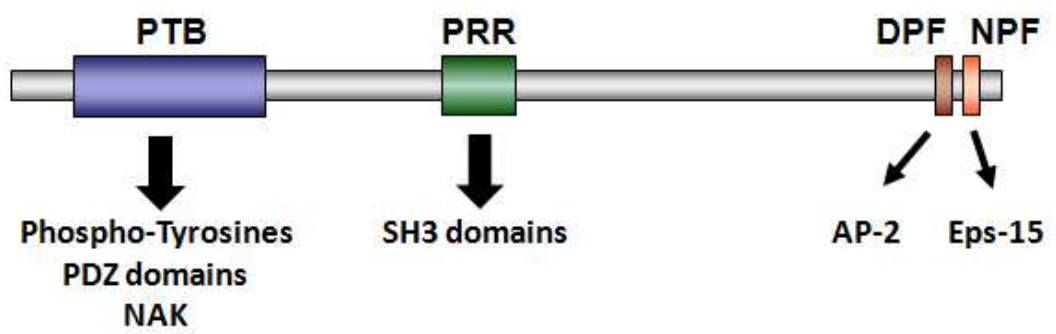

Figure 10: Protein-protein interaction domains of Numb. Scheme of mNumb1 protein with protein-protein interaction domains and interacting protein domains/ proteins.

\subsection{Numb and Numblike isoforms}

Four different isoforms of Numb (Numb1-4), which are generated by alternative splicing, have been described. The isoforms differ by the presence or absence of an 11 amino acid insert in the PTB domain or the PRR domain (Dho et al., 1999) (Figure 11). NumbL lacks both inserts and isoforms for NumbL have not been reported.

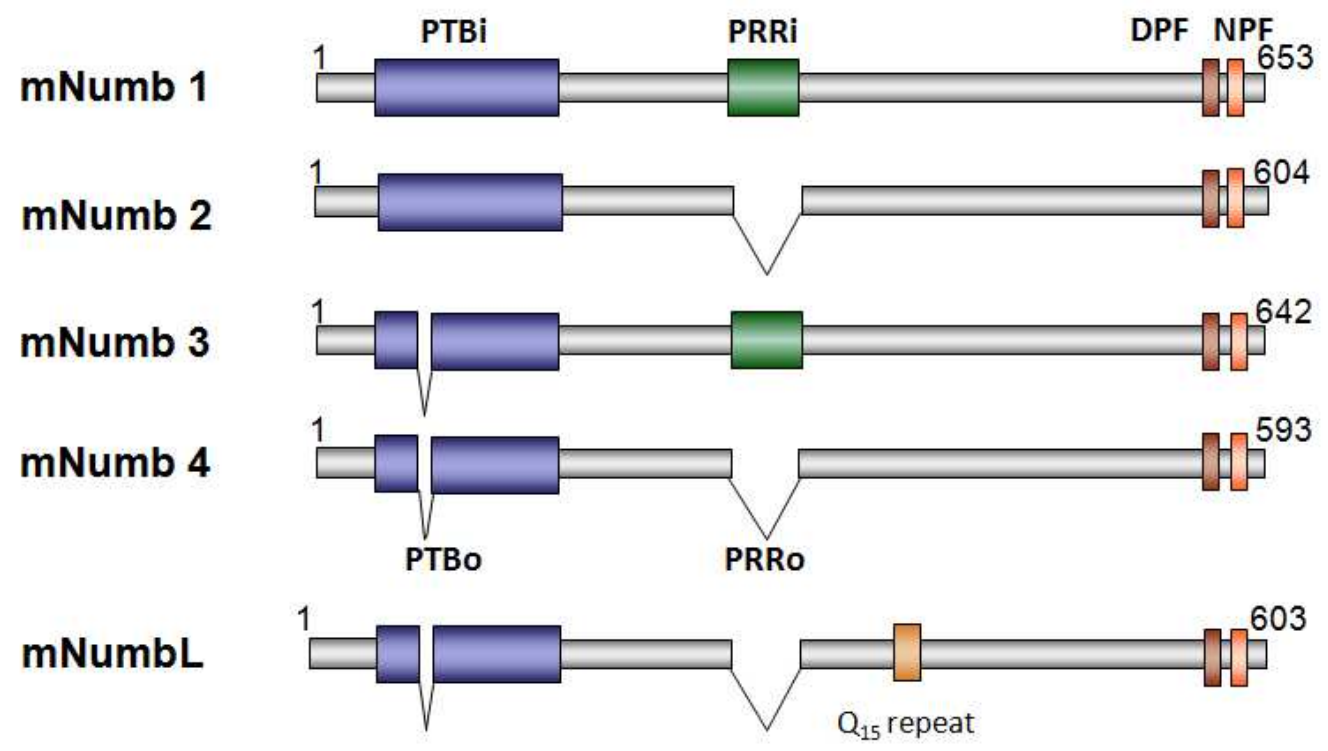

Figure 11: Numb isoforms. Four different Numb isoforms are generated due to different splicing. The isoforms differ from each other in the presence or absence of an insert in the PTB domain and the PRR domain. NumbL lacks both inserts. 
The PTB insert was found to be crucial for membrane localization of Numb (Verdi et al., 1996). Membrane localization of Numb can be achieved by either binding phosphotyrosine residues of tyrosine kinase receptors via the PTB domain (Verdi et al., 1996) or with assistance of an adaptor protein, Partner of Numb (Pon) (Lu et al., 1998). Numb isoforms that are localized to the membrane are able to be asymmetrically distributed upon cell division and therefore distinguish between different cell fates. Asymmetric segregation of Numb is a consequence of phosphorylation of Numb by the asymmetrically localized Bazooka/Par-6/aPKC complex (Par-3/Par-6/aPKC) (Wirtz-Peitz et al., 2008; Smith et al., 2007) or phosphorylation of Pon by Polo, a cell cycle connected kinase (Wang et al., 2007). Both events trigger Numb release from the cortex and therefore its localization to the opposite side of the cell.

The Numb isoforms have also been shown to exhibit different biological activities. Specific expression of PRRi isoforms of Numb in murine neural progenitors resulted in increased proliferation and decreased differentiation, while expression of PRRo isoforms resulted in the opposite effect (Verdi et al., 1999; Bani-Yaghoub et al., 2007). These results suggest that not only different targets of Numb, but different context-specific downstream isoform responses exist. This is in agreement with the changing expression patterns of the Numb isoforms during mouse cortical development. In contrast to the differentiation promoting PRRo isoforms, the proliferating promoting PPRi isoforms are expressed mainly between E7 and E10 and become undetectable by E13 during a rapid expansion the of neural progenitor cell population (Dho et al., 1999; Verdi et al., 1999; Bani-Yaghoub et al., 2007). The divergent functions of the mammalian Numb isoforms were further demonstrated by their overexpression in the Drosophila other optic anlage (OOA) (Toriya et al., 2006). Even in Drosophila, where no endogenous splice variants of Numb are present, the PRRi Numb constructs promoted proliferation, while the PRRo isoforms strongly increased neuronal differentiation in the OOA. Independent of the presence of the PRR domain, Numb isoforms lacking the insert in the PTB domain were shown to increase the sensitivity of transfected Drosophila PC12 cells to 
neurotrophic growth factors and therefore to undergo neuronal differentiation (Pedersen et al., 2002).

\subsection{Multiple functions of Numb}

The most well characterized function of Numb is its ability to negatively regulate Notch signaling (Rhyu et al., 1994). Two mechanisms are known by which Numb can inhibit Notch. Numb and NumbL can antagonize Notch signaling through simultaneous interaction with the AP-2 complex and the Notch receptor, which results in endocytosis of the receptor (Santolini et al., 2000). Numb also activates the E3 ligase Itch, which was found to target the Notch receptor as well as the cleaved NICD for ubiquitination and subsequent proteasomal degradation (McGill et al., 2003). High levels of Notch signaling were found to downregulate Numb expression in the chick neuroepithelium (Chapman et al., 2006), which is proposed as a mechanism to reinforce and maintain cell fate decisions.

In addition to Numbs ability to regulate Notch signaling levels, numerous distinct functions have been described. Numb was found to activate Itch, which targets Gli-1 for ubiquitination and degradation in mouse cerebellar granule cell progenitors (GCPs) and GCP derived cancer cell lines (Di Marcotullio et al., 2006; Di Marcotullio et al., 2010). As Gli1 is a downstream effector of SHH signaling, this results in an inhibition of SHH signaling. Numb was also shown to function in directional cell migration by mediating integrin endocytosis in the rear of migrating HeLa cells (Nishimura et al., 2007). Furthermore, Numb was found to function in stabilization of the tumor supressor p53 through the formation of a trimeric complex with p53 and the E3 ligase MDM2 (also known as HDM2). Complex formation prevents ubiquitination of $p 53$, enabling cell cycle arrest and DNA repair (Colaluca et al., 2008). A function of Numb in oncogenesis is also suggested by its frequent mutation in different cancer types (Westhoff et al., 2009; Ostrakhovitch, 2009; Rennstam et al., 2010). 


\subsection{Regulation of Numb}

The critical role Numb plays during embryogenesis is underscored by the multiple mechanisms by which it is regulated at the post-transcriptional level. Numb was shown to be regulated on the translational level by Musashi, a neural RNA binding protein, which was shown to bind Numb mRNA and prevent its translation (Okano et al., 2002). Numb mRNA translation was also inhibited by the micro-RNA miR146a in mouse satellite cells, were Numb promotes differentiation into muscle cells by inhibiting Notch signaling (Kuang et al., 2009). Furthermore, Numb activity is regulated via phosphorylation of two specific serine residues, $\operatorname{Ser}^{291}$ and $\operatorname{Ser}^{310}$ (Tokumitsu et al., 2006). If phosphorylated, these two serine residues trigger the binding of ubiquitously present 14-3-3 proteins to Numb, which mask the remaining protein-protein interaction sites and prevent Numb from binding its targets. Also, in the context of endocytosis, the adaptor-associated kinase 1 (aak1) was described to phosphorylate Numb, resulting in its redistribution to perinuclear endosomes in HeLa cells thereby regulating the endocytotic activity of Numb (Sorensen et al., 2008).

\subsection{Xenopus Numb and Numblike}

In a previous study, it could be shown that $X$. laevis NumbL was exclusively expressed in the presumptive neuroectoderm, the territories of primary neurogenesis and later throughout the nervous system (Nieber 2007). In whole embryos, NumbL was positively regulated by Ngn2 and inhibited by the Notch pathway. A knockdown of NumbL using antisense MO inhibited neuronal differentiation demonstrating NumbL is essential for neurogenesis. The knockdown effect could be rescued by coinjection of $X$. laevis NumbL and mouse NumbL RNA. Of the four murine Numb isoforms, only the structurally related Numb4 rescued the NumbL MO phenotype.

An expression analysis of proneural genes in NumbL morphant embryos revealed that the neuronal determination factor Ngn2 was still expressed, but all 
downstream targets were inhibited (Figure 12). Although NumbL exhibited in luciferase reporter assays the ability to decrease the activation of a Notch reporter, no increase in Notch target gene expression was observed upon NumbL knockdown.

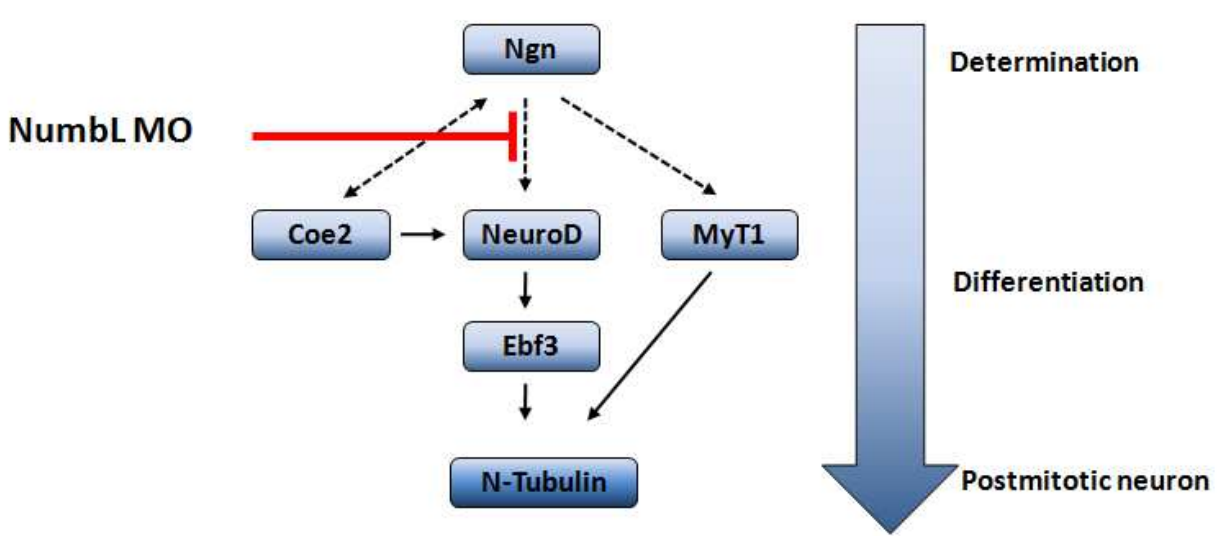

Figure 12: NumbL knockdown inhibits proneural factors downstream of Ngn. Upon injection of the NumbL MO, all proneural transcription factors downstream of Ngn were inhibited, suggesting a function for NumbL downstream of neuronal determination in the process of neuronal differentiation. (Nieber 2007)

\section{$1.11 \quad$ Aims}

NumbL was identified as an essential gene in the process of primary neurogenesis in Xenopus. However, a role for NumbL during neurogenesis could not be explained by the classical model of Numbs function as a Notch inhibitor during cell fate determination. Therefore, to understand NumbL role during primary neurogenesis, a detailed analysis of NumbL function during the development of the nervous system was performed. 


\section{Materials and Methods}

\subsection{Organsims}

\subsubsection{Xenopus laevis and Xenopus tropicalis}

The African clawed frog Xenopus laevis (X. laevis) and the western clawed frog Xenopus tropicalis ( $X$. tropicalis) were used as model organisms during this study. Pigmented or albino frogs were purchased from Nasco (Ft. Atkinson, USA). The developmental stages were distinguished according to Nieuwkoop and Faber (1967).

\subsubsection{Escherichia coli}

XL1-Blue recA1, endA1, gyrA96, thi-1, hsdR17, supE44, relA1, lac[F' proAB, laclqZDM15, TN10(Tetr)] $]^{\mathrm{C}}$ (Bullock et al., 1987)

\subsection{Oligonucleotides}

\subsubsection{RT-PCR oligonucleotides}

RT-PCR oligonucleotides (primers) were purchased from Sigma-Aldrich. They were dissolved in $\mathrm{HPLC} \mathrm{H}_{2} \mathrm{O}$ to a concentration of $500 \mu \mathrm{M}$.

\begin{tabular}{|c|c|c|c|}
\hline \multirow{2}{*}{ Xt Numb PTB } & for & 5'-AGGAATCAAGAGGGATGCAC-3' & \multirow{2}{*}{$63^{\circ} \mathrm{C}, 35$ cycles } \\
\hline & rev & $5^{\prime}$-CATCCACAACTCGAAGTCCA-3' & \\
\hline \multirow[t]{2}{*}{ Xt Numb PRR } & for & 5'-ACACTTTCAGCATGCCACCT-3' & \multirow[t]{2}{*}{$65^{\circ} \mathrm{C}, 35$ cycles } \\
\hline & rev & 5'-CTTCTTCAAGCCAACGGTCT-3' & \\
\hline \multirow[t]{2}{*}{ Xt NumbL PTB } & for & 5'-AGGAGTCGAGGGGAATGC-3' & \multirow[t]{2}{*}{$64^{\circ} \mathrm{C}, 35$ cycles } \\
\hline & rev & 5'-ACAACACGCAGCCCATCA-3' & \\
\hline
\end{tabular}




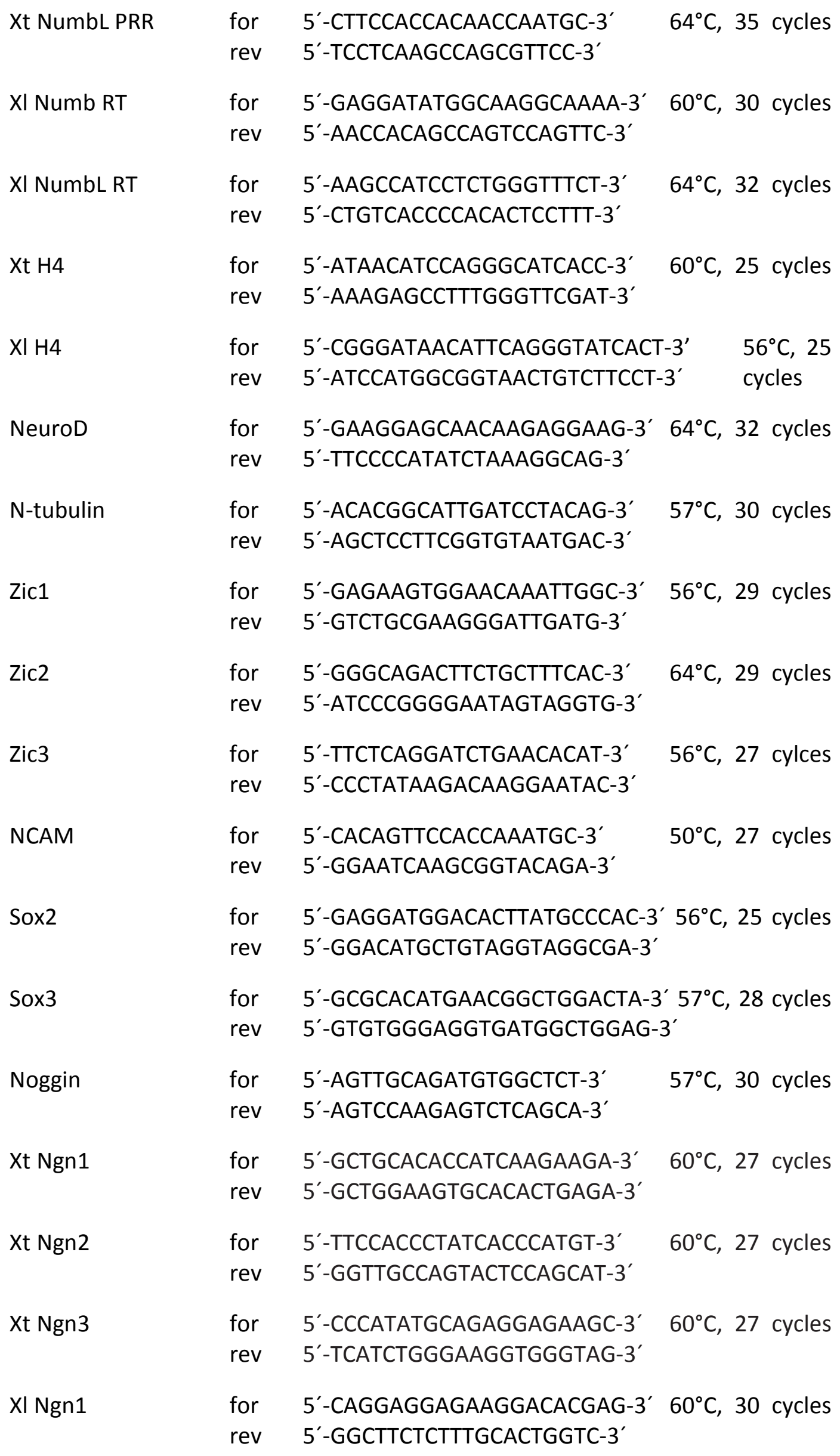




\begin{tabular}{|c|c|c|c|}
\hline \multirow[t]{2}{*}{$\mathrm{XI}$ Ngn2 } & for & 5'-GCGCGTTAAAGCTAACAACC-3' & \multirow[t]{2}{*}{$60^{\circ} \mathrm{C}, 30$ cycles } \\
\hline & rev & 5'-GTTCAGGTGGAGCTCAGAGG-3' & \\
\hline \multirow[t]{2}{*}{ XI Ngn3 } & for & 5'-AACGAGGTCTCCCCTCTCTC-3' & \multirow[t]{2}{*}{$60^{\circ} \mathrm{C}, 30$ cycles } \\
\hline & rev & 5 -GAGTCCCATTCACTGGAGGA-3' & \\
\hline
\end{tabular}

\subsubsection{General oligonuclotides}

Oligonucleotides (primers) were purchased from Sigma-Aldrich. They were dissolved in $\mathrm{HPLC} \mathrm{H}_{2} \mathrm{O}$ to a concentration of $100 \mu \mathrm{M}$.

$\begin{array}{lll}\text { SP6 } & \text { 5'-TATTTAGGTGACACTATAG-3' }^{\prime} & 56^{\circ} \mathrm{C} \\ \text { T7 } & \text { 5'-TAATACGACTCACTATAGGGCGA-3' }^{\prime} & 56^{\circ} \mathrm{C} \\ \text { T7 (pCS2 }+) & 5^{\prime} \text {-TCTACGTAATACGACTCACTATAG-3' } & 56^{\circ} \mathrm{C}\end{array}$

\subsubsection{Morpholino oligonucleotides}

Antisense morpholino oligonucleotides (Morpholinos, MO's) were purchased from Gene Tools , LLC (Philomath, USA). They were dissolved in RNAse free water to a concentration of $10 \mu \mathrm{g} / \mu \mathrm{l}$. MO were stored at $-20^{\circ} \mathrm{C}$. Prior to use, $\mathrm{MO}$ were heated to $65^{\circ} \mathrm{C}$ for 5 minutes.

NumbL MO: $\quad$ 5'-GCGCAGTAGTTGATGTTTGCCCTCA-3'

NumbL mmMO: $\quad$ 5'-GCCCAGTACTTCATCTTTGGCGTCA-3' 


\subsection{Constructs}

\subsubsection{Overexpression constructs}

NumbLpCS2+ harbors the full open reading frame of XI NumbL, including ATG and stop codon. The fragment was generated by PCR amplification using NumbLpKBCMV (previously isolated by Dr. K. Henningfeld) as template, 5’ NumbL (EcoRI/ATG) 5'- ATGAATTCATGAACAAACTGCGTCAG-3' and 3'NumbL (Xhol) 5'CGCTCGAGCTATCAATTCTATTTGAAAAGTC-3' as primers and inserted into EcoRI/Xhol linearized pCS2+ (D. Turner and R. Rupp, http://sitemaker.umich.edu/dlturner.vectors). For sense RNA, the construct was linearized with Notl and transcribed with SP6 RNA polymerase

MT-NumbLpCS2+ harbors the full open reading frame of XI NumbL, including ATG and stop codon. The fragment was generated by PCR amplification, using NumbLpCS2+ as template, NumbL MT sc for EcoRI 5'ATGAATTCAATGAACAAACTGCGTCAG-3' and NumbL MT sc rev Xhol 5'CGCTCGAGCTATCAATTCTATTTGAAAAGTC-3' as primers and inserted into EcoRI/Xhol linearized MTpCS2+. For sense RNA, the construct was linearized with Notl and transcribed with SP6 RNA polymerase.

NumbL(SA)pCS2+ harbors the full open reading frame of XI NumbL, including ATG and stop codon. The fragment was generated using the QuikChange XI SiteDirected Mutagenesis Kit (Stratagene), using NumbL pCS2+ as template and XLN S291A for 5'- GCTGGTGAGACAGGGAgCCTTTCGTGGATTCC-3', XLN S291A rev 5'GGAATCCACGAAAGGCTCCCTGTCTCACCAGC-3', XLN S310A for 5'CCTTTTAAACGGCAGCTTgCGCTGAAACTCAATGAGC-3'and XLN 310A rev 5'GCTCATTGAGTTTCAGCGcAAGCTGCCGTTTAAAAGG-3'as primers (introduced mutations in small letters) in two subsequent rounds of mutagenesis. For sense 
RNA, the construct was linearized with Notl and transcribed with SP6 RNA polymerase.

NumbL(SD)pCS2+ harbors the full open reading frame of XI NumbL, including ATG and stop codon. The fragment was generated using the QuikChange XL SiteDirected Mutagenesis Kit (Stratagene), using NumbL pCS2+ as template and XLN S291D for 5'- GCTGGTGAGACAGGGAgaCTTTCGTGGATTCCCTGC-3', XLN S291D rev 5'- GCAGGGAATCCACGAAAGtcTCCCTGTCTCACCAGC-3', XLN S310D for 5'CCTTTTAAACGGCAGCTTgacCTGAAACTCAATGAGCTCCCG-3'and XLN 310D rev 5'CGGGAGCTCATTGAGTTTCAGgtcAAGCTGCCGTTTAAAAGG-3' as primers (introduced mutations in small letters) in two subsequent rounds of mutagenesis. For sense RNA, the construct was linearized with Notl and transcribed with SP6 RNA polymerase.

NumbL-CTappCS2+ harbors the full open reading frame of XI NumbL cloned upstream of the GS-TAP tag (Kyriakakis et al., 2008). For cloning, the NumbL fragment was generated using XI NumbL pCS2+ as template and 5'NumbL EcoRI 5'- ATGAATTCATGAACAAACTGCGTCAG-3' and NL-CTap fusion rev 5'CTTCTCGTCCAT CAATTCTATTTGAAAAGTC-3' as primers. CTap fragment was generated using pMK33-CTap (Kyriakakis et al., 2008) as template and NL-CTap fusion for 5'-CAAATAGAATTGATGGACGAGAAGACCACC-3' and 3'Xhol CTap 5'ATCTCGAG TCATTATTCAGTGACAGTG-3'as primers. Both fragments were fused a primerless PCR and then inserted into EcoRI/Xhol linearized pCS2+. For sense RNA, the construct was linearized with Notl and transcribed with SP6 RNA polymerase.

NumbL(DLA)pCS2+ harbors the full open reading frame of XI NumbL, including ATG and stop codon. The fragment was generated using the QuikChange XL SiteDirected Mutagenesis Kit (Stratagene), using NumbLpCS2+ as template and NL 
mut AP2 for 5'- AGGAAGTGGACCtGgcTGAAGCTCAATGGG-3'and NL mut AP2 rev 5' - CCCATTGAGCTTCAgcCaGGTCCACTTCCT-3'as primers (introduced mutations in small letters). For sense RNA, the construct was linearized with Notl and transcribed with SP6 RNA polymerase.

MT-NumbL(DLA)pCS2+ harbors the full open reading frame of XI NumbL, including ATG and stop codon. The fragment was generated using the QuikChange XL Site-Directed Mutagenesis Kit (Stratagene), using MT-NumbL pCS2+ as template and NL mut AP2 for 5'AGGAAGTGGACCtGgcTGAAGCTCAATGGG-3'and NL mut AP2 rev 5'CCCATTGAGCTTCAgCCaGGTCCACTTCCT-3'as primers (introduced mutations in small letters). For sense RNA, the construct was linearized with Notl and transcribed with SP6 RNA polymerase.

NumbL(DLA-SA)pCS2+ harbors the full open reading frame of XI NumbL, including ATG and stop codon. The fragment was generated using the QuikChange XL Site-Directed Mutagenesis Kit (Stratagene), using NumbL(SA)pCS2+ as template and NL mut AP2 for 5'AGGAAGTGGACCtGgctGAAGCTCAATGGG-3'and NL mut AP2 rev 5'CCCATTGAGCTTCAgcCaGGTCCACTTCCT-3'as primers (introduced mutations in small letters). For sense RNA, the construct was linearized with Notl and transcribed with SP6 RNA polymerase.

Xt Numb3pCS107 harbors the full Xt Numb3 open reading frame including ATG and stop codon. It was obtained from an EST Clone library (clone TEgg132/24) (Gene Service, Gilchrist et al., 2004): For sense RNA, the construct was linearized with Apal and transcribed with SP6 RNA polymerase. 
MT-Xt NumbpCS2+ harbors the full open reading frame of Xt Numb, including ATG and stop codon. The fragment was generated using the Xt Numb-pCS107 as template and MT-Xt Numb sc for 5'- GAATTCGATGAACAAACTGCGTCAG-3'and MT-Xt Numb sc rev 5' - CTCGAGCTACAATTCTATTTGAAAAGTCTTTTG-3'as primers and inserted into EcoRI/Xhol linearized pCS2+-MT. For sense RNA, the construct was linearized with Notl and transcribed with SP6 RNA polymerase.

mNumb1-4pCS2+ harbor the full open reading frames of the mNumb1-4 isoforms (Dho et al., 1999). The clones mNumb1-4pEN clones were obtained from Dr. J. Mc Glade (Dho et al., 1999). For cloning mNumb1-4 isoforms into pCS2+, the inserts were excised with EcoRI and ligated into EcoRI linearized pCS2+ . For sense RNA, the constructs were linearized with Notl and transcribed with SP6 RNA polymerase.

MT-mNumb1pCS2+ harbors the full open reading frame of mNumb1, including ATG and stop codon. The fragment was generated using mNumb1-pCS2+ as template and mN1-MT sc for 5'-GAATTCAATGAACAAACTACGGCAA-3 and mN1MT sc rev 5'- CTCGAGCTAAAGTTCTATTTCAAATGTTTTC- 3 ' as primers and inserted in EcoRI/Xhol linearized pCS2+-MT. For sense RNA, the construct was linearized with Notl and transcribed with SP6 RNA polymerase.

mNumbLpCS2+ harbors the full open reading frame of mNumbL (GenBank \#U70674), including ATG and stop codon. It was excised with EcoRI and Xhol from mNumbL pBSK(-) (received from Dr. W. Zhong, Zhong et al., 1997) and subcloned (EcoRI/Xhol) into pCS2+. For sense RNA, the construct was linearized with Notl and transcribed with SP6 RNA polymerase. 
Xt Ngn1pCS2+ harbors the full open reading frame of Ngn1, including ATG and stop codon. The fragment was generated using Ngn1pCS108 (RZPD/imaGenes, CX475730) as template and Xt Ngn1 sc for 5'CGgAATTCATGGCTTCCAACATGGACAG and Xt Ngn1 sc rev 5'GCTCTAGATGTCATTGGAGTTAGCAGGC-3' as primers and inserted into EcoRI/Xbal linearized pCS2+. For sense RNA, the construct was linearized with Notl and transcribed with SP6 RNA polymerase.

Xt Ngn2pCS2+ harbors the full open reading frame of Ngn2, including ATG and stop codon. The fragment was generated using Ngn2pCS108 (RZPD/imaGenes, CX510880) as template and Xt Ngn2 sc for 5'-CGGAATTCATGGTGCTGCTGAAGTG3' and Xt Ngn2 sc rev 5'- GCCTCGAGGTATGCAAGAACTCAAGTGGAA-3' as primers and inserted into EcoRI/Xhol linearized pCS2+. For sense RNA, the construct was linearized with Notl and transcribed with SP6 RNA polymerase.

Xt Ngn3pCS2+ harbors the full open reading frame of Ngn3, including ATG and stop codon. The fragment was generated using Ngn3pCS108 (RZPD/imaGenes, CX366256) as template and Xt Ngn3 sc for 5'- CGGAATTCATGGTGCTGCTGAAGTG and Xt Ngn3 sc rev 5'- GCTCTAGAGTATGCAAGAACTCAAGTGGAA-3' as primers and inserted into EcoRI/Xbal linearized pCS2+. For sense RNA, the construct was linearized with Notl and transcribed with SP6 RNA polymerase.

XI Ngn1pCS2P+ harbors the full open reading frame of XI Ngn1 including ATG and stop codon, 102bp 5'UTR and 227bp 3'UTR. XI Ngn1pCS2P+ was received from NIBB (XL267p21ex). For sense RNA, the construct was linearized with Notl and transcribed with SP6 RNA polymerase. 
XI Ngn3pCS2P+ harbors the full open reading frame of XI Ngn3 including ATG and stop codon, 31bp of 5'UTR and 741bp of 3'UTR. XI Ngn3pCS2P+ was received from NIBB (XL265d10ex). For sense RNA, the construct was linearized with Notl and transcribed with SP6 RNA polymerase.

Following overexpression constructs have been described previously: Su(H) ${ }^{\text {DBM }}$ pCS2+ (Wettstein et al., 1997); Delta-1 ${ }^{\text {STU }}$ pCS2+ (Chitnis et al., 1995); NICDpCS2 (Coffman et al., 1993); NogginpGEM5ZF (Smith et al., 1993), XI Ngnr-1 (Ngn2)pCS2+ (Ma et al., 1996); LacZpCS2+ (Chitnis et al., 1995); mGFPpCS2+ (Moriyoshi et al., 1996, provided by A.Schambony, University of Erlangen, Germany).

\subsubsection{Constructs for whole mount in situ}

XI NumbLpBKCMV harbors the full open reading frame of XI NumbL including 98 bp of 5'UTR and 1233bp 3'UTR. XI NumbL-pBKCMV was isolated by Dr. K. Henningfeld in a $\lambda$ Phage screen from a $X$. laevis tadpole head library (Hollemann et al. 1999). For antisense RNA synthesis, the construct was linearized with EcoRI and transcribed with T7 RNA polymerase.

XI NumbpBLuescript SK- harbors 475 bp of the Numb 3'UTR and was received from the RZPD/imaGenes (BE189039). For antisense RNA synthesis, the construct was linearized with EcoRI and transcribed with T7 RNA polymerase.

Xt Ngn1pCS108 harbors the full Ngn1 open reading frame, including $362 \mathrm{bp}$ of 3'UTR. It was purchased from the RZPD/imaGenes (CX475730). For antisense RNA synthesis, the construct was linearized with Sall and transcribed with T7 RNA polymerase. 
Xt Ngn2pCS108 harbors the full Ngn2 open reading frame, including 260 bp of 3'UTR. It was purchased from the RZPD/imaGenes (CX510880). For antisense RNA synthesis, the construct was linearized with Sall and transcribed with T7 RNA polymerase.

Xt Ngn3pCS108 harbors the full Ngn3 open reading frame, including $529 \mathrm{bp}$ of 3'UTR. It was purchased from the RZPD/imaGenes (CX366256). For antisense RNA synthesis, the construct was linearized with Sall and transcribed with T7 RNA polymerase.

XI Ngn1pCS2P+ harbors the full open reading frame of XI Ngn1 including ATG and stop codon, 102 bp 5'UTR and 227 bp 3'UTR. XI Ngn1pCS2P+ was received from NIBB (XL267p21ex). For antisense RNA synthesis, the construct was linearized with EcoRI and transcribed with T7 RNA polymerase.

XI Ngn3pCS2P+ harbors the full open reading frame of XI Ngn3 including ATG and stop codon, $31 \mathrm{bp}$ of $5^{\prime} \mathrm{UTR}$ and $741 \mathrm{bp}$ of 3'UTR. XI Ngn3pCS2P+ was received from NIBB (XL265d10ex). For antisense RNA synthesis, the construct was linearized with EcoRI and transcribed with T7 RNA polymerase.

Following constructs were previously described: $\mathbf{N}$-tubulin (Oschwald et al, 1991); Ngnr-1 (Ngn2) (Ma et al., 1996); MyT1 (Bellefroid et al., 1996), NeuroD (Lee et al., 1995); NCAM (Tonissen et al., 1993); Sox3 (Penzel et al., 1997); Sox2 (Mitzuseki et al., 1998); Zic1 (Aruga et al., 2001); Zic2 (Brewster et al., 1998); Zic3 (Nakata et al., 1997); XDelta1 (Chitnis et al., 1995); XDelta2 (Jen et al., 1997); ESR1 (Schneider et al., 2001); ESR3/7 (Perron et al., 1998); ESR5 (Jen et al., 
1997); ESR8; ESR9; ESR10 (Gawantka et al., 1998); epidermal keratin (Jonas et al., 1985); Twist (Hopweed et al., 1989)

\subsection{Total RNA extraction and cDNA synthesis}

Total RNA was isolated using the TRIZOL reagent (TriFast, Peqlab). To lyse the cells, 3-5 whole embryos or 30-50 animal caps were macerated with a 29-Gauge syringe in $500 \mu \mathrm{l}$ TRIZOL reagent and centrifuged 10 minutes at maximum speed to remove debris. Further steps were performed according to the manufacturer's manual. The RNA was re-suspended in $30 \mu \mathrm{l}$ RNAse free $\mathrm{H}_{2} \mathrm{O}$ and treated for 1 hour at $37^{\circ} \mathrm{C}$ with DNAsel to digest genomic DNA. DNAsel was inactivated by addition of 1/10 vol. of DNAse inactivation solution (Ambion).

For cDNA synthesis, $100 \mathrm{ng}$ total RNA was used in a $10 \mu \mathrm{l}$ reaction containing 5 $\mathrm{mM} \mathrm{MgCl} 2,2.5 \mathrm{ng}$ random hexamer, $5 \mathrm{mM}$ dNTP mix, 0.8 units RNAse out (Invitrogene) and 20 units reverse transcriptase (Roche) in $1 \mathrm{X} \mathrm{MgCl}_{2}$-free GoTaq incubation buffer (Promega). After a 20 minute annealing step at $20^{\circ} \mathrm{C}$, the reaction was carried out at $42^{\circ} \mathrm{C}$ for 60 minutes and terminated by heating to $95^{\circ} \mathrm{C}$ for 5 minutes.

\subsection{RT-PCR analysis}

For semi-quantitative RT-PCR analysis, $5 \mu \mathrm{l}$ cDNA was used in total reaction volume of $25 \mu \mathrm{l}$, containing $0.2 \mathrm{mM}$ of each RT primer, $1.5 \mathrm{mM} \mathrm{MgCl}_{2}, 0.5$ units GoTaq polymerase (Promega) in $1 \times \mathrm{MgCl}_{2}$-free GoTaq incubation buffer (Promega). Histone $\mathrm{H} 4$ was used as a loading control for equal cDNA concentrations and to test for cDNA contamination by genomic DNA. 


\subsection{In vitro synthesis of RNA}

\subsubsection{Capped sense RNA}

The capped mRNA for microinjections was synthesized using the mMessage mMachine $^{\mathrm{TM}}$ Kit (Ambion) according to the manufacturer's protocol. In $20 \mu \mathrm{l}$ total reaction volume, $1 \mu \mathrm{g}$ of linearized template plasmid was used. The transcription was incubated for at least two hours at $37^{\circ} \mathrm{C}$. After incubation, template DNA was removed by addition of 5 units DNAsel followed by 30 minutes incubation at $37^{\circ} \mathrm{C}$. The mRNA was purified using the RNeasy ${ }^{\mathrm{TM}}$ Mini Kit (Qiagen), eluted in $30 \mu \mathrm{l}$ of RNAse-free $\mathrm{H}_{2} \mathrm{O}$, aliquoted in $2 \mu \mathrm{l}$ and stored at $-80^{\circ} \mathrm{C}$.

\subsubsection{Antisense RNA}

Labeled antisense RNA, used for probes in whole mount in situ hybridization, was synthesized in a total reaction volume of $25 \mu \mathrm{l}$, containing $1 \mu \mathrm{g}$ of linearized template plasmid, $1 \mathrm{mM}$ ATP, $1 \mathrm{mM}$ GTP, $1 \mathrm{mM}$ CTP, $0.64 \mathrm{mM}$ UTP, $0.36 \mathrm{mM}$ digoxigenin or fluorescein labeled UTP, $0.03 \mu \mathrm{M}$ DTT, 1.6 units RNAse out (Invitrogene), 0.05 units Pyrophosphatase and 0.08 units RNA polymerase in 1x transcription buffer. After 3 hours of incubation at $37^{\circ} \mathrm{C}$, the template DNA was removed by addition of 5 units DNAsel and subsequent incubation for 30 minutes at $37^{\circ} \mathrm{C}$. The labeled antisense RNA was purified using the RNeasy ${ }^{\mathrm{TM}}$ Mini Kit (Qiagen), eluting twice with $50 \mu \mathrm{l}$ of pre-heated RNAse free $\mathrm{H}_{2} \mathrm{O}\left(80^{\circ} \mathrm{C}\right)$ and stored in Hybridization Mix at $-20^{\circ} \mathrm{C}$.

\section{7 $\mathrm{T}_{\mathrm{N}} \mathrm{T}$ in vitro translation}

In vitro transcription and translation was performed using the $\mathrm{T}_{N} \mathrm{~T}^{\circledR}$ Coupled Reticulocyte Lysate System (Promega) according to the manufacturer's protocol. Proteins were separated by denaturing SDS-polyacrylamide gel electrophoresis (Sambrook and Russel, 2001). The dried gels were exposed to phosphoimager screens (Amersham) and scanned using a Typhoon Phosphoimager (Amersham). 


\subsection{Embryo culture an microinjections}

10x MBS Salts: $880 \mathrm{mM} \mathrm{NaCl}, 1 \mathrm{mM} \mathrm{KCl}, 10 \mathrm{mM} \mathrm{MgSO}_{4}, 25 \mathrm{mM} \mathrm{NaHCO}_{3}, \mathrm{pH} 7.8$

1x MBS: 1x MBS Salts, $0.7 \mathrm{mM} \mathrm{CaCl} 2$

5x MBS AC (animal caps): $880 \mathrm{mM} \mathrm{NaCl}, 10 \mathrm{mM} \mathrm{KCl}, 10 \mathrm{mM} \mathrm{MgSO}_{4}, 25 \mathrm{mM}$ $\mathrm{NaHCO}_{3}, 2.05 \mathrm{mM} \mathrm{CaCl}_{2}, 1.65 \mathrm{mM} \mathrm{Ca}\left(\mathrm{NO}_{3}\right)_{2}, \mathrm{pH} 7.8$

Agar dishes: $60 \mathrm{~mm}$ petri dishes coated with $0.7 \%-1.5 \%$ agar made with $0.8 \mathrm{x}$ MBS AC.

Dejelly solution: $2 \%(w / v)$ L-cysteine hydrochloride in $\mathrm{H}_{2} \mathrm{O}, \mathrm{pH} 8$

Injection buffer: 1\% (w/v) Ficoll in 1x MBS

Nile Blue staining solution: $0.01 \%(\mathrm{w} / \mathrm{v})$ Nile Blue chloride, $89.6 \mathrm{mM} \mathrm{Na} \mathrm{HPO}_{4}$, $10.4 \mathrm{mM} \mathrm{NaH}_{2} \mathrm{PO}_{4}, \mathrm{pH} 7.8$

$X$. laevis embryos were obtained by HCG-induced egg-laying, using 800 units of HCG per frog. Spawns were in vitro fertilized and embryos staged after Nieuwkoop and Faber, 1967. Embryos were injected in one blastomere of the two- or four-cell stage. For in situ analysis, 75 pg nuclear LacZ mRNA was coinjected. Embryos were injected in injection buffer, incubated for several hours and then incubated at $12.5-18{ }^{\circ} \mathrm{C}$ in $0.1 \mathrm{x}$ MBS until they reached the desired developmental stage. For ectodermal explants and pulldown experiments, the embryos were injected in both animal blastomeres at the twocell stage.

Animal caps were dissected from stage 8-9 embryos in 0.8x MBS AC in agarose coated dishes and cultured in $0.8 \mathrm{x}$ MBS AC until control embryos reached the desired developmental stage.

$X$. tropicalis embryos were either obtained by natural mating or HCG-induced egg-laying, as well. For mating, male and female frog were pre-primed with 20 units of HCG, incubated for at least 12 hours and then boosted with 100 units of HCG. For in vitro fertilization, females were primed with $150-200$ units of HCG. 
$X$. tropicalis embryos were injected like $X$. laevis embryos and cultured in $0.11 x$ MBS at room temperature until they reached the desired developmental stage.

\subsection{X-Gal staining}

10x MEM: $1 \mathrm{M}$ Mops, $20 \mathrm{mM}$ EGTA, $10 \mathrm{mM} \mathrm{MgSO}_{4}$, pH 7.4 sterile filtered and stored in the dark

10x PBS: $1.75 \mathrm{M} \mathrm{NaCl}, 1 \mathrm{M} \mathrm{KCl}, 65 \mathrm{mM} \mathrm{Na}_{2} \mathrm{HPO}_{4}, 18 \mathrm{mM} \mathrm{KH}_{2} \mathrm{PO}_{4}, \mathrm{pH} 7.4$

Dent's solution: $20 \%(\mathrm{v} / \mathrm{v})$ DMSO in methanol

$\mathrm{K}_{3} \mathrm{FE}(\mathrm{CN})_{6}: 0.5 \mathrm{M}$ in $\mathrm{H}_{2} \mathrm{O}$, stored in the dark

$\mathrm{K}_{4} \mathrm{FE}(\mathrm{CN})_{6}$ : $0.5 \mathrm{M}$ in $\mathrm{H}_{2} \mathrm{O}$, stored in the dark

MEMFA: $4 \%(v / v)$ formaldehyde (37\%) in 1x MEM

X-Gal: $\quad 40 \mathrm{mg} / \mathrm{ml} \quad$ 5-Bromo-4-chloro-3-indolyl-ß-D-galactopyranoside in formamide, stored at $-20^{\circ} \mathrm{C}$ in the dark.

X-Gal staining solution: $1 \mathrm{mg} / \mathrm{ml} \mathrm{X-Gal,} 5 \mathrm{mM} \mathrm{K}_{3} \mathrm{FE}(\mathrm{CN})_{6}, 5 \mathrm{mM} \mathrm{K}_{4} \mathrm{FE}(\mathrm{CN})_{6}, 2 \mathrm{mM}$ $\mathrm{MgCl}_{2}$ in $1 \times \mathrm{PBS}$

Embryos were cultivated to the desired developmental stage and fixed for 30 minutes in MEMFA. After washing three times with 1x PBS, embryos were transferred to X-Gal staining solution and incubated in the dark until sufficient staining was observed (10-30 minutes). The staining was stopped by washing the embryos three times with 1xPBS, followed by a second fixation step in MEMFA for 30 minutes. For whole mount in situ, the embryos were dehydrated by washing several times in absolute ethanol and then stored at $-20^{\circ} \mathrm{C}$. For $\mathrm{pH} 3$ staining, embryos were dehydrated with absolute methanol and stored in Dent's solution for at least 24 hours at $-20^{\circ} \mathrm{C}$. 


\subsection{Whole mount in situ hybridization}

10X PBS: $1.75 \mathrm{M} \mathrm{NaCl}, 1 \mathrm{M} \mathrm{KCl}, 65 \mathrm{mM} \mathrm{Na}_{2} \mathrm{HPO}_{4}, 18 \mathrm{mM} \mathrm{KH}_{2} \mathrm{PO}_{4}, \mathrm{pH} 7.4$

20X SSC: $3 \mathrm{M} \mathrm{NaCl}, 0.3 \mathrm{M} \mathrm{NaCitrat,} \mathrm{pH} 7.2$ - 7.4

5X MAB: 500 mM maleic acid, 750 mM NaCl, pH 7.5

Antibody solution: $2 \% \mathrm{BMB}, 20 \%$ heat treated horse serum, 1:2000 dilution of anti-digoxigenin or anti-fluorescein antibody coupled to alkaline phosphatase (Roche) in $1 \mathrm{XMAB}$

APB: $100 \mathrm{mM}$ Tris-HCl, $\mathrm{pH} 9.0,50 \mathrm{mM} \mathrm{MgCl} 2,100 \mathrm{mM} \mathrm{NaCl}, 0.1 \%$ TWEEN20

BCIP: $50 \mathrm{mg} / \mathrm{mL}$ in $100 \%$ Dimethylformamide; stored at $-20^{\circ} \mathrm{C}$

Color reaction solution: $80 \mu \mathrm{g} / \mathrm{ml} \mathrm{NBT}, 175 \mu \mathrm{g} / \mathrm{ml} \mathrm{BCIP} \mathrm{in} \mathrm{APB}$

EtOH series: $100 \%, 75 \%, 50 \%$ ethanol in $\mathrm{H}_{2} \mathrm{O}, 25 \%$ ethanol in PTw

Hybridization Mix (Hyb Mix): 50\% Formamid, $1 \mathrm{mg} / \mathrm{ml}$, Torula-RNA, $10 \mu \mathrm{g} / \mathrm{ml}$ Heparin, 1X Denhardt's, 0.1\% Tween-20, 0.1\% CHAPS, 10 mM EDTA in 5X SSC

MeOH series: $100 \%, 75 \%, 50 \%, 25 \%$ methanol in $\mathrm{H}_{2} \mathrm{O}$

MAB/BMB: $2 \%$ BMB in $1 X$ MAB

MAB/BMB/HS: 2\% BMB, 20\% heat-treated horse serum in 1X MAB

NBT: $100 \mathrm{mg} / \mathrm{mL}$ in $70 \%$ Dimethylformamide; stored at $-20^{\circ} \mathrm{C}$

PTw: 0.1\% Tween-20 in 1X PBS

PTw/FA: 4\% (v/v) formaldehyde in PTw

Proteinase K: $5 \mu \mathrm{g} / \mathrm{ml}$ Proteinase $\mathrm{K}$ in 0.1X PBS

RNAse Solution: $10 \mu \mathrm{g} / \mathrm{ml}$ RNAse $\mathrm{A}, 0.01 \mathrm{U} / \mathrm{ml}$ RNAse T1 in 2X SSC

Whole mount in situ was performed as described (Harland, 1991, Hollemann et al., 1999), using antisense RNA probes labeled with digoxigenin-11UTP or fluorescein-UTP. Double in situ hybridization was performed according to Knecht et al., 1995. All steps were performed at room temperature with mild shaking. The embryos were rehydrated in the EtOH series to PTw, washed three times with PTw for 10 minutes and the subjected to Proteinase $\mathrm{K}$ treatment for 
several minutes to enhance penetration of the antisense probe. To stop Proteinase $\mathrm{K}$ digestion, embryos were washed twice in $0.1 \mathrm{M}$ triethanolamine and $\mathrm{pH} 7.5$ were acetylated by adding $25 \mu \mathrm{l}$ of acetic anhydride to the triethanolamine to reduce unspecific binding of the probe. After treatment, embryos were fixed in PTw/FA for 25 minutes, washed five times in PTw, transferred to HybMix and incubated for 5 hours at $65^{\circ} \mathrm{C}$ in a shaking incubator. Subsequently, HybMix was exchanged for the antisense probe, and hybridization took place overnight at $65^{\circ} \mathrm{C}$.

On the second day, the RNA probes were recovered and stored at $-20^{\circ} \mathrm{C}$ for further use. After washing the embryos for 10 minutes at $65^{\circ} \mathrm{C}$ in $\mathrm{HybMix}$ and three times $2 \mathrm{x}$ SSC for 15 minutes at $65^{\circ} \mathrm{C}$, non hybridized RNA probe was removed by RNAse digestion for 1 hour in RNAse solution at $37^{\circ} \mathrm{C}$. After washing once for 15 minute in $2 x$ SSC and washing twice in $0.2 x$ SSC for 30 minutes at $65^{\circ} \mathrm{C}$, embryos were transferred to $\mathrm{MAB}$ for blocking. After $2 \mathrm{MAB}$ washing steps, embryos were incubated for 20 minutes in $M A B / B M B$ and 40 minutes in $\mathrm{MAB} / \mathrm{BMB} / \mathrm{HS}$ to reduce unspecific binding of the antibody. Antibody incubation took then place for 4 hours shaking at ambient temperature, followed by three MAB washing steps. Embryos were stored in $M A B$ at $4^{\circ} \mathrm{C}$ overnight.

At the third day, embryos were washed twice with MAB and the caps of the vials exchanged followed by another three MAB washings. After transfer of the embryos to $A P B$ and three washing steps using $A P B$, the embryos were transferred to the color reaction solution and incubated at $4^{\circ} \mathrm{C}$ in the dark until staining was sufficient. To stop the reaction, embryos were transferred absolute methanol and washed in the methanol series to reduce background staining. Samples were stored in MEMFA. 


\subsection{Phosphorylated Histone $3(\mathrm{pH} 3)$ staining}

10X PBS: $1.75 \mathrm{M} \mathrm{NaCl}, 1 \mathrm{M} \mathrm{KCl}, 65 \mathrm{mM} \mathrm{Na}_{2} \mathrm{HPO}_{4}, 18 \mathrm{mM} \mathrm{KH}_{2} \mathrm{PO}_{4}, \mathrm{pH} 7.4$

$1^{\circ}$ AB solution: $20 \%$ horse serum, $5 \%$ DMSO, 1:200 dilution rabbit anti-pH3 antibody (Biomol)

$2^{\circ}$ AB solution: $20 \%$ horse serum, $5 \%$ DMSO, 1:200 dilution goat anti-rabbit IgG horseradish peroxidase-coupled secondary antibody (Sigma)

MeOH series: $100 \%, 75 \%, 50 \%$, in $\mathrm{H}_{2} \mathrm{O}$ and $25 \%$ methanol in $1 x P B S$

PBS-TB: $0.05 \%$ Tween-20, 0.2\% BSA in 1x PBS

PBS-TBN: $0.3 \mathrm{M} \mathrm{NaCl}$ in PBS-TB

The pH3 assay was performed as described (Dent et al., 1989). All steps were performed at ambient temperature with mild shaking. After rehydration in the $\mathrm{MeOH}$ series to PBS, the embryos were pre-incubated in $20 \%$ horse serum in PBS for 2 hours. The solution was exchanged to the $1^{\circ} A B$ solution and incubated for 3 hours. After washing twice with PBS-TB for two hours, the embryos were washed overnight in PBS-TB. On the second day, after incubation in PBS-TBN for 3 hours followed by a brief wash in PBS-TB, the embryos were transferred to the $2^{\circ} \mathrm{AB}$ solution and incubated for 5 hours. The embryos were washed twice in PBS-TB for 2 hours, once in PBS TBN for 2 hours and again in PBS-TB for 2 hours before they were washed overnight in PBS-TB. HRP activity was detected as for wmISH.

\subsection{Sections}

Gelatin/albumin: $4.88 \mathrm{mg} / \mathrm{ml}$ gelatin, $0.3 \mathrm{~g} / \mathrm{ml}$ bovine serum albumin, 0.2 $\mathrm{mg} / \mathrm{ml}$ sucrose in PBS. The gelatin was dissolved by heating the solution to $60^{\circ} \mathrm{C}$ followed by the addition of Albumin and sucrose, filtered with a $0.45 \mu \mathrm{m}$ filter (Sartorius) and stored at $-20^{\circ} \mathrm{C}$. 
Mowiol: $5 \mathrm{~g}$ Mowiol was stirred overnight in $20 \mathrm{ml}$ PBS. After addition of 10 $\mathrm{ml}$ glycerol, the solution was stirred again overnight. Mowiol that was undissolved was collected by centrifugation for $30 \mathrm{~min}$ at 20,000 g. The supernatant was $\mathrm{pH}$ adjusted to $\mathrm{pH} 7.0$ (using $\mathrm{pH}$ strips) and stored at $-20^{\circ} \mathrm{C}$.

Samples were transferred to PBS and after equilibration in gelatin/albumin for 20 minutes mounted by addition of glutardialdehyde. Sections $(30 \mu \mathrm{m})$ were cut on a Leica VT1000M vibratome and mounted in Mowiol (Hollemann et al., 1999).

\subsection{Fluorescent labeling of animal caps}

10X PBS: $1.75 \mathrm{M} \mathrm{NaCl}, 1 \mathrm{M} \mathrm{KCl}, 65 \mathrm{mM} \mathrm{Na}_{2} \mathrm{HPO}_{4}, 18 \mathrm{mM} \mathrm{KH}_{2} \mathrm{PO}_{4}, \mathrm{pH} 7.4$

$1^{\circ}$ AB solution: 1:100 goat anti-myc-Cy3 (Sigma) and 1:1000 rabbit anti-GFP (Abcam) in Ptw

$2^{\circ}$ AB solution: 1:200 swine anti-rabbit IgG-FITC (DAKO) in PTw

DAPI solution: 1:1000 DAPI in 1xPBS

MEMFA: $4 \%(v / v)$ formaldehyde (37\%) in 1x MEM

PTw: $0.1 \%$ Tween-20 in 1X PBS

For fluorescent labeling, animal caps were incubated until control siblings reached the desired developmental stage. The caps were fixed in MEMFA for 1 hours at ambient temperature or overnight at $4^{\circ} \mathrm{C}$. After three $10 \mathrm{~min}$ washes of PTw, the first Antibody solution was applied for 2 hours at ambient temperature in the dark. After three 10 min washes of PTw, the second Antibody solution was applied for 1 hour at ambient temperature in the dark. Caps were then washed for 10 min once with PTw and once with PBS. To label nuclear DNA, DAPI solution was applied for $10 \mathrm{~min}$. Caps were then transferred to PTw and stored up to one week at $4^{\circ} \mathrm{C}$ in the dark before evaluation at the confocal microscope. 


\subsection{Tandem affinity purification (TAP)}

Lysis buffer: $5 \mathrm{mM}$ Tris, 5\% (v/v) Glycerol, 0.2\% (v/v) NP-40, $1.5 \mathrm{mM} \mathrm{MgCl} 2,125$ $\mathrm{mM} \mathrm{NaCl}, 25 \mathrm{mM} \mathrm{NaF}, 1 \mathrm{mM}$ NaVO4, $1 \mathrm{mM}$ DTT, $1 \mathrm{mM}$ EDTA, 1 protease inhibitor tablet (Roche) per $50 \mathrm{ml}$, pH 7.5

TEV cleavage buffer: $10 \mathrm{mM}$ Tris, $100 \mathrm{mM} \mathrm{NaCl}, 0.1 \%$ NP-40, 1mM DTT, $0.5 \mathrm{mM}$ EDTA, pH 7.5

Tandem affinity purification was essentially performed as described (Kyriakakis et al., 2008). All steps were performed at $4^{\circ} \mathrm{C}$. For tandem affinity purification of NumbL, 2000 embryos each were injected in both blastomeres at the 2-cell stage with NumbL-CTap or CTap alone (500 pg/injection), grown until they reached stage 15 and then shock frozen in liquid nitrogen. Embryos were lysed in $10 \mu \mathrm{l}$ lysis buffer per embryo, using first a yellow pipette tip, then a 29-gauge syringe. After 30 minutes centrifugation at $4^{\circ} \mathrm{C}$ and maximum speed, the supernatant was transferred without any debris into new vials and mixed 1:1 with Freon to remove remaining yolk. After 10 minutes centrifugation at $4000 \mathrm{rpm}$ at $4^{\circ} \mathrm{C}$, the supernatant was again recovered into $15 \mathrm{ml}$ falcon tubes (aliquots kept for "input"). $200 \mu$ of IgG-sepharose beads were added in each tube and samples were incubated on a nutator for 2 hours at $4^{\circ} \mathrm{C}$. After 1 minute centrifugation at $4^{\circ} \mathrm{C}$, samples were three times washed with $2 \mathrm{ml}$ of TEV cleavage buffer. For TEV cleavage, $1 \mathrm{ml}$ of TEV cleavage buffer and $10 \mu \mathrm{l}$ of TEV (AcTev, Invitrogen) were added and samples were incubated overnight on a nutator at $4^{\circ} \mathrm{C}$.

For the second pulldown, samples were centrifuged 1 minute at $4000 \mathrm{rpm}$ at $4^{\circ} \mathrm{C}$, supernatant was recovered (aliquot saved for " $1^{\text {st }}$ pulldown") into new tubes and $100 \mu \mathrm{l}$ of streptavidin-beads were added, followed by a 2 hours incubation on a nutator at $4^{\circ} \mathrm{C}$. After three washing steps with $2 \mathrm{ml} \mathrm{TEV} \mathrm{cleavage}$ buffer, $500 \mu$ of $2 x$ SDS loading buffer were added and samples were boiled 5 minutes at $95^{\circ} \mathrm{C}$ to elute bound proteins. Samples were cooled on ice, centrifuged 1 minute at max speed and supernatant was recovered. To reduce 
the volume of the eluate, samples were loaded on Amicon centrifugation columns (cut-off $5 \mathrm{kDa}$ ) and were centrifuged 1 hour at $4000 \mathrm{rpm}$ at $4^{\circ} \mathrm{C}$ until sample volume reached $100 \mu \mathrm{l}$. To separate the eluted proteins, $25 \mu \mathrm{l}$ of each sample were loaded on $10 \%$ SDS gel.

Protein bands were visualized first by Colloidal Coomassie staining (Neuhoff, 1988, modified by Dr. O. Jahn, (Proteomics Unit, MPI for Experimental Medicine, Göttingen, Germany) and then subjected to mass spectrometry analysis using a Bruker Ultraflex MALDI-TOF-MS and a Thermo Finnigan LCQ Deca XP plus ES-ITMS. 


\section{Results}

\subsection{Xenopus Numb isoforms switch during neural development}

Mammalian Numb and NumbL have been shown to play an essential role during early development, particularly in the context of the nervous system (Gulino et al., 2010). However, the functional role and molecular mechanism of action has been under debate. Therefore, to gain further insight into the function of this important class of proteins during early vertebrate development, the role of the Numb proteins during Xenopus embryogenesis was evaluated. Four different isoforms of mammalian Numb, which are generated by alternative splicing, have thus far been described (Verdi et al., 1999; Dho et al., 1999). These isoforms differ by the presence or absence of an insert in the PTB and PRR domain and were shown to exhibit different functional activities (Toriya et al., 2006). Therefore, in a first approach to analyze the expression of the Numbs in Xenopus, RT-PCR analysis on staged embryos was performed as it can distinguish between the possible different isoforms.

$X$. tropicalis cDNA was used, as genomic sequence information is available allowing the design of primer sets spanning the putative insert regions of the splice variants. As shown in Fig. 13, multiple bands for Numb and a single size PCR product for NumbL were generated using the specific primers pairs. To unambiguously confirm that the observed PCR products indeed represent the different isoforms of Numb indicated, the amplified products were isolated and sequenced (see Appendix Fig. 1).

Starting at gastrula stages and throughout all later developmental stages analyzed, NumbL transcripts were detected that encode for a single protein lacking both the insert in the PTB and PRR domain (PTBo/PRRo). In contrast, PCR products corresponding to the PTBo/PTBi and PRRo/PRRi splice variants of Numb were detected, which is consistent with the previously described murine isoforms. Furthermore, a switch in Numb isoform expression occurs during development. In early cleavage stages the maternal transcripts encode for Numb 
PTBo isoforms, which do not harbor the PTB insert (Numb3 or Numb4). However, starting from stage 15 and during subsequent developmental stages, increasing levels of PTBi isoforms (Numb1 or Numb2) with a simultaneous decrease in PTBo isoform levels are detected. Throughout development, most Numb isoforms contain the PRR insert (Numb1, Numb3) since only low but stable levels of PRRo transcripts (Numb2, Numb4) are detected. In contrast to the PTBi/PTBo ratio, the PRRi/PRRo ratio does not change during ongoing development. Thus during early developmental stages Numb3 is the most abundant Numb transcript expressed and during later developmental stages transcripts encoding Numb1 and Numb3 are both present.

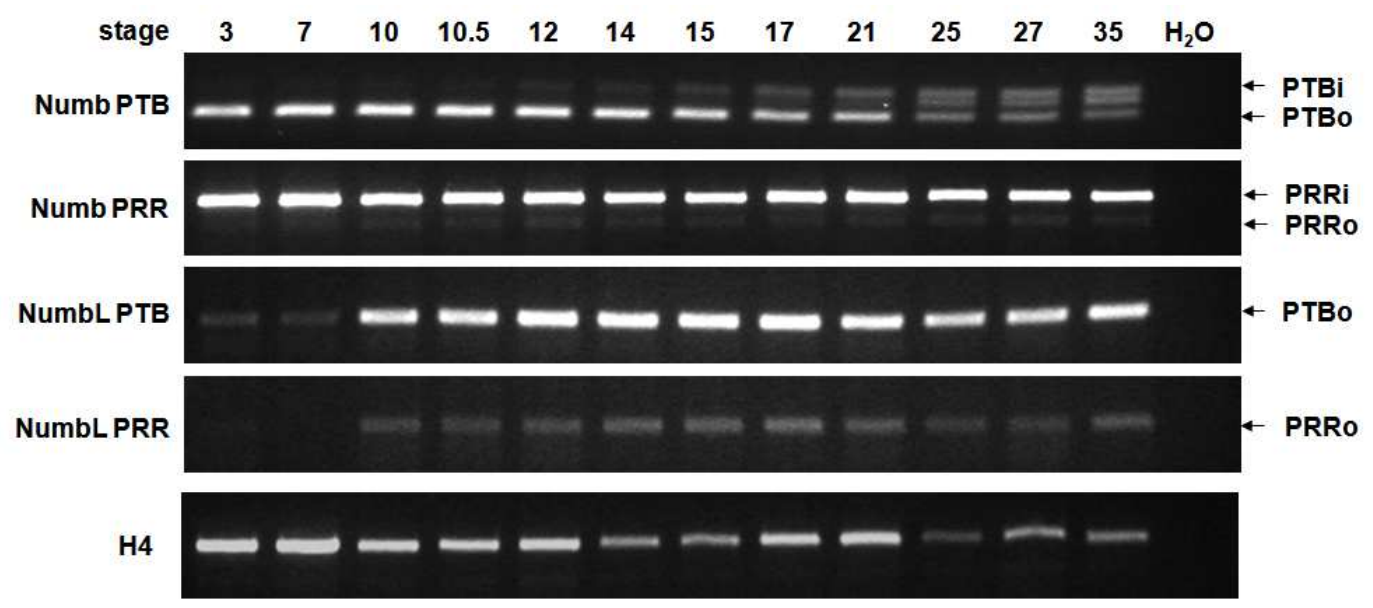

Figure. 13: Temporal expression analysis of $X$. tropicalis Numb and NumbL isoforms. Semi-quantitative RT-PCR analysis of staged embryo cDNA. Stages are indicated in the upper lane, the primer sets used at the left. To control for genomic DNA, a control RTPCR reaction was done on the staged RNA in the absence of reverse transcriptase. Histone 4 was used as a loading control. Arrows at the right indicate the expected PCR product size of the isoforms.

\subsection{NumbL is expressed in the territories of primary neurogenesis}

Numb and NumbL are expressed in partially overlapping expression patterns in the mouse (Zhong et al., 1996; Zhong et al., 1997). Thus it is anticipated that they have common as well as distinct functions that correlate with their specific expression patterns. While Numb is expressed at low levels ubiquitously throughout the developing embryo, NumbL expression is highly restricted to the nervous system. Moreover, while Numb is found throughout all 
layers of the neural tube, NumbL is only present in the mantle layer where cells are actively differentiating (Zhong et al., 1997).

To evaluate their potential role in the development of the nervous system in Xenopus embryos, a detailed comparative expression analysis of Numb and NumbL was performed (Fig. 14). Whole mount in situ hybridization analysis was performed to determine the spatial expression of Numb and NumbL in X. laevis embryos. Numb is expressed at low levels throughout the embryo during early cleavage and gastrula stages (Fig. 14A, B). At open neural plate stages, Numb is weakly detected throughout the ectoderm and is enriched in a single longitudinal domain on both sides of the midline as well as in a horse-shoe domain that marks the panplacodal primordium (Schlosser 2006) (Fig. 14C, D). At stage 30, Numb transcripts are concentrated in the anterior region of the embryo including the brain and throughout the spinal cord. High expression levels of Numb are also found in the otic vesicle and the pronephros (Fig. 14J). As previously described (see Nieber 2007), during gastrula stages, NumbL is strongly detected above the blastopore lip, which demarcates the presumptive neural ectoderm (Fig. 14E, F). At the open neural plate stage, NumbL is detected in the midline and strikingly found in the territories of primary neurogenesis including the three longitudinal domains in the posterior neural plate, as well as in neurogenic trigeminal and olfactory placodes (Fig. 14G, H). At tailbud stages, NumbL continues to be expressed in the nervous system and is detected throughout the brain, spinal cord, eye and branchial arches (Fig. 14L).

The tissue-specific differences in NumbL and Numb expression in the neuroectoderm of open neural plate stage embryos are shown in transversal sections (Fig. 14l, K). Numb is found adjacent to the midline in the superficial epidermal layer of the bilayered neuroectoderm, which stays in a proliferative state and primarily undergoes differentiation in the later, secondary wave of neurogenesis (Chalmers et al., 2002; Hartenstein 1989). In contrast, all three longitudinal expression domains of $N u m b L$ are located in the deep layer of the neuroectoderm, which mainly gives rise to the primary neurons (Fig 14K). The midline staining of NumbL is also located in the deeper sensorial layer in the 
tissue that will give rise to the spinal cord floorplate. At tailbud stages, Numb is weakly expressed throughout the neural tube (Fig. 14M), while the expression of NumbL is more restricted (Fig. 14N) and is excluded from the ventricular zones were proliferating progenitor cells are located. In a double in situ for NumbL and $\mathrm{N}$-tubulin (Fig. 140), both expression domains partially overlap in the outer mantle zone, but in addition, NumbL is expressed in the intermediate zone, suggesting a function for NumbL during the onset of neuronal differentiation.
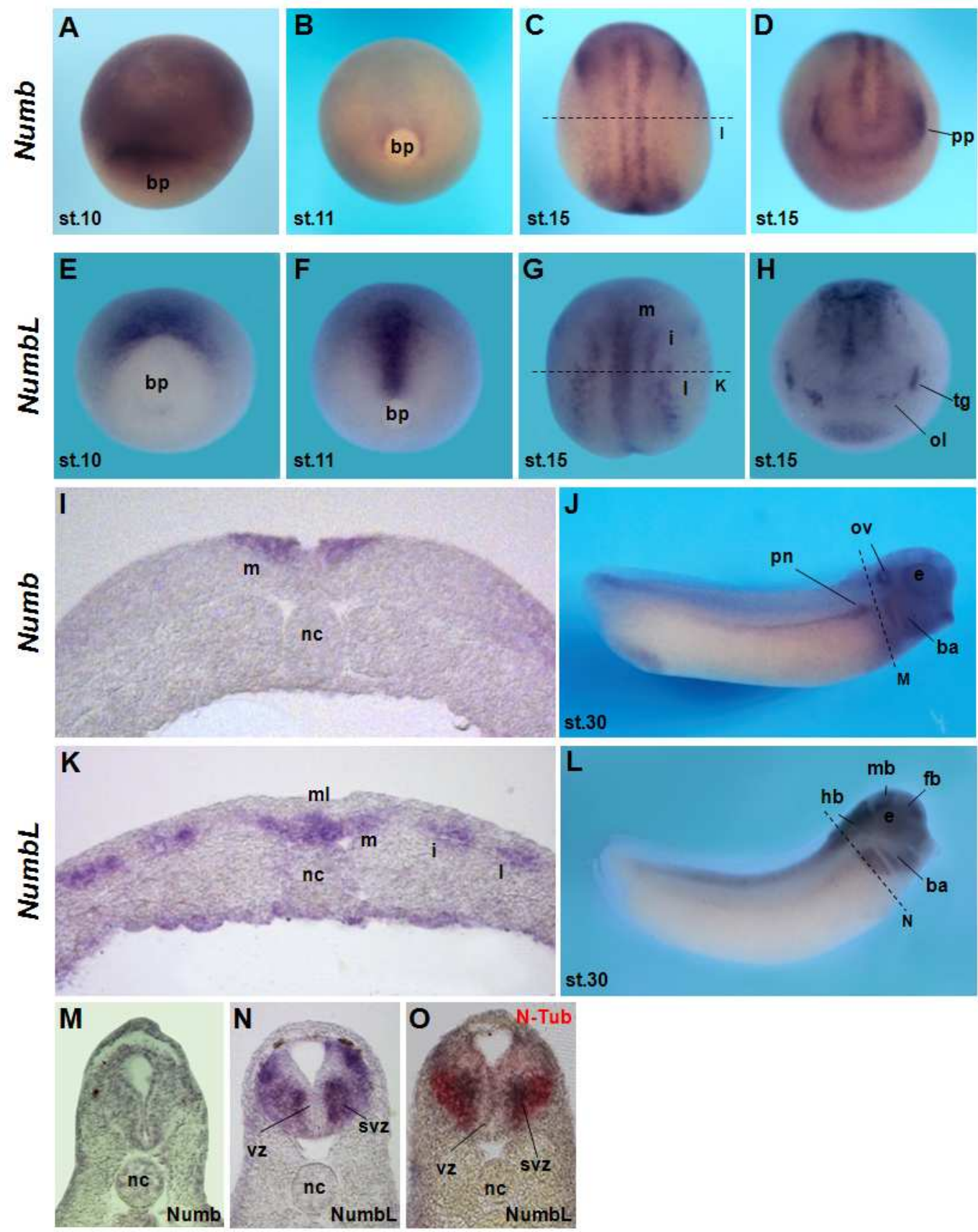
Figure 14: Comparison of spatiotemporal expression of $X$. laevis Numb and NumbL. Whole mount in situ expression analysis of Numb (A-D, I-J,M) and NumbL (E-H, K,L, $\mathbf{N}, \mathbf{O}$ ). (A,B and $E, F)$ Gastrula stage embryo shown in view of the blastopore. (C and $G$ ) Neurula stage embryo, dorsal view, anterior up. Dashed line indicates plane of the transversal section shown below. (D and H) Neurula stage embryo, anterior view, dorsal up. (J and L) Tailbud stage embryo shown in a lateral view. Dashed line indicates plane of the transversal section shown below. (0) Transversal section of a stage 30 embryo hindbrain. Double in situ on NumbL (black) and N-tubulin (red). bp, blastopore; nc, notochord; st, stage; m, medial stripe; i, intermediate stripe; I, lateral stripe; ov, otic vesicle; pn, pronephros; ba, branchial arches; fb, forebrain; mb, midbrain; hb, hindbrain; ol, olfactory placode; pp, panplacodal primordium; tg, trigeminal placode; vz, ventricular zone; svz, subventricular zone.

\subsection{NumbL is positively regulated by Neurogenin 1-3}

As Xenopus NumbL exhibited a restricted expression in the areas of primary neurogenesis and loss-of-function experiments suggested an essential role of NumbL (Nieber 2007) in the process of primary neurogenesis, a detailed functional analysis of NumbL in this context was performed. A knockdown of NumbL has been shown to inhibit the expression of neuronal differentiation factors such as MyT1 and NeuroD, which act downstream of the proneural determination factor Ngn2 (Nieber 2007). Moreover, both the temporal expression of NumbL in the territories of primary neurogenesis, as well as the expression in the intermediate zone of the neural tube suggest a role for NumbL in Xenopus neurogenesis as cells have already started to initiate differentiation. It was therefore tested, if NumbL is indeed regulated by the Ngn family of proneural transcription factors. $X$. laevis embryos were injected in one of two cells with Ngn1, Ngn2 or Ngn3 mRNA and the influence on NumbL expression examined at stage 15 by whole mount in situ hybridization (Fig. 15). As shown in Fig. 15G-I, all three Ngns activate $N$-tubulin and NumbL in both the neural and nonneural ectoderm (Fig. 15A-C). Corresponding to the induction of $\mathrm{N}$-tubulin only in the sensorial layer upon Ngn2 overexpression (Chalmers et al., 2002), NumbL is also exclusively activated in the sensorial layer of the epithelium (Fig. 15D-F). 
In a second approach, the animal cap assay was used where both animal blastomeres of two-cell stage embryos were injected with Ngn mRNA. The animal caps were excised at the blastula stage, cultured until control siblings reached stage 15 and the expression level of target genes analyzed by semiquantitative RT-PCR. As shown in Figure 15J, all three Ngns strongly activated $\mathrm{N}$ tubulin and NumbL in naïve ectoderm. This is consistent with the Ngn-induced activation in the nonneural ectoderm of the embryo. Moreover, Numb was not activated by Ngn, which further demonstrates that NumbL, but not Numb, is activated during neuronal differentiation downstream of the proneural factors.

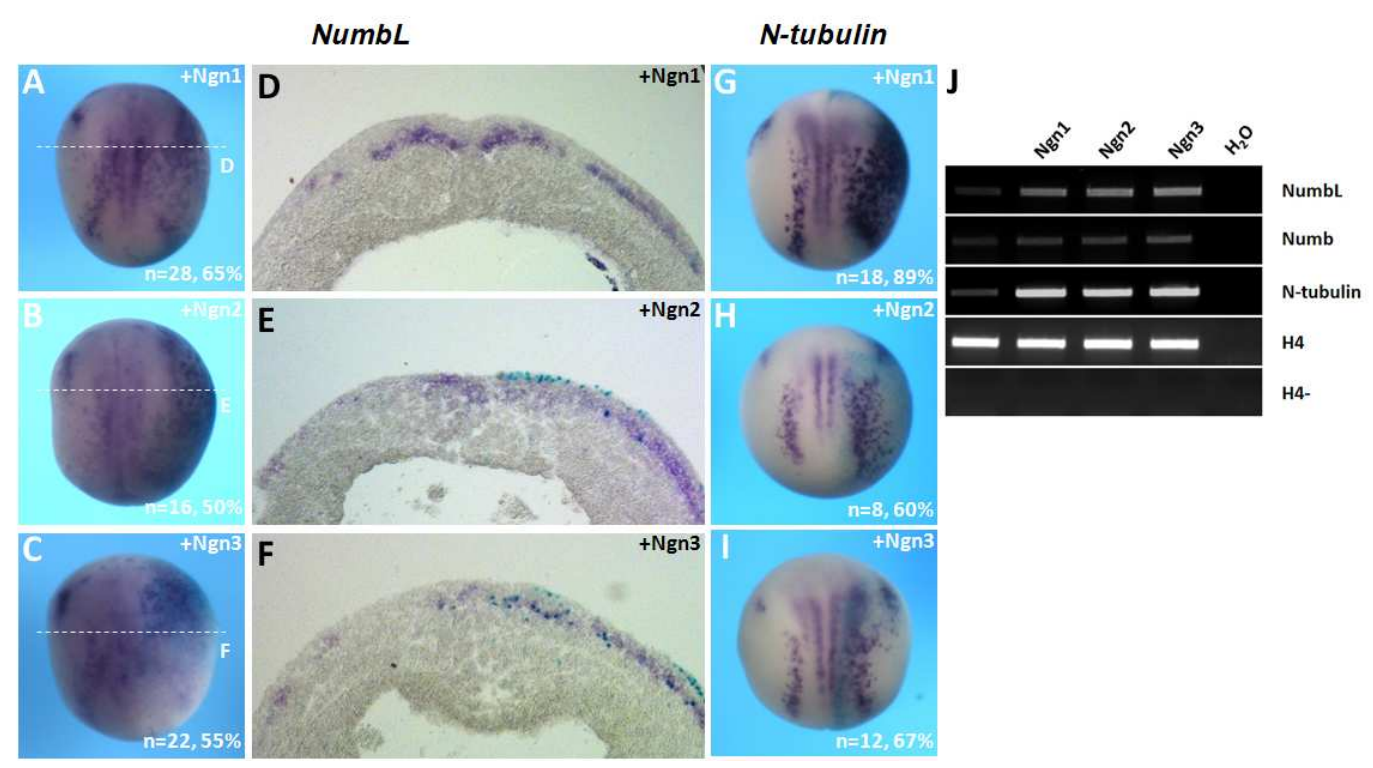

Figure 15: NumbL is positively regulated by the neurogenins. (A-C and G-I) Whole mount in situ hybridization analysis of neuronalized embryos. $X$. laevis embryos were injected with $20 \mathrm{pg}$ of Ngn1, Ngn2 or Ngn3 mRNA, as indicated in the upper right corner, and fixed at stage 15 prior to analysis. $50 \mathrm{pg}$ of $ß$-Gal mRNA were co-injected as lineage tracer and mark the injected side, which is blue and always on the right. Embryos are shown in a dorsal view, anterior up. In situ probes are indicated at the top, statistics in the lower right corners. Dashed lines indicate plane of transversal sections adjacent to the embryos. All three Neurogenins induce $N u m b L$ as well as $N$-tubulin. (D-F) Transversal sections as indicated in A-C. (J) Semi-quantitative RT-PCR analysis of CDNA of $X$. laevis animal caps injected with $20 \mathrm{pg}$ of Ngn1, Ngn2 or Ngn3 mRNA, as indicated. Explants were cultured until control siblings reached stage 15 and then total RNA was extracted. To control for genomic DNA a control RT-PCR reaction was done on the staged RNA in the absence of reverse transcriptase. $\mathrm{H}_{2} \mathrm{O}$ represents a negative control were no RNA was added to the RT reaction. All three Neurogenins induce NumbL and $N$-tubulin, but not Numb. 


\subsection{NumbL gain-of-function leads to an increase in neural tube size}

As the expression, regulation and loss-of-function analysis support a role for NumbL during Xenopus primary neurogenesis, a detailed analysis of NumbL function in this context was performed. At first, MT-NumbL mRNA was overexpressed in $X$. laevis embryos and the influence on primary neuron formation was monitored by whole mount in situ hybridization (Fig. 16). At the open neural plate stage, a slight increase in density of $\mathrm{N}$-tubulin positive cells in the lateral stripe was observed (Fig. 16A). In a transversal section of the neural plate, all $\mathrm{N}$-tubulin positive cells were located in the sensorial layer of the neuroepithelium (Fig. 18B). The same effect was obtained by overexpression of the NumbL(SA) double mutant, in which two serines (S264 and S281) that represent phosphorylation sites for negative post-translational regulation of NumbL (Kobayashi et al., 2006) were exchanged to alanine (Fig. 16C). At tailbud stage, the embryos overexpressing NumbL do not exhibit an obvious phenotype except a slight bending of the embryo axis (Fig. 16D). In transverse, an increase in the size of the neural tube with a concomitant increase in $N$-tubulin positive cells is observed (Fig. 16E). Taken together, in gain-of-function analysis of NumbL in $X$. laevis embryos, NumbL is not sufficient to induce ectopic neurogenesis, but rather increases differentiation of primary neurons in the territories of primary neurogenesis. 


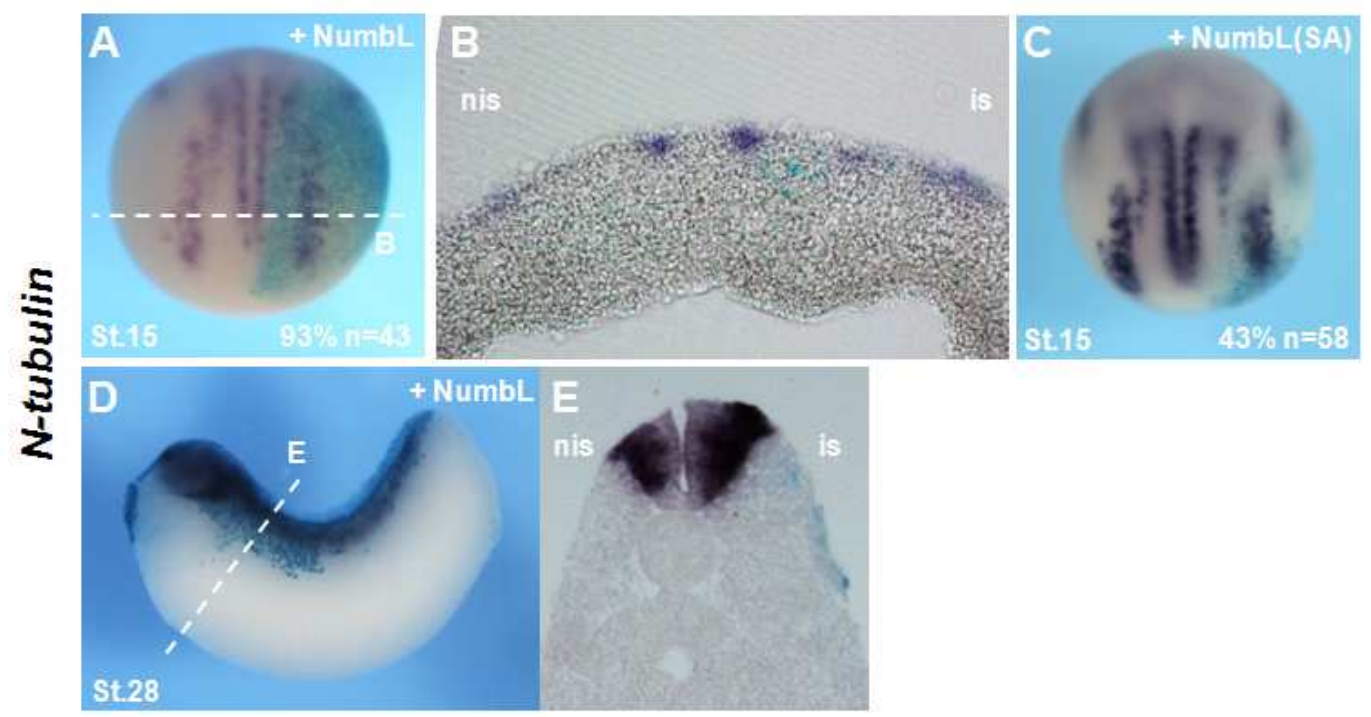

Figure 16: NumbL overexpression promotes neurogenesis and enlarges the neural tube. Whole mount in situ analysis of embryos that were injected with $500 \mathrm{pg}$ of NumbL or NumbL(SA) mRNA as indicated in the upper right corner. B-Gal mRNA was co-injected as a lineage tracer. Embryos were cultured until the stage indicated in the lower left corner, fixed and probed for $\mathrm{N}$-tubulin. Statistics are indicated in the lower right corner. (A) Embryo shown in a dorsal view, anterior up. Dashed line indicates the plane of the section shown in B. (C) Embryo shown in a dorsal view, anterior up. At open neural plate stage, overexpression of NumbL or NumbL(SA) results in a slight increase in $\mathrm{N}$-tubulin positive cells on the injected side. (D) Embryo shown in a lateral view, anterior to the left. Dashed line indicated the plane of section shown in E. At tailbud stages, NumbL overexpression results an increased neural tube and an increased number of $\mathrm{N}$-tubulin positive cells.

\subsection{NumbL knockdown does not activate the Notch pathway}

One of the best-described functions of members of the Numb family is their ability to act as an inhibitor of Notch signaling (Uemura et al., 1989; McGill et al., 2003). The loss of neuronal differentiation observed upon knock-down of NumbL in X. laevis (Nieber 2007) may therefore be the result of increased Notch signaling, which then suppresses neurogenesis. As described previously, neither the Notch target genes ESR1 and ESR9 nor the Notch ligand Delta1 were found to be upregulated upon NumbL knockdown (Nieber 2007; Fig. 17A,B,F). To further provide evidence that Notch activity is indeed not increased by knock-down of NumbL, additional Notch target genes were analyzed by whole mount in situ in NumbL MO injected embryos (Fig. 17). The expression of all tested ectodermal 
Notch target genes, ESR3, ESR8 and ESR10 (Fig. 17A-C, E-G), was not altered upon NumbL knockdown. The Notch target gene ESR5 and the Notch ligand Delta2 were shown to act in segmentation of the paraxial mesoderm (Sparrow et al., 1998). Corresponding with previous studies that demonstrated defects in somite formation in the mesoderm upon Numb/NumbL double knockout in mice (Petersen et al, 2005), ESR5 and Delta-2 were inhibited upon NumbL knockdown (Fig. 17D,H), indicating decreases in Notch signaling levels upon NumbL knockdown in the mesoderm.
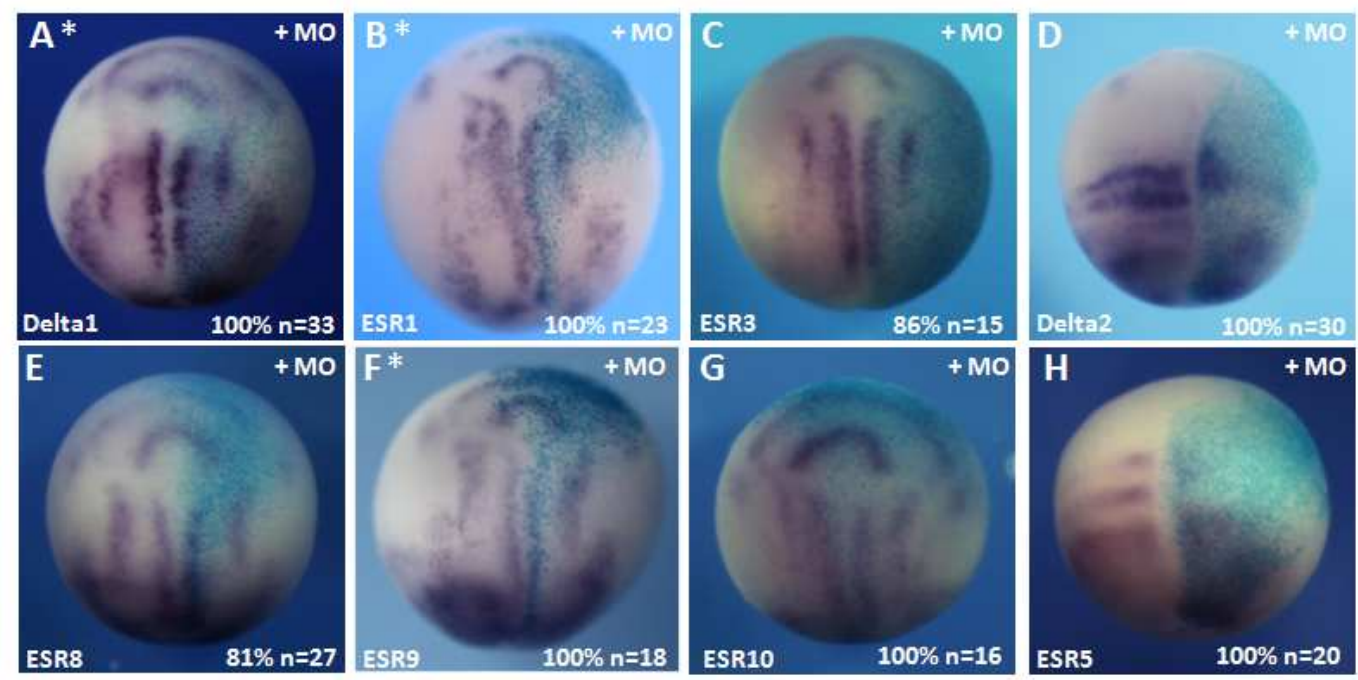

Figure 17: NumbL knockdown does not cause an increase of the Notch signaling pathway in the open neural plate. Whole mount in situ hybridization analysis of Notch target genes and Notch ligands in NumbL morphant embryos. Embryos were injected with $12.5 \mathrm{ng}$ of NumbL $\mathrm{MO}$ and $50 \mathrm{pg}$ of ß-Gal mRNA as a lineage tracer in one blastomere of 2-cell embryos and cultured until stage 15 . The injected side is marked by blue ß-Gal staining and is always at the right. Embryos are shown in a dorsal view, anterior up. Probed genes are indicated in the lower left corner, statistics in the lower right corner. (A-C; E-G) NumbL knockdown does not upregulate ectodermal Notch target genes or the Notch ligand Delta-1. (D,H) NumbL knockdown results in an inhibition of the mesodermal Notch target gene ESR5 and the Notch ligand Delta-2. *: previously published (Nieber, 2007)

\subsection{Notch inhibition does not rescue NumbL knockdown}

To further provide evidence that the NumbL knockdown phenotype in the neural ectoderm is not a result of elevated Notch levels, the Notch inhibitors Delta-Stu (Chitnis et al., 1996) and $S u(H)^{D B M}$ (Wettstein et al., 1997) were 
employed in co-injections with the NumbL MO. As a read-out, whole mount in situ on N-tubulin was performed, as it shows a strong phenotype upon NumbL knockdown (Nieber 2007). Injection of mRNA encoding both dominant-negative constructs induced the typical increase in neuronal density in the territories of primary neurogenesis (Chitnis et al, 1996; Wettstein et al., 1997) as shown by the expression of $\mathrm{N}$-tubulin (Fig. 18A,B). However, inhibition of Notch signaling by these constructs could not rescue the loss of $\mathrm{N}$-tubulin positive cells in the NumbL knockdown embryos (Fig. 18C,D). These results further support the hypothesis that the function of NumbL is independent of Notch signaling in the context of primary neurogenesis

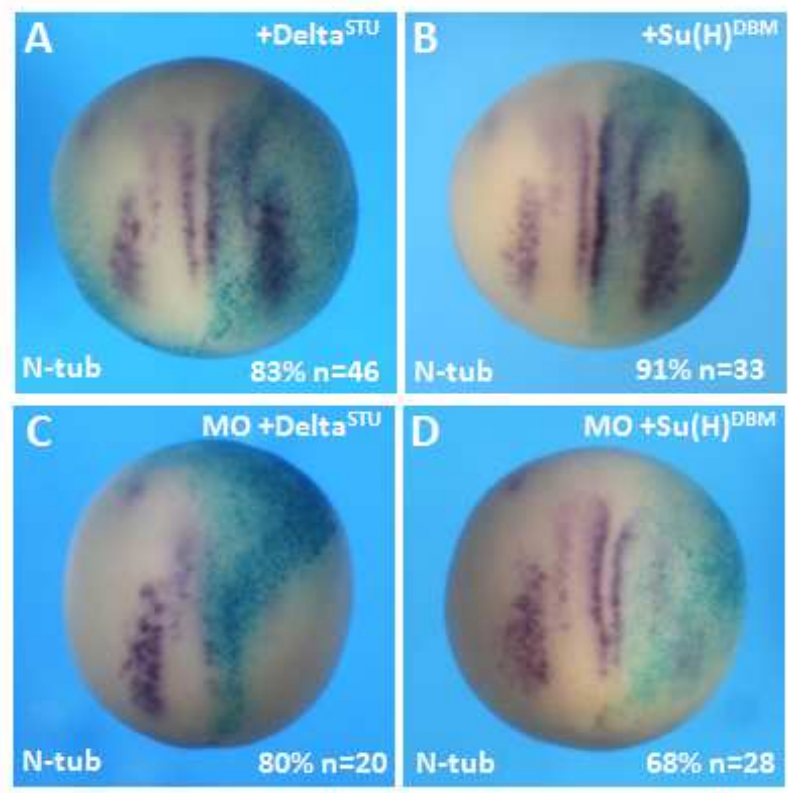

Figure 18: Notch inhibition does not rescue NumbL knockdown. Whole mount in situ analysis of NumbL morphants that were co-injected with $12.5 \mathrm{ng}$ NumbL MO and $100 \mathrm{pg}$ of the indicated Notch signaling inhibitor. B-Gal mRNA was co-injected as a lineage tracer. Inhibitors are indicated in the upper right corner, probed genes in the lower left corner. Statistics are shown in the lower right corner. Embryos were fixed at stage 15 prior to analysis. Embryos are shown in dorsal view, anterior up. (A and B) Notch pathway inhibition results in increase in $\mathrm{N}$-tubulin density in the areas of primary neurogenesis. (C and D) Notch inhibition does not rescue the loss of $\mathrm{N}$-tubulin upon a knockdown of NumbL. 


\subsection{A knockdown of NumbL leads to an increase in neural progenitors}

The Numb/NumbL double knockout mice exhibit a severe influence on the neural progenitor cell population (Petersen et al., 2002; Li et al., 2003, Petersen et al., 2004). Dependent on the stage of development that gene inactivation occurs, either depletion of neural progenitors as a consequence of premature differentiation, hyperproliferation of the neural progenitors or impaired differentiation of the progenitor population was observed. To determine, whether the observed loss of postmitotic neurons upon NumbL knockdown in $X$. laevis embryos was the consequence of alterations in the neural progenitor pool, the expression of the early neural genes Sox3 and NCAM was evaluated by whole mount in situ in NumbL knockdown embryos (Fig. 19). The expression domains of Sox3 and NCAM were significantly increased on the side of the embryo injected with the NumbL MO compared with the uninjected side (Fig. 19A and B). This demonstrates that the inhibition of neuronal differentiation is not due to the loss of the progenitor population and suggests that a loss of NumbL function may in fact increase proliferation of the neural progenitors and thereby impairing differentiation.

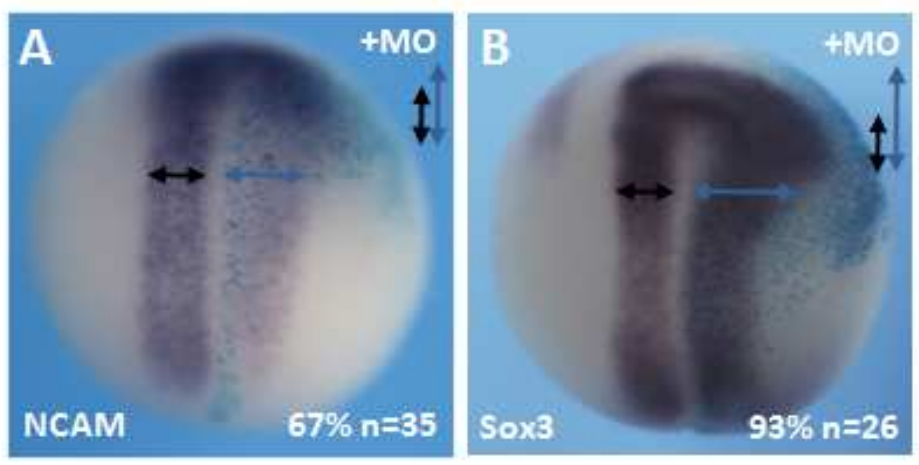

Figure 19: NumbL knockdown leads to an increase in early neural gene expression. Whole mount in situ analysis of NumbL morphant embryos. Embryos were injected with $12.5 \mathrm{ng}$ NumbL MO and $50 \mathrm{pg}$ ß-Gal mRNA and cultured until stage 15 prior to analysis. The probed genes are indicated in the lower left corner, statistics in the lower right corner. The injected side is marked by blue B-Gal staining and is always at the right. Embryos are shown in a dorsal view, anterior up. Neuroepithelium size is represented by the double arrow for the injected site (blue) and the uninjected site (black). (A) NumbL 
knockdown leads to a broadened expression domain of NCAM. (B) NumbL knockdown leads to an increased expression domain of Sox3.

\subsection{NumbL knockdown increases the number of mitotically active cells in the ectoderm at early gastrula stages}

As the expression domains of panneural genes like Sox3 or NCAM were found to be increased in size upon NumbL knockdown, proliferation rates in the neuroectoderm were analyzed at different stages by immuno-labeling of phosphorylated Histone 3 (pH3), which marks mitotically active cells (Fig. 20). Embryos were unilaterally injected with the NumbL MO, cultured to the desired developmental stages and then subjected to $\mathrm{pH} 3$ staining. The stained embryos were sectioned and $\mathrm{pH} 3$ signals in a reference area on each side were counted in 15 consecutive sections. At neurula stages when loss of $N$-tubulin expression is observed, there was no difference in the number of $\mathrm{pH} 3$ positive cells on the NumbL MO injected side compared with the uninjected control side. Although, at stage 15 no significant difference in mitotically active cell number was observed, a knockdown of NumbL resulted in a thickening of the neuroectoderm on the injected site at this stage (Fig. 20F). Therefore to determine if increased proliferation was occurring during the establishment of the neural plate, we performed the $\mathrm{pH} 3$ assay on earlier stage embryos. While at stage 12 only a slight increase in pH3 positive cells could be detected (Fig. 20C, D and E), a significant increase in mitotically active cells in the prospective neuroectoderm was observed at the onset of gastrulation at stage 10 (Fig. 20A, B and E).

Differentiation of progenitor cells requires withdrawal from the cell cycle. This is achieved by the expression of cell cycle regulators like Gadd45 $\gamma$, Pak3 and p27 ${ }^{\text {xic1 }}$ (Souopgui et al., 2002; De la Calle-Mustienes et al., 2002; Vernon et al., 2005). Consistent with the increase in mitotically active cells, a loss of Gadd45 $\mathrm{V}$ and Pak3 expression was observed in stage 15 NumbL morphants (Fig. 20G and $\mathrm{H})$, thus raising the possibility that the neuronal progenitors are prevented from 
undergoing differentiation and stay in a proliferative state because they are not able to exit the cell cycle.

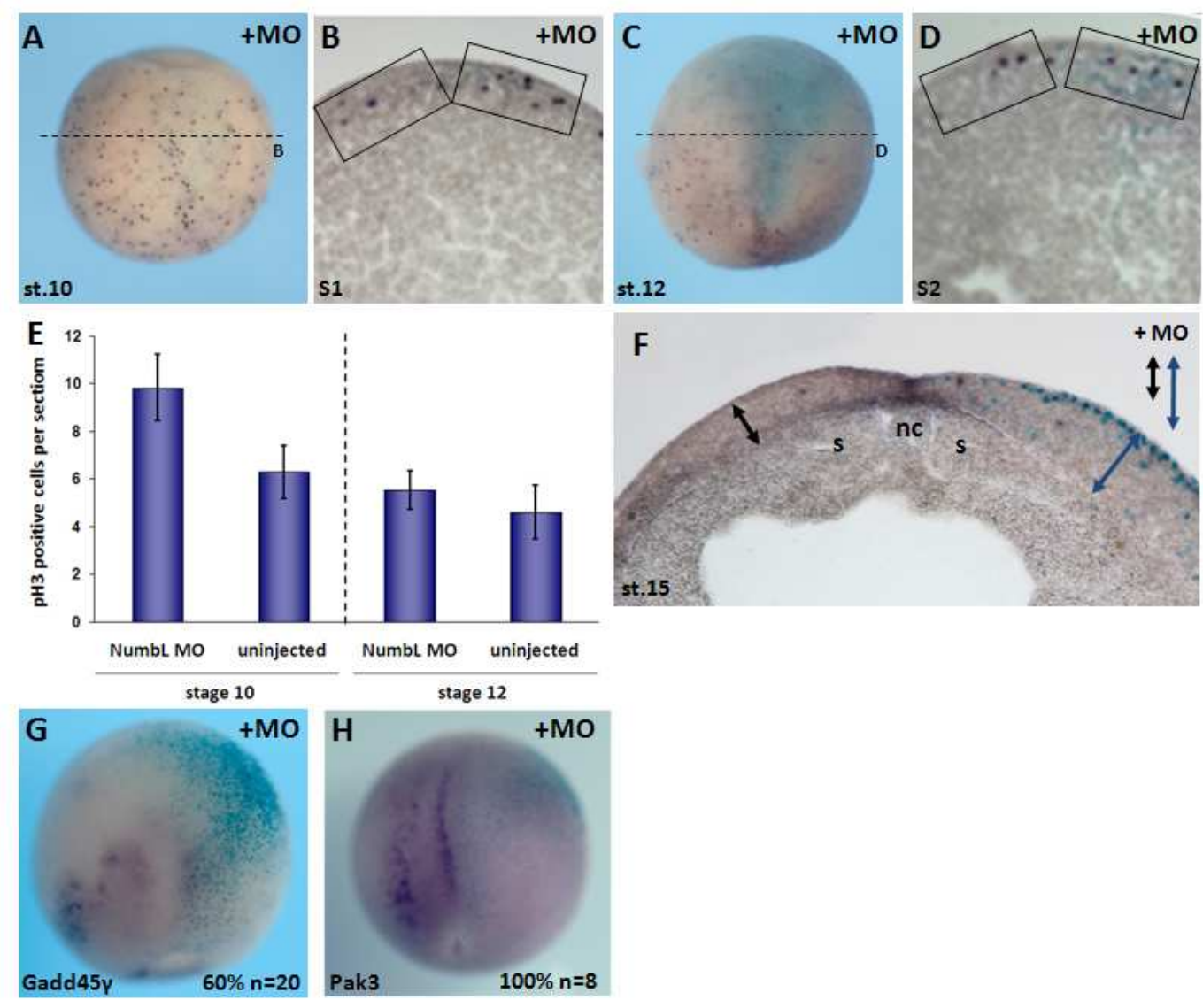

Figure 20: NumbL knockdown leads to increased proliferation during gastrula stages and loss of cell cycle regulators. Phosphoryllated Histone 3 staining of NumbL MO injected embryos. Embryos were injected with $12.5 \mathrm{ng} \mathrm{NumbL} \mathrm{MO}$ and $50 \mathrm{pg}$ ß-Gal as lineage tracer. Embryos were cultured until they reached the indicated stage and then fixed for $\mathrm{pH} 3$ immuno-labeling. Stained embryos were sectioned and $\mathrm{pH} 3$ positive cells on injected and uninjected side were counted in 15 consecutive sections. (A,C) Embryos are shown in a dorsal view, anterior up. Dashed line represent plane of transverse sections shown in S1 and S2. Stage is indicated at the lower right corner. (B, D) Boxes indicate evaluated area on each side. (E) Graph summarizing the results. NumbL knockdown cause a significant increase in proliferation rates on the injected side during gastrula stages but not at later stages. (F) Transversal section of the neuroepithelium of a stage 15 NumbL morphant embryo. Epithelium thickness is represented by the double arrow for the injected site (blue) and the uninjected site (black). (G,H) In situ analysis of stage 15 NumbL morphants. Embryos are shown in a dorsal view, anterior up. The injected site is marked by blue ß-Gal staining and is always on the right. Stained markers are indicated in the lower left corner, statistics in the lower right corner. nc, notochord; s, somite 


\subsection{NumbL knockdown promotes neural crest formation at tailbud stages}

As described above, the knockdown of NumbL resulted in an increase in Sox3 and NCAM positive cells at stage 15 (Fig. 19). To elucidate the fate of the observed increased progenitor population upon NumbL knockdown, the identity of the formed tissue was analyzed at stage 30 (Fig. 21). All NumbL MO injected embryos showed a thickened neuroepithelium on the injected side. The progenitor markers Sox2 and Sox3 were tested to ensure that the cells of the neuroepithelium were able to exit the progenitor state (Fig. 21A,B). While Sox2 was only slightly expanded (Fig. 21A), Sox3 appeared normal in comparison to the uninjected control side, indicating that the cells were not kept in a progenitor state. N-tubulin as marker for postmitotic neurons was found to be downregulated (Fig. 21C), with a slight recovery effect on expression on the $\mathrm{MO}$ injected side. Epidermal keratin expression was not altered upon NumbL knockdown (Fig. 21D). The head neural crest instead, marked by Twist, was found to be increased in NumbL morphants (Fig. 21E, E') 


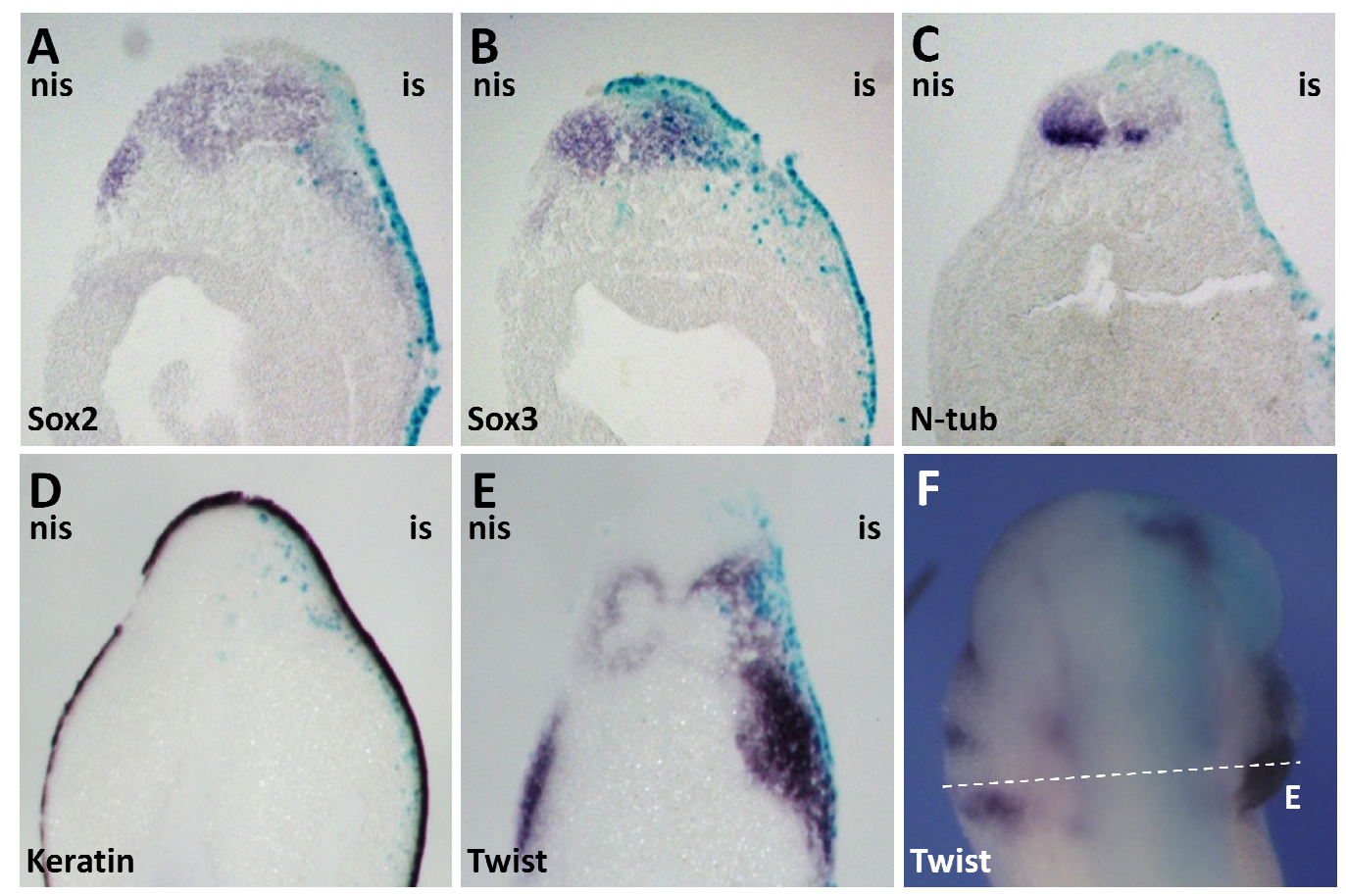

Figure 21: NumbL knockdown promotes neural crest fate at tailbud stages. Whole mount in situ analysis of NumbL morphants at tailbud stage. Embryos were injected with $12.5 \mathrm{ng} \mathrm{MO}$, cultured until stage 30, fixed for in situ, probed for the genes that are indicated in the upper right corner and then transversally sectioned. The injected side is marked by blue B-Gal staining. Compared to the uninjected side, some additional tissue developed on the MO injected side. This tissue was weakly positive for Sox2 and Sox 3 (A,B), negative for $\mathrm{N}$-tubulin and epidermal Keratin (C,D) and strongly positive for Twist (E, F). is, injected side; nis, non-injected side.

An expansion of neural progenitors marked by Sox3 was detected and important cell cycle regulators that are induced during neuronal differentiation were lost upon knockdown of NumbL. Therefore, the question arose whether these cells were prevented from undergoing neuronal differentiation due to the loss of essential neuronal determination factors, thereby causing the loss of differentiated neurons. The best-characterized proneural factors expressed in the open neural plate are members of the $\mathrm{Ngn}$ family (Ngn1-3). We therefore tested the influence of NumbL MO on the expression of the Ngns in X. laevis embryos by whole mount in situ hybridization. As observed previously, on the NumbL MO-injected side of the embryo (Nieber 2007), the expression of Ngn2 
was still present, however, the expression domains appeared dispersed (Fig. 22B). The expression of Ngn1 was also not inhibited by the presence of the NumbL MO. Ngn1 expression domains were slightly extended and strongly increased in density on the injected side (Fig. 22A). The Ngn3 expression domain was elongated on the NumbL MO injected side and at the same time appeared condensed in comparison to the uninjected control side (Fig. 22C). All together, all three $\mathrm{Ngns}$ are still expressed in NumbL morphants and loss of $\mathrm{Ngn}$ expression cannot be the reason for the complete loss of neuronal differentiation in the presence of the NumbL MO.
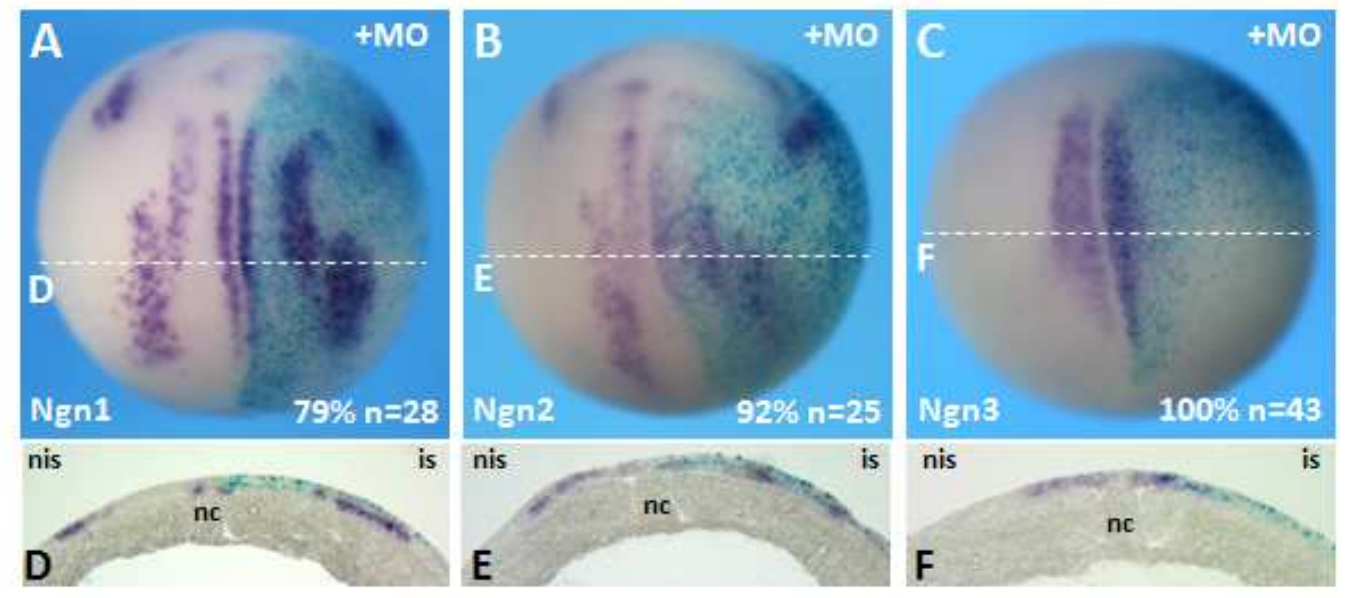

Figure 22: NumbL knockdown influences Neurogenin expression. Whole mount in situ hybridization analysis of NumbL morphants. Embryos were injected with $12.5 \mathrm{ng} \mathrm{MO}$, cultured until stage 15, fixed for in situ and probed for the genes indicated in the lower left corner. Embryos are shown in a dorsal view, anterior up. The injected side is marked by blue ß-Gal staining. Dashed lines represent the plane of the section shown below the embryo. Statistics are shown in the lower right corner. (A, D) Ngn1 expression appears condensed upon NumbL knockdown. (B,E) Ngn2 expression pattern is disturbed upon NumbL knockdown. (C, F) Ngn3 expression domain appears condensed upon NumbL knockdown. nc, notochord; is, injected side; nis, non-injected side.

\subsection{NumbL knockdown leads to an increase in early neural gene expression}

In order to explain why a knockdown of NumbL prevented activation of neuronal differentiation factors downstream of the Ngns, the expression levels of negative regulators of neurogenesis were analyzed by whole mount in situ in 
NumbL morphants (Fig. 23). We have already shown that expression of the ESR family of bHLH repressors is not increased upon knockdown of NumbL. An additional negative regulator is Zic2, which is a member of the Zic family of zincfinger transcription factors. Zic2 is expressed at the borders of the neural plate and in between the stripes of primary neurons (Brewster et al., 1998). Functionally, Zic2 was shown to promote a general neural fate in the ectoderm during neural induction and later to inhibit Ngn2 expression and function resulting in an inhibition of neuronal differentiation at the expense of a neural crest fate. Upon knockdown of NumbL, Zic2 expression was strongly increased on the injected side (Fig. 23B). The other members of the Zic family, Zic1 and Zic3, also promote a general neural fate, but distinguish themselves from Zic2 by promoting neuronal differentiation (Nakata et al., 1997; Mitzuseki et al., 1998b). Both Zic1 and Zic3 were strongly increased upon NumbL knockdown (Fig. 23A,C). Remarkably, the increased Zic expression is predominantly found in the anterior neural plate and weaker in the posterior region of the embryo.
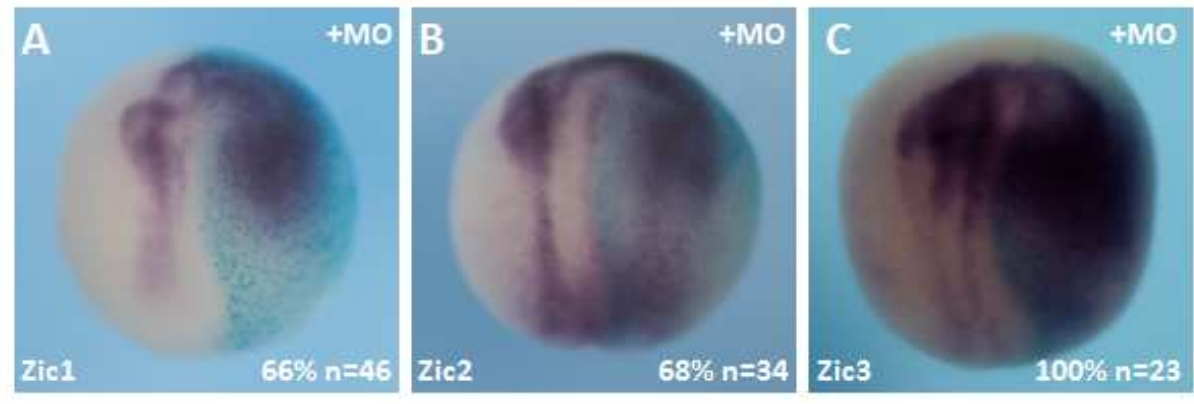

Figure 23: NumbL knockdown leads to an increase in Zic gene expression. Whole mount in situ analysis of NumbL morphant embryos. Embryos were injected with 12.5 ng NumbL MO and $50 \mathrm{pg}$ ß-Gal mRNA and cultured until stage 15 prior to analysis. The probed genes are indicated in the lower left corner, statistics in the lower right corner. The injected side is marked by blue ß-Gal staining and is always at the right. Embryos are shown in a dorsal view, anterior up. (A-C) Expression domains of all three neural Zics are increased. 


\subsection{Zic expression is increased in a Notch independent manner upon NumbL knockdown}

In mammalian cell lines, Numb and NumbL were shown to act as potent Notch inhibitors (McGill et al., 2003), and also in X. laevis embryos NumbL has the ability to attenuate Notch activation of a luciferase reporter (Nieber 2007). In addition to its function in neuronal differentiation, Notch signaling has been shown to be involved in the activation of early neural genes like Zic2 (Yan et al., 2009a). Given two different modes of Zic activity depending on the developmental stage, the hypothesis was tested, whether NumbL could act as Notch inhibitor during gastrula stages where Notch signaling would influence Zic expression and thereby its function during neural induction. Embryos were injected with the constitutively active form of the Notch receptor, NICD, in one blastomere of the two-cell stage and the influence on Zic expression analyzed by whole mount in situ hybridization (Fig. 24). At stage 10, no alteration in Zic1, Zic2 and Zic3 expression was observed upon Notch activation (Fig. 24A, C and E). At stage 15, Notch activation by NICD injection lead to an increase in all three Zics (Fig. 24B, D and F), while $N$-tubulin was found to be inhibited (Fig. 24G), indicating that Notch pathway activation leads to increased Zic expression levels at the open neural plate stage, but does not influence early Zic expression during gastrulation.

To determine if the activation of Zic genes upon NumbL knockdown at stage 15 could be the result of Notch activation, Zic3 expression was analyzed in NumbL morphants that were co-injected with the Notch signaling inhibitors Delta ${ }^{S t u}$ or $S u(H)^{D B M}$ (Fig. $24 I$ and K). The inductive effect of the NumbL knockdown on Zic3 expression was not rescued by Notch inhibition, indicating Notch activation upon loss of NumbL is not the reason for the expansion of the Zic3 expression domain. Notch inhibition alone did not influence Zic3 expression, suggesting Zic3 is regulated independent of Notch (Fig. $24 \mathrm{H}$ and J). 


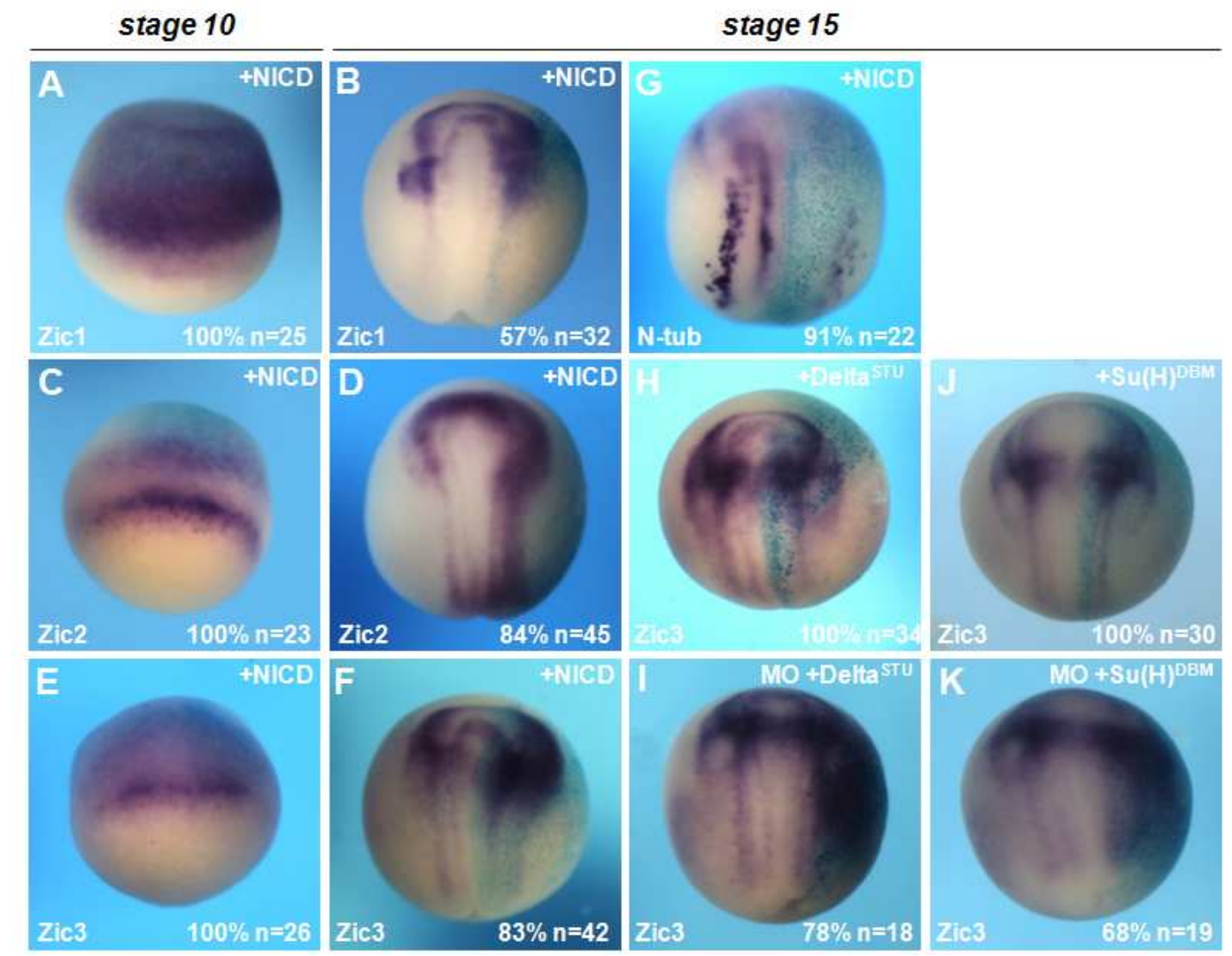

Figure 24: Zic genes are activated by Notch but Notch inhibition does not rescue the NumbL knockdown phenotype. Whole mount in situ analysis of embryos injected as indicated with $75 \mathrm{pg}$ of NICD, $12.5 \mathrm{ng}$ NumbL MO or $100 \mathrm{pg}$ of the indicated Notch inhibitor. Embryos were cultured until they reached the stage indicated in the upper lane. Embryos were probed for the genes that are indicated in the lower left corner. Statistics are shown in the lower right corner. All embryos are shown in a dorsal view, anterior up. $(A, C, E) N I C D$ overexpression does not influence Zic gene expression during gastrula stages. (B,D,F) NICD overexpression causes an expansion of Zic expression domains at the open neural plate stage. (G) NICD inhibits $N$-tubulin expression at the open neural plate stage. $\mathbf{( H , J )}$ Inhibition of Notch signaling does not influence Zic3 expression. (I,K) Notch inhibition does not rescue the NumbL MO effect on Zic3 expression.

\subsection{Xenopus Numb and NumbL are localized in the cytoplasm}

Numb proteins have been shown to act as intrinsic cell determinants that are differentially inherited to daughter cells during cell division (Uemura et al., 1989) or being asymmetrically distributed within single cells for example during migration (Nishimura et al., 2007). These described functional activities of Numb 
require its ability to localize to the membrane of a cell. Membrane localization of Numb can be achieved by either binding phosphotyrosine residues of tyrosine kinase receptors via the PTB domain (Verdi et al., 1996) or with assistance of the adaptor protein Partner of Numb (Pon) (Lu et al., 1998). In addition, studies in which the single Numb isoforms were overexpressed suggest different functions of the cytoplasmatically and membrane localized isoforms (Bani-Yaghoub et al., 2007; Kyriazis et al., 2010).

Therefore, to gain insight in the possible function of Numb and NumbL in the ectoderm of developing Xenopus embryos, the subcellular localization of Myc-tagged (MT) versions of $X$. laevis NumbL and $X$. tropicalis Numb3 in animal caps (ectodermal explants) was analyzed. The $X$. tropicalis MT-Numb3 was used as it is the predominant Numb isoform during neurula stages (Fig. 13) and a fulllength $X$. laevis Numb3 has not been isolated to date. Mouse MT-Numb1 was used as a control and was found to localize to the membrane (Fig. 25A-C) as described previously (Dho et al., 1999). Neither MT-NumbL (Fig. 25D-F) nor MTNumb3 (Fig. 25G-I) localized to the membrane and instead both were distributed symmetrically in the cytoplasm. The distribution of both constructs correlates with the structure of NumbL and Numb3, as the PTB insert, which was found to be essential for membrane localization of Numb is absent in both proteins (Verdi et al., 1999; Dho et al., 1999; Zhong et al., 1997). 

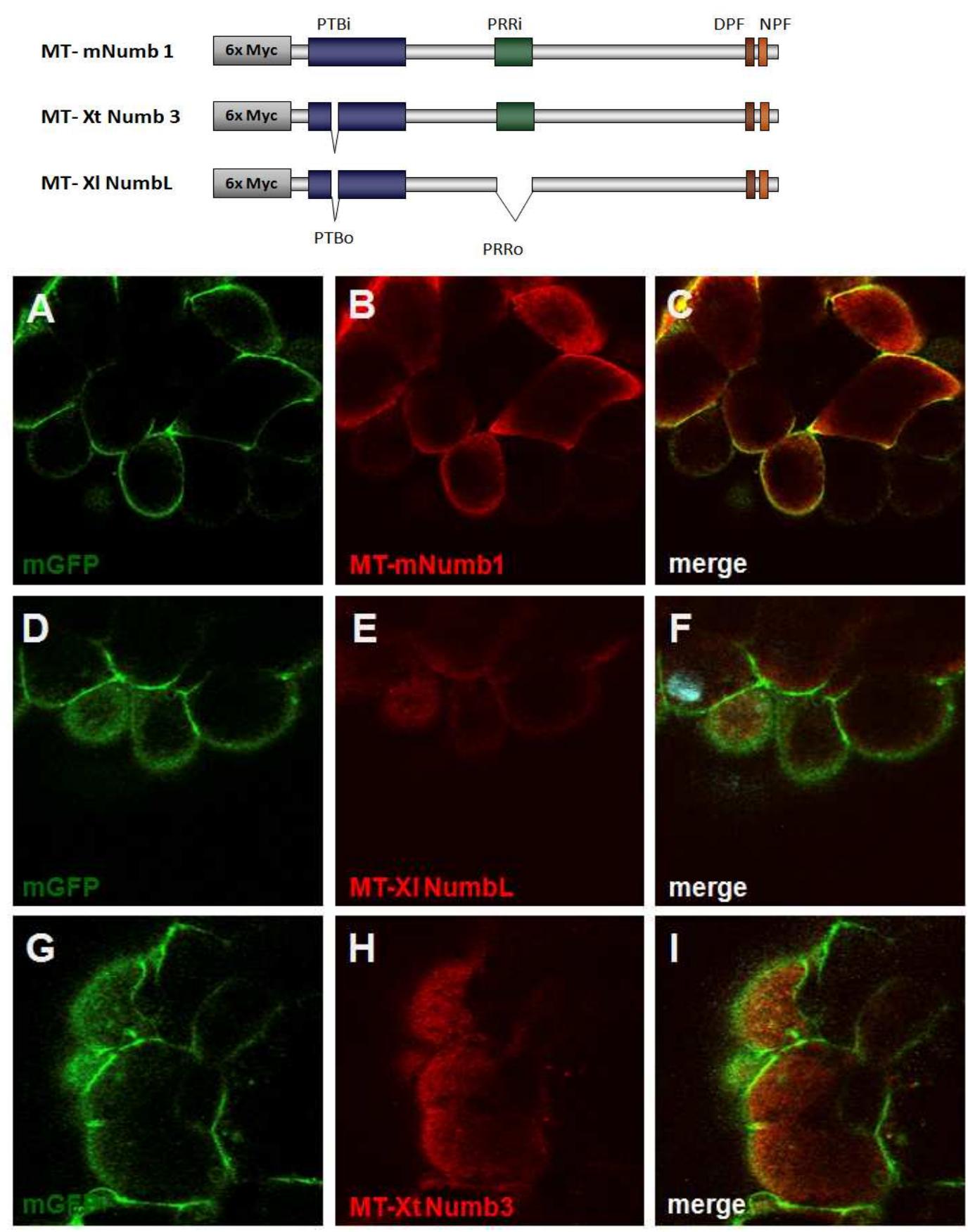

Figure 25: Subcellular localization of mouse MT-Numb1, X.laevis MT-NumbL and X.tropicalis MT-Numb3. Confocal images of labeled fluorescent proteins in animal caps. Caps were isolated from embryos injected with $500 \mathrm{pg}$ of the indicated MT-Numb mRNA together with $100 \mathrm{pg}$ mGFP mRNA and fixed at stage 15. Fluorescent labels are indicated in the lower left corner. Mouse MT-Numb1 is localized at the membrane, while $X$. laevis MT-NumbL and $X$. tropicalis MT-Numb3 are distributed in the cytoplasm. $X$. laevis MTNumbL and $X$. tropicalis MT-Numb3 form clusters at the cell membrane. The scheme at the top represents the domain structure of the isoforms used. 
Numb and NumbL are adaptor proteins containing many protein-protein interaction domains (Verdi et al., 1996). Therefore, we tested the hypothesis that the subcellular localization of the Numbs could change during the differentiation of the ectoderm to a neuron, depending on the presence or absence of regulatory proteins or signals. To examine this possibility, $X$. laevis animal caps were prepared from embryos injected with the indicated MT-Numb mRNA that were neuralized by co-injection of mRNA encoding the BMP inhibitor Noggin (Nog) or driven to undergo neuronal differentiation by the co-injection of mRNA encoding the proneural bHLH factor Neurogenin2 (Ngn2) (Fig. 26). Both MTNumbL (Fig. 26A-C) and MT-Numb3 (Fig. 26D-F) were found to persist in the cytoplasm even when coinjected with Noggin or Ngn2 mRNA, confirming the necessity of the PTB insert to localize to the membrane. Thus, a function of Xenopus NumbL or Numb3 via asymmetrical distribution in dividing or polarized cells is unlikely.
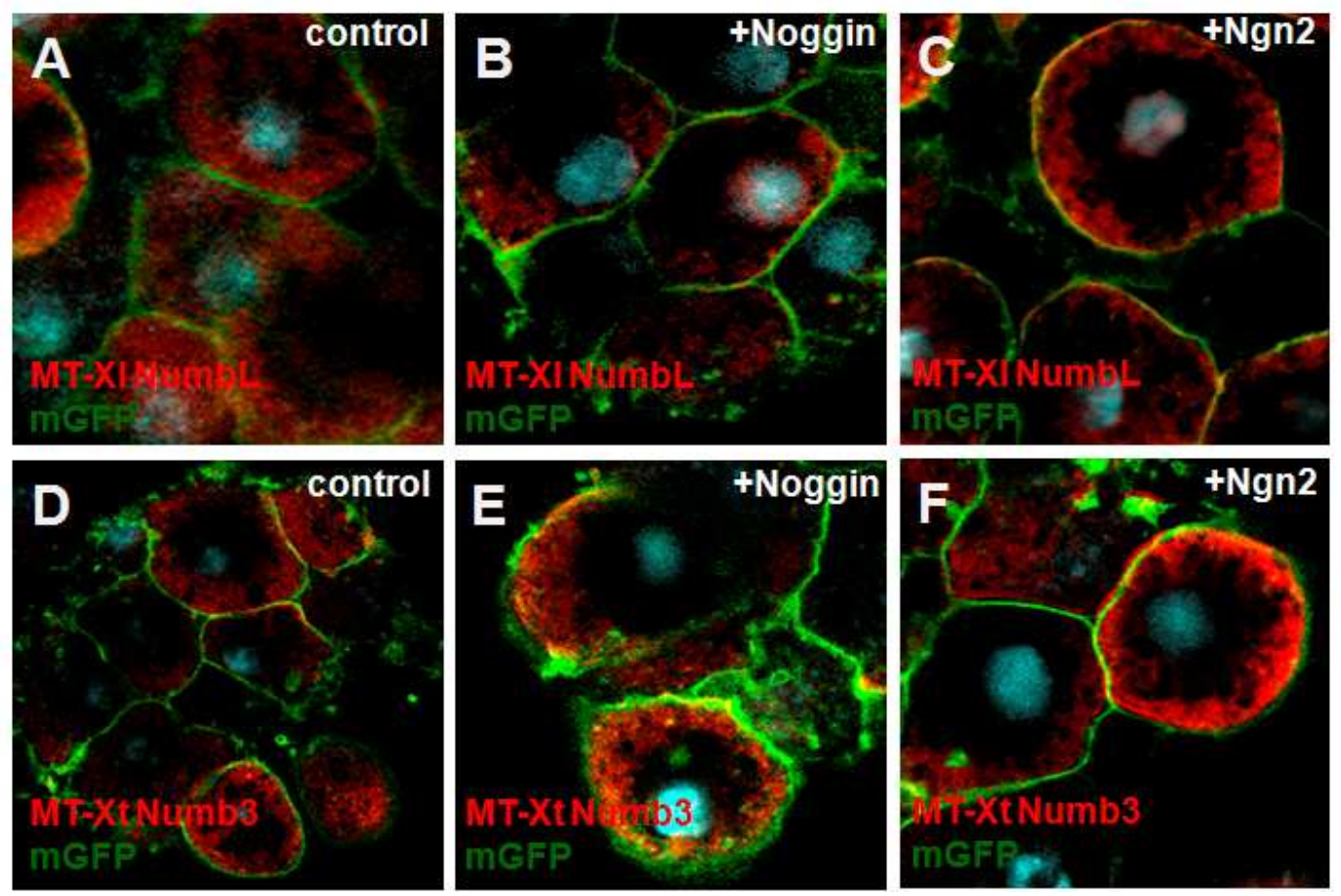

Figure 26: Subcellular localization of $X$. laevis NumbL and $X$. tropicalis Numb under wildtype and neuralized conditions. Confocal images of fluorescently labeled proteins in animal caps. $X$. laevis embryos were injected with 500 pg MT-Numb mRNA, 100 pg mGFP mRNA and 20 pg Ngn2 mRNA or 50 pg Noggin mRNA. Fluorescent labels are indicated in the lower left corner, co-expressed mRNAs in the upper right corner. 
Neuralization or neuronalization of the explanted tissue does not change the subcellular distribution of MT-NumbL and MT-Numb3.

\subsection{NumbL interacts with the AP-2 complex}

Numb family proteins are scaffold proteins containing multiple protein interaction domains. In order to understand NumbL function in the context of the developing nervous system, its direct interaction partners in this context have to be identified. To achieve this, a tandem affinity purification approach was used, by injecting mRNA encoding a double-tagged version of NumbL into $X$. laevis embryos. The TAP-tag containing a Streptavidin binding protein (SBP) and a Proteing (ProtG), separated by 2 TEV precision protease cleavage sites, was cloned c-terminally to NumbL, creating NumbL-CTap (see Fig. 27 for scheme). NumbL-CTap or control CTap mRNA were injected in both blastomeres at the two-cell stage, the embryos cultivated until stage 15 and protein extracts prepared. In two subsequent pull-downs against ProtG and SBP, NumbL-CTap and CTap interacting proteins were isolated. The recovered proteins were separated by SDS-PAGE, first visualized by colloidal coomassie blue staining and then silver staining (Fig. 27).

As shown in the gel in Fig 27, two prominent bands are observed after the $2^{\text {nd }}$ pull-down in both the CTap and Numb-CTap lanes that correspond to the streptavidine subunits. In addition, in the NumbL-Ctap lane several protein bands were present that were not found in the CTap control lane. To identify the proteins, the bands were excised from the gel and analyzed by mass spectrometry (Fig. 27, table). The interacting proteins that were identified were the $\beta 1$ subunit of the AP-2 complex, the $\alpha 2$ subunit of the AP-2 complex and the $\mu 1$ subunit of the AP-2 complex. These results strongly indicate an interaction of NumbL with the Adaptor-related protein complex 2 (AP-2) in Xenopus embryos at the time primary neurons are differentiating. 


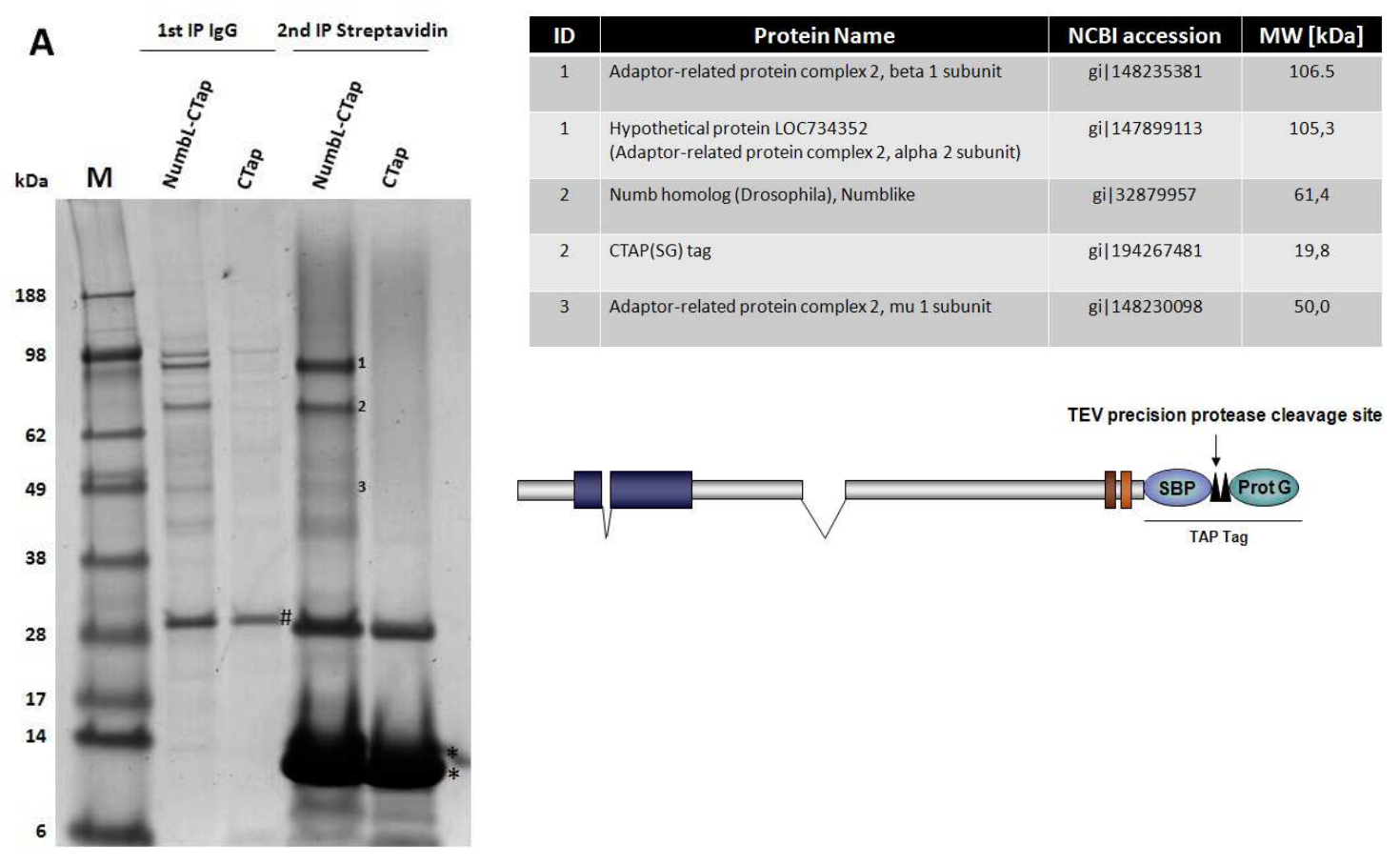

Figure 27: NumbL interacts with components of the AP-2 complex. Tandem affinity purification of NumbL-CTap from whole embryo lysates. Embryos were injected with 500 pg of NumbL-CTap oder CTap mRNA, cultured until stage 15 and frozen for protein extraction. The gradient gel is colloidal coomassie blue stained, loaded samples are indicated at the top. Marker sizes are indicated at the left. Identified bands are marked with numbers and described in the table at the right. Streptavidin subunit bands are marked by asterisks, TEV protease band by the pound sign on the gel.

\subsection{Interaction with the AP-2 complex is essential for NumbL function}

To determine if the identified interaction of NumbL with the AP-2 complex was of functional relevance, mutants of NumbL and NumbL(SA) were designed. In Numb, mutation of the DPF motif to DLA has been shown to abolish Numb binding to AP-2 (Santolini et al., 2000). Therefore, the corresponding motif in NumbL, the DQF motif, was mutated to DLA. NumbL(DLA)-CTap was then used in a second TAP experiment that paralleled the one previously done with the wild-type NumbL. In this experiment, interactions with the AP-2 subunits were not observed (Appendix Fig. 2). These results suggest that this domain in NumbL is indeed responsible for interaction with the AP-2 complex. In vitro verification of NumbL interaction with the single AP-2 subuntis by co-immunoprecipitation 
were not performed as the isolated adaptins of the do not fold properly when expressed alone (Collins et al., 2002).

The NumbL DLA mutants were then tested for a possible dominantnegative effect by overexpressing them in $X$. laevis embryos and analyzing the influence on $\mathrm{N}$-tubulin expression at stage 15 (Fig.28 A-C). Overexpression of mRNA encoding NumbL(DLA) and NumbL(SA-DLA) caused a phenotype, comparable to wild-type NumbL, exhibiting slightly increased numbers of $N$ tubulin positive cells in the lateral stripe. To show the necessity of the AP-2 interaction for NumbL function, rescue experiments were done. In these experiments, in contrast to the wild-type NumbL, the $N u m b L(D L A)$ mutants could not rescue the MO phenotype (Fig. 28,D-F). These results strongly suggest that the interaction with the AP-2 complex is essential for activity of NumbL during neuronal differentiation.
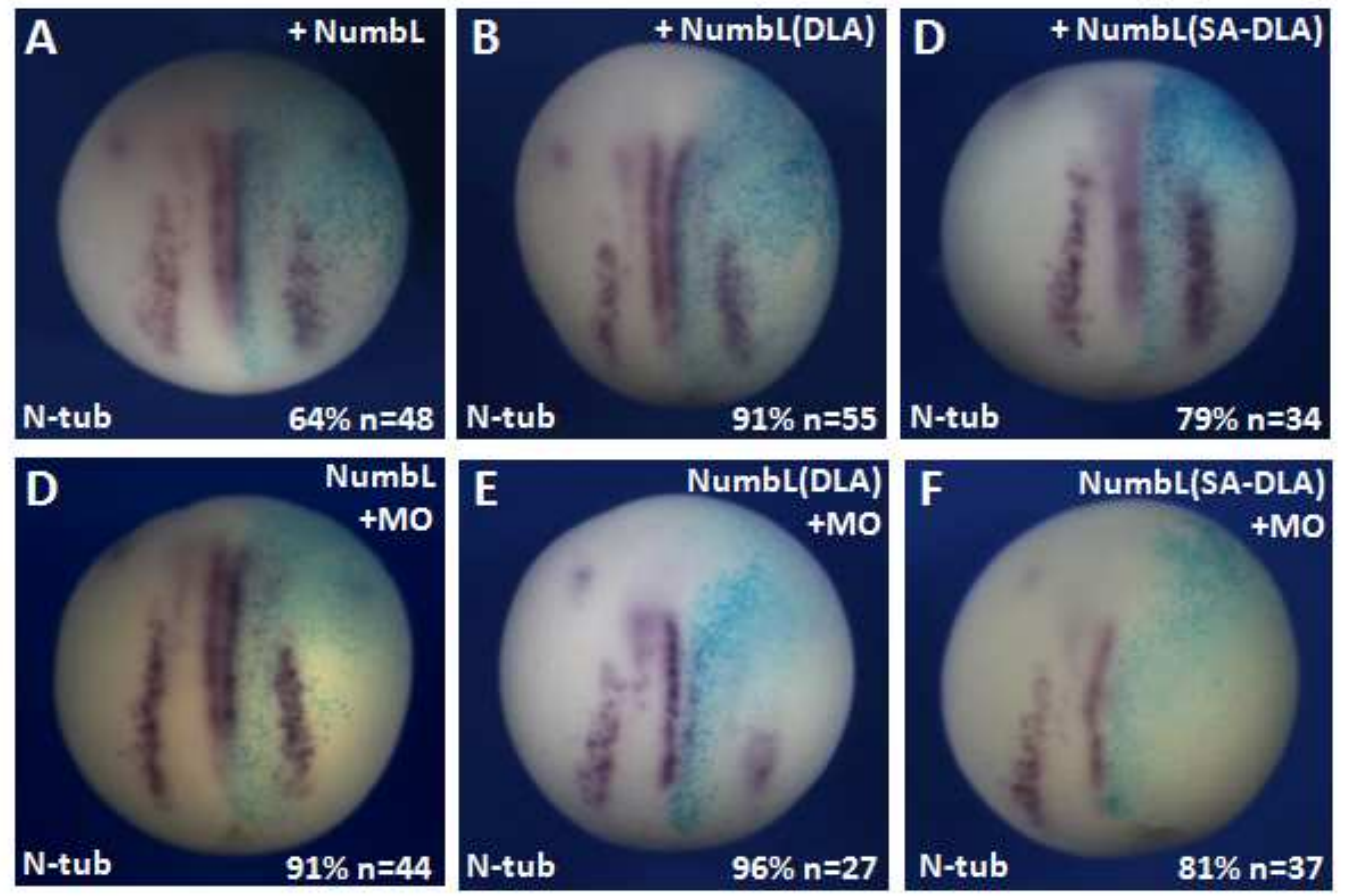

Figure 28: Interaction with the AP-2 complex is crucial for NumbL function. Whole mount in situ analysis of embryos that were injected with 500 pg NumbL construct mRNA and $12.5 \mathrm{ng} \mathrm{NumbL} \mathrm{MO}$, as indicated in the upper left corner. Embryos were cultured until stage 15 , fixed and probed for $N$-tubulin. Statistics are shown in the lower right corner. Embryos are shown in a dorsal view, anterior up. (A-C) Overexpression of NumbL, NumbL-DLA or NumbL SA DLA does not show a dominant negative effect on $N$ tubulin expression. (D-I) The NumbL MO phenotype can be rescued by coinjection of mRNA encoding NumbL, but not by NumbL(DLA) or NumbL(SA-DLA). 


\section{Discussion}

\subsection{NumbL has a dual function during Xenopus primary neurogenesis}

Numb and NumbL are expressed in the developing nervous system of mice, chicken and zebrafish (Zhong et al, 1997; Niikura et al., 2006; Wakamatsu et al., 1999; Reugels et al., 2006). Numb is expressed ubiquitously, including the mitotically active progenitor cells within the neural epithelium (Zhong et al., 1996; Zhong et al., 1997; Wakamatsu et al., 1999; Reugels et al., 2006), while NumbL is expressed specifically in the developing nervous system in post-mitotic differentiating cells (Zhong et al., 1997). Correlating with its expression in other organisms (Zhong et al., 1997), X. laevis NumbL is exclusively expressed in differentiating neurons in the open neural plate as well as in the closed neural tube, while Numb is more ubiquitously expressed. The conserved expression patterns of the Numb family genes already suggests that the functions of the Numbs in the context of neurogenesis may also be also be conserved. In addition to the expression of NumbL in the differentiating neurons, we also observe an early expression of in the dorsal ectoderm of gastrula stage embryos. At this stage when NumbL is expressed in prospective neural ectoderm, this tissue is characterized by BMP inhibition and FGF signals (Marchal et al., 2009). Simultaneously, the first cells express the Ngn proneural genes and become determined to enter a neuronal fate (Sommer et al., 1996; Ma et al., 1998), however, downstream markers for neuronal differentiation are not yet present. Thus the expression of NumbL during $X$. laevis early embryogenesis suggests at least two unique functions of NumbL during the development of the nervous system (Fig.14); one early function during the establishment of the neural ectoderm and a later function in the process of neuronal differentiation.

Previously we showed that a knockdown of NumbL resulted in a complete loss of postmitotic neurons at the open neural plate stage (Nieber 2007). This differs from the mouse NumbL homozygous mutants that were reported to be viable but show no obvious phenotype (Petersen et al., 2002). 
The lack of phenotype was attributed to partial redundancy with other Numbs (Petersen et al., 2002). Consistent with redundancy, Numb mutant mice exhibit severe cranial neural tube closure defects and die around E11.5, and double mutants of Numb and NumbL die earlier at around E9.5 with more widespread and severe defects than the single mutant (Petersen et al., 2002). Moreover, several conditional knockouts (cKO) were created where Numb was eliminated at different time points from E8.5 to E12.5. While Numb cKO are viable and fertile and do not distinguish from wild-type animals, the Numb cKO in a NumbL deficient background results in embryonic lethality and a loss of differentiated neurons at E10.5 - 11.5. Taken together the mouse knockouts clearly demonstrate an essential role of the Numbs during neurogenesis. Furthermore, in Xenopus we could show that NumbL is essential for primary neurogenesis. The failure to observe a neural phenotype in mouse NumbL knockouts may be attributed to the incompleteness of the knockdown, as still low levels of NumbL are detectable in the homozygous mutants (Petersen et al., 2002).

A knockdown of NumbL with a morpholino antisense oligonucleotide in $X$. laevis was found not only to inhibit differentiation of primary neurons but also to increase proliferation in the ectoderm specifically during gastrula and early neurula stages (Fig. 20). This results in a thickened neuroepithelium at stage 15. The expression domains of the neural progenitor gene Sox3 and the panneural gene NCAM were increased at stage 15 following NumbL knockdown. This suggests a dual function of NumbL and is consistent with the results obtained in mouse. Depending on the developmental stage of gene inactivation in mouse, cDKO of Numb and NumbL either promoted premature differentiation and therefore depletion of the neural progenitor population (Petersen et al., 2002; Petersen et al., 2004) or impaired differentiation with concomitant hyperproliferation of these cells (Li et al., 2003). This suggests a dual function for the Numb and NumbL in both progenitor cells maintenance and differentiation.

Similar to Numb proteins, the Zic zinc-finger transcription factors exhibit two different functions during neural induction and neuronal differentiation. In $X$. laevis, one early function of the Zics is to induce neural markers like NCAM and 
to promote a general neural fate. During neuronal differentiation, Zic1 and Zic3 promote differentiation through activation Ngn2 (Nakata et al., 1997; Mitzuseki et al., 1998). Zic2, in contrast, inhibits neuronal differentiation by inhibiting Ngn2 expression and function (Brewster et al., 1998) and is expressed between the stripes of primary neurogenesis. In addition, the Zics were described to function in patterning of the spinal cord by antagonizing $\mathrm{SHH}$ signals from the notochord and therefore confer dorsal neuronal and neural crest cell fates to neural progenitors (Nakata et al., 1998; Aruga et al., 2004). At the open neural plate stage, Zic1, Zic2 and Zic3 are strongly increased in NumbL morphants (Fig. 23). Corresponding to the strong activation in the anterior neural plate (Fig. 23) and the neural crest inducing activity of all three Zic genes (reviewed by Aruga, 2004), increased expression of the neural crest marker Twist is observed at tadpole stages (Fig. 21). Thus, the early activation of the Zic genes would explain the observed increase in proliferation in the neuroepithelium while the later increase in Zic expression could impair neuronal differentiation by promoting a neural crest cell fate in neural progenitors. However, since Ngn expression is not lost upon a NumbL knockdown (Fig. 22), the neuronal precursors exit the cell cycle and enter the differentiation pathway nevertheless. Therefore, the early function of NumbL to commit neuronal differentiation in the progenitors of the dorsal ectoderm may be independent of its later function during the process of neuronal differentiation itself.

Overexpression of mNumb in murine neural precursor cells caused isoform dependent either differentiation or proliferation of these cells (BaniYaghoub et al., 2007). Consistent with the overexpression of mNumb4, the structurally most similar isoform to NumbL, NumbL gain-of-function in $X$. laevis does not promote ectopic formation of primary neurons, but rather a slight increase in neuronal density in the territories of primary neurogenesis at the open neural plate stage (Fig. 16). NumbL role during differentiation of primay neurons is further supported by its regulation through Ngn1-3 (Fig. 15). The failure to obtain a strong gain-of-function phenotype may be due to posttranscriptional negative regulatory mechanisms. For example, the RNA binding protein Musashi inhibits translation of Numb transcripts (Okano et al., 2002). As 
Musashi, like most RNA-regulatory proteins characterized to date, bind within the untranslated regions of its target mRNA (Imai et al., 2001), the used NumbL mRNA did not harbor its endogenous untranslated regions. However, one cannot exclude regulatory binding sites within the coding sequence for other regulatory proteins. Furthermore, translation of Numb mRNA was shown to be regulated by miR146a in mouse satellite cells (Kuang et al., 2009), raising the possibility that NumbL mRNA translation might be regulated by micro RNAs, as well. Numb is also on a post-translational level by phosphorylation of two serine residues, $\operatorname{Ser}^{291}$ and $\operatorname{Ser}^{310}$ (Tokumitsu et al., 2006). If phosphorylated, these two residues promote the binding of ubiquitous present 14-3-3 proteins, which mask Numbs protein-protein interaction domains and prevent it from binding it targets. Overexpression of phosphorylation mutants of NumbL in which the two conserved serines were exchanged to alanine ( $\mathrm{NumbL}(\mathrm{SA})$ ), did not result in a significantly stronger phenotype than wild-type gain-of-function (Fig. 16C). However, additional uncharacterized sites of negative regulation within NumbL may still be present. Alternatively, since NumbL functions as a scaffold protein, its activity is most likely dependent on the availability of its interaction partners. Therefore, the weak phenotype upon NumbL overexpression may also be explained by limiting amounts of interacting proteins.

\subsection{NumbL function during Xenopus primary neurogenesis is independent of Notch signaling}

Overexpression of Drosophila Numb results in an inhibition of Notch activity and an increased neuronal differentiation of SOP cells (Rhyu et al., 1994; Guo et al., 1996). As the comparable phenotype in X. laevis can be created by overexpression of Notch inhibitors and is much stronger than the effect observed for NumbL overexpression (compare Fig. 16A and Fig. 18A,C), it is likely that the increase in neuron density relies on a mechanism different from Notch signaling inhibition. Overexpression of distinct mouse Numb isoforms in murine neural 
progenitor cells or Drosophila other optic anlage cells (OOA) revealed that although the different Numb isoforms possess different developmental potential in driving either proliferation or differentiation, Notch signaling was equally inhibited by the single isoforms (Toriya et al., 2006; Bani-Yaghoub et al., 2007). These results strongly support that the opposing isoform activities are independent of Notch signaling.

The knockdown of NumbL in $X$. laevis was shown to efficiently inhibit the formation of differentiated neurons (Nieber 2007). While the impaired neuronal differentiation upon a knockdown of NumbL phenocopies an activation of the Notch signaling pathway, no evidence for NumbL acting as an inhibitor of Notch signaling in this context was found. Neither were Notch target genes activated upon a loss of NumbL (Fig. 17), nor could the NumbL knockdown effect on neuronal differentiation be rescued by inhibition of Notch signaling (Fig. 18). These results further suggest a Notch independent function of NumbL during neuronal differentiation. Also, the underlying molecular mechanism of Zic activation is unclear as the induction of the Zic genes is subject to recent debate. Notch activation by overexpression of NICD resulted in an increase in Zic expression (Fig. 24). This could be either a direct effect, as Notch signals were shown to be essential for the induction of Zic2 expression during neural induction (Yan et al., 2009b), or an indirect effect as Notch activation increases proliferation of neural progenitors, leading to an enlarged neural plate (Louvi et al., 2006). However, as shown for the NumbL knockdown phenotype on $N$ tubulin expression (Fig. 18), the increase in Zic expression was also found to be Notch independent. Inhibition of Notch did not rescue the knockdown phenotype in Zic gene expression (Fig. $24 \mathrm{I}$ and K).

Similar to the Notch activation upon Numb knockdown in Drosophila SOPs (Guo et al., 1996), Notch signaling was suggested to be de-regulated and influence progenitor cell maintenance in the mouse Numb/NumbL double knockout, but no evidence for elevated Notch signaling has been demonstrated thus far. However, cNumb was described to bind and modulate Notch-1 activity upon overexpression in the chick neuroepithelium (Wakamatsu et al., 1999). In 
addition, NumbL overexpression in $X$. laevis embryos could decrease the activation of a Notch luciferase reporter by NICD (Nieber 2007). These data raise the possibility that Numb and NumbL can under certain developmental contexts act as Notch inhibitors.

Additional pathways that might be regulated by NumbL in the context of primary neurogenesis in Xenopus are BMP and FGF, as they are active in the ectoderm during neural induction. While BMP inhibition was shown to be sufficient for induction of Zic1, Zic3 can only be activated if FGF4 signaling is not compromised at the same time (Marchal et al., 2009). Zic2 activation requires in turn Notch signaling downstream of the forkhead transcription factor FoxD5, an immediate target of Zic1 and Zic3 (Yan et al., 2009b). Thus, candidate pathways for being regulated by NumbL at this stage are either BMP signaling, FGF signaling or events like calcium signals that might mediate the activation of target genes upon activation of FGF signals. Interestingly, Numb4, the structurally most similar isoform to NumbL, was recently described to influence calcium signaling in the context of neuronal differentiation. Numb4 was found to trigger neuronal differentiation upon overexpression in cultured mouse neuronal progenitor cells depending on a calcium influx via L-Type calcium channels and subsequent MAPK pathway activation (Lu et al., 2009). Furthermore, a stress induced switch in Numb isoforms from PTBi (Numb1, Numb2) to PTBo (Numb3, Numb4) in PC12 cells specifically led to elevated Notch signaling levels and subsequent transcription of the transient receptor potential channel 6 (TRP6), an L-Type calcium channel (Kyriazis et al., 2010). These data suggest the possibility that NumbL might be involved in calcium signaling regulation downstream of FGF signaling and upstream of early neural gene expression as well as in the context of neuronal differentiation. However, the context specific regulation of the Zic genes has to be evaluated in further studies. 


\subsection{NumbL is localized in the cytoplasm and interacts with the AP-2 complex}

Numb is known to act as asymmetrical distributed cell fate determinant in Drosophila SOPs and neural progenitor cells (Uemura et al., 1989, Lu et al., 1998). Numb has also been shown to function in mediating localized interactions between target proteins like the AP-2 complex and integrins (Nishimura et al., 2007; Ezratty et al., 2009). Both activities are dependant on Numbs ability to localize to the membrane, either prior to cell division or during a specific function carried out by the cell, i.e. migration. An insert within the PTB domain was found to be crucial for membrane localization of mammalian Numb (Verdi et al., 1996). In this thesis, Xenopus Numb proteins lacking this insert (Numb3 and NumbL) were also found not to localize to the membrane in ectodermal explants (Fig. 25), even under neuralizing and neuronalizing conditions (Fig. 26). These results strongly suggest that NumbL protein will not be asymmetrically distributed during cell division. On the functional level, cytoplasmatic isoforms of hNumb were shown to specifically induce differentiation of rat PC12 cells upon growth factor withdrawal while cell expressing membrane localized isoforms stayed in a proliferative state (Pedersen et al., 2002). Therefore, also the cytoplasmatic localization of $X$. laevis MT-NumbL would correlate with a possible function in neuronal differentiation.

Numb proteins were shown to interact with components of the AP-2 complex (Santolini et al., 2000) and attach target proteins for endocytosis. Although the AP-2 interaction motif DPF in Numb is exchanged to a DQF motif in NumbL, strong interactions with AP-2 could nevertheless be detected in Xenopus open neural plate stage embryos (Fig. 27). As this interaction is crucial for NumbL ability to rescue the MO effect (Fig. 28), NumbL might act in vivo as an endocytotic protein, as well. The seemingly contradiction, that NumbL could act in endocytosis although it is not membrane localized per se can be explained by adaptor proteins that mediate interaction under certain conditions. Taking into account that mouse Numb was reported also to interact with adaptor proteins to 
localize to the membrane (Lu et al., 1998), this raises the possibillity that $X$. laevis NumbL might nevertheless function as scaffold protein in membrane-associated processes like for instance endocytosis. Furthermore, Numb was shown to regulate not only endocytosis but also post-endocytotic trafficking and is localized to endosomes, as well (McGill et al., 2009; Nishimura et al., 2007). Therefore, a role for NumbL in downstream events of endocytosis in endosomal trafficking or recycling is possible.

Known targets endocytosed by Numb are the Notch receptor or integrins during directional cell migration (Santolini et al., 2000; Nishimura et al., 2007). Since Notch de-regulation could be excluded from causing the NumbL knockdown phenotype (Fig. 19; Fig. 20), NumbL target for promoting endocytosis remains to be identified. Possible targets for endocytosis by NumbL are FGF receptors (FGFR). FGFRs are tyrosine receptor kinases (TRKs) and dimerize to form an active ternary complex upon binding of an FGF ligand. They activate a downstream signaling cascade via mutual phosphorylation of both TRK domains (Ornitz et al., 2001). After activation, the ternary complexes are endocytosed to terminate the signal and either degraded in lysosomes (mainly FGFR1-3) or recycled (mainly FGFR-4) (Haugsten et al., 2005). Thus, since MAPK activation and calcium influx as readouts for FGF activation were observed upon mNumb4 overexpression in cultured neural progenitors (Lu et al., 2009), mNumb4 could promote endocytosis and recycling of FGF receptors in this context. NumbL as closely related protein could possess similar activities and function in FGFR endocytosis or alternatively in recycling of the endocytosed membrane components, as it was suggested for Numb in the context of integrin recycling (Nishimura et al., 2007). A knockdown of NumbL would then result in an increased number of ternary FGF/FGFR complexes that reside active at the membrane and increase FGF signaling levels, leading to increased neural gene expression but inhibited differentiation. The identification of the specific target proteins of NumbL will be an interesting topic of future studies. This is important not only due to the essential of NumbL during Xenopus neurogenesis, but also the emerging role of Numb proteins in cancer (Pece et al., 2010). 


\section{Summary}

In summary, two functions of NumbL were shown during neurogenesis. One in the context of neural induction, were NumbL is important for the activation of early neural genes upon inductive stimuli and a second function during the process of neuronal differentiation were NumbL is found in differentiating neurons and is essential for this process (Fig. 29). Mechanistically, one aspect of NumbL function lies in endocytosis by attaching targets to the AP-2 complex, which is essential for NumbL functionality. Howwever, the specific targets and influenced signaling pathways could not be identified so far, also other possible functions of NumbL like interactions with E3 ligases remain to be revealed in future studies. Interestingly, NumbL functions, in contrast to what was expected, independent of Notch signaling since a loss of NumbL does not elevate Notch activity.

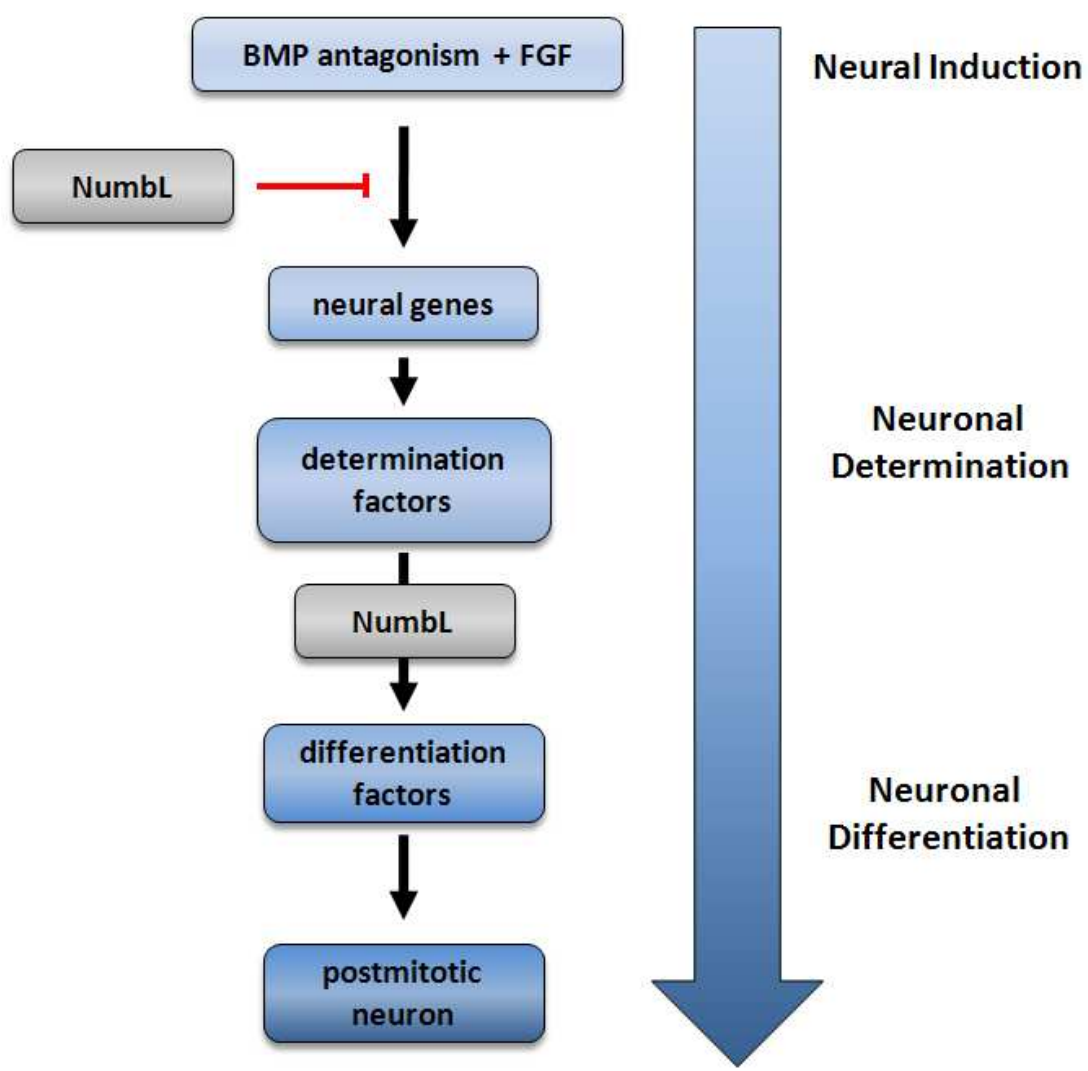

Figure 29: Scheme of NumbL dual function during primary neurogenesis. NumbL is involved in regulation of early neural gene expression. In addition, NumbL function is essential in the process of neuronal differentiation. 


\section{Bibliography}

Agius, E., Oelschläger, M., Wessely, O., Kemp, C., De Robertis, EM. (2000). Endodermal Nodal-related signals and mesoderm induction in Xenopus. Development 127, 1173-1183.

Artavanis-Tsakonas, S., Rand, MD., Lake, RJ. (1999). Notch signaling: cell fate control and signal integration in development. Science 284, 770-776.

Aruga, J., Mizugishi, K., Koseki, H., Imai, K., Balling, R., Noda, T., Mikoshiba, K. (1999). Zic1 regulates the patterning of vertebral arches in cooperation with Gli3. Mech Dev. 89, 141-150.

Bani-Yaghoub, M., Kubu, CJ., Cowling, R., Rochira, J., Nikopoulos, G.N., Bellum, S., Verdi, J.M. (2007). A switch in numb isoforms is a critical step in cortical development. Dev Dyn. 236, 696-705.

Batut, J., Vandel, L., Leclerc, C., Daguzan, C., Moreau, M., Néant, I. (2005). The Ca2+-induced methyltransferase XPRMT1b controls neural fate in amphibian embryo. Proc Natl Acad Sci U S A. 102, 15128-15133.

Bellefroid, E.J., Bourguignon, C., Hollemann, T., Ma, Q., Anderson, D.J., Kintner, C., Pieler, T. (1996). X-MyT1, a Xenopus C2HC-type zinc finger protein with a regulatory function in neuronal differentiation. Cell 87, 1191-1202.

Bellefroid, E.J., Kobbe, A., Gruss, P., Pieler, T., Gurdon, J.B., Papalopulu, N. (1998). Xiro3 encodes a Xenopus homolog of the Drosophila Iroquois genes and functions in neural specification. EMBO J. 17, 191-203.

Blaikie, P., Immanuel, D., Wu, J., Li, N., Yajnik, V., Margolis, B. (1994). A region in Shc distinct from the $\mathrm{SH} 2$ domain can bind tyrosine-phosphorylated growth factor receptors. J Biol Chem. 269, 32031-32034.

Boy, S., Souopgui, J., Amato, MA, Wegne, M., Pieler, T., Perron, M. (2004). XSEB4R, a novel RNA-binding protein involved in retinal cell differentiation downstream of bHLH proneural genes. Development 131, 851-862.

Brewster, R., Lee, J., Ruiz i Altaba, A. (1998). Gli/Zic factors pattern the neural plate by defining domains of cell differentiation. Nature 393, 579-583.

Bullock, W.O., Fernandez, J.M., Short, J.M. (1987). XL1-Blue: A high efficiency plasmid transformation recA Escherichia coli strain with betagalactosidase selection. Biotechniques 5, 376-379.

Carruthers, S., Mason, J., Papalopulu, N. (2003). Depletion of the cell-cycle inhibitor 27(Xic1) impairs neuronal differentiation and increases the number of ElrC(+) progenitor cells in Xenopus tropicalis. Mech Dev. 120, 607-616. 
Chalmers, A.D., Welchman, D., Papalopulu, N. (2002). Intrinsic differences between the superficial and deep layers of the Xenopus ectoderm control primary neuronal differentiation. Dev Cell. 2, 171-182.

Chapman, G., Liu, L., Sahlgren, C., Dahlgvist, C., Lendahl, U. (2006). High levels of Notch signaling down-regulate Numb and Numblike. J Cell Biol. 175, 535-540.

Chien, C.T., Wang, S., Rothenberg, M., Jan, L.Y., Jan, Y.N. (1998). Numbassociated kinase interacts with the phosphotyrosine binding domain of Numb and antagonizes the function of Numb in vivo. Mol Cell Biol. 18, 598-607.

Chitnis, A., Henrique, D., Lewis, J., Ish-Horowicz, D., Kintner, C. (1995). Primary neurogenesis in Xenopus embryos regulated by a homologue of the Drosophila neurogenic gene Delta. Nature 375, 761-766.

Colaluca, I.N., Tosoni, D., Nuciforo, P., Senic-Matuglia, F., Galimberti, V., Viale, G., Pece, S., Di Fiore, P.P. (2008). NUMB controls p53 tumour suppressor activity. Nature 451, 76-80.

Collins, B.M., McCoy, A.J., Kent, H.M., Evans, P.R., Owen, D.J. (2002) Molecular Architecture and Functional Model of the Endocytotic AP-2 complex. Cell 109, 523-535

Coffman, C.R., Skoglund, P., Harris, W.A., Kintner, C.R. (1993). Expression of an extracellular deletion of Xotch diverts cell fate in Xenopus embryos. Cell 73, 659671.

Davis, R.L., Turner, D.L. (2001). Vertebrate hairy and Enhancer of split related proteins: transcriptional repressors regulating cellular differentiation and embryonic patterning. Oncogene 20, 8342-8357.

Dawson, S.R., Turner, D.L., Weintraub, H., Parkhurst, S.M. (1995). Specificity for the hairy/enhancer of split basic helix-loop-helix (bHLH) proteins maps outside the bHLH domain and suggests two separable modes of transcriptional repression. Mol Cell Biol. 15, 6923-6931.

Deblandre, G.A., Wettstein, D.A., Koyano-Nakagawa, N., Kintner, C. (1999). A two-step mechanism generates the spacing pattern of the ciliated cells in the skin of Xenopus embryos. Development 126, 4715-4728.

Dee, C.T., Hirst, C.S., Shih, Y.H., Tripathi, V.B., Patient, R.K., Scotting, P.J. (2008). Sox3 regulates both neural fate and differentiation in the zebrafish ectoderm. Dev Biol. 320, 289-301.

De la Calle-Mustienes, E., Glavic, A., Modolell, J., Gomez-Skarmeta, J.L. (2002). Xiro homeoproteins coordinate cell cycle exit and primary neuron formation by upregulating neuronal-fate repressors and downregulating the cell-cycle inhibitor XGadd45-gamma. Mech Dev. 119, 69-80. 
Delaune, E., Lemaire, P., Kodjabachian, L. (2005). Neural induction in Xenopus requires early FGF signalling in addition to BMP inhibition. Development 132, 299-310.

Dent, J.A., Polson, A.G., Klymkowsky, M.W. (1989). A whole-mount immunocytochemical analysis of the expression of the intermediate filament protein vimentin in Xenopus. Development 05, 61-74.

De Robertis, E.M., Kuroda, H. (2004). Dorsal-ventral patterning and neural induction in Xenopus embryos. Annu Rev Cell Dev Biol. 20, 285-308.

Dho, S.E., French, M.B., Woods, S.A., McGlade, C.J. (1999). Characterization of four mammalian numb protein isoforms. Identification of cytoplasmic and membrane-associated variants of the phosphotyrosine binding domain. J Biol Chem. 274, 33097-33104.

Di Marcotullio, L., Ferretti, E., Greco, A., De Smaele, E., Po, A., Sico, M.A., Alimandi, M., Giannini, G., Maroder, M., Screpanti, I., Gulino, A. (2006). Numb is a suppressor of Hedgehog signalling and targets Gli1 for Itch-dependent ubiquitination. Nat Cell Biol. 12, 1415-1423.

Di Marcotullio, L., Greco, A., Mazzà, D., Canettieri, G., Pietrosanti, L., Infante, P., Coni, S., Moretti, M., De Smaele, E., Ferretti, E., Screpanti, I., Gulino, A. (2010). Numb activates the E3 ligase Itch to control Gli1 function through a novel degradation signal. Oncogene (Epub ahead of print).

Dubios, L., Bally-Cuif, L., Crozatier, M., Moreau, J., Paquerereau, L., Vincent, A. (1998). XCoe2, a transcription factor of the Col/Olf-1/EBF family involved in the specification of primary neurons in Xenopus. Curr Biol. 8, 199-209.

Ezratty, E.J., Bertaux, C., Marcantonio, E.E., Gundersen, G.G. (2009). Clathrin mediates integrin endocytosis for focal adhesion disassembly in migrating cells. J Cell Biol. 187, 733-747.

Fletcher, R.B., Harland, R.M. (2008). The role of FGF signaling in the establishment and maintenance of mesodermal gene expression in Xenopus. Dev Dyn. 237, 1243-1254.

Gawantka, V., Delius, H., Hirschfeld, K., Blumenstock, C., Niehrs, C. (1995). Antagonizing the Spemann organizer: role of homeobox gene Xvent-1. EMBO J. $14,6262-6279$.

Gawantka, V., Pollet, N., Delius, H., Vingron, M., Pfister, R., Nitsch, R., Blumenstock, C., Niehrs, C. (1998). Gene expression screening in Xenopus identifies molecular pathways, predicts gene function and provides a global view of embryonic patterning. Mech Dev. 77, 95-141. 
Gerhart, J. (2001). Evolution of the organizer and the chordate body plan. Int J Dev Biol. 45, 133-153.

Glinka, A., Wu, W., Delius, H., Monaghan, A.P., Blumenstock, C., Niehrs, C. (1998). Dickkopf-1 is a member of a new family of secreted proteins and functions in head induction. Nature 391, 357-362.

Gulino, A., Di Marcotullio, L., Screpanti, I. (2010). The multiple functions of Numb, Exp. Cell Res. 316, 900-906.

Guo, M., Jan, L.Y., Jan, Y.N. (1996). Control of daughter cell fates during asymmetric division: interaction of Numb and Notch. Neuron. 17, 1-4

Hardcastle, Z., Chalmers, A.D., Papalopulu, N. (2000). FGF-8 stimulates neuronal differentiation through FGFR-4a and interferes with mesoderm induction in Xenopus embryos. Curr Biol 10, 1511-1514.

Harland, R.M. (1991). In situ hybridization: an improved whole-mount method for Xenopus embryos. Methods Cell Biol. 36, 685-695.

Harland, R., Gerhart, J. (1997). Formation and function of Spemann's organizer. Annu Rev Cell Dev Biol. 13, 611-667.

Hartenstein, V. (1989). Early neurogenesis in Xenopus: the spatio-temporal pattern of proliferation and cell lineages in the embryonic spinal cord. Neuron. 3, 399-411.

Haugsten, E.M., Sørensen, V., Brech, A., Olsnes, S., Wesche, J. (2005). Different intracellular trafficking of FGF1 endocytosed by the four homologous FGF receptors. J. Cell. Sci. 118, 3869-3881

Heeg-Truesdell, E., LaBonne, C. (2006). Neural induction in Xenopus requires inhibition of Wnt-beta-catenin signaling. Dev. Biol. 298, 71-86.

Hollemann, T., Pieler, T. (1999). Xpitx-1: a homeobox gene expressed during pituitary and cement gland formation of Xenopus embryos. Mech Dev. 88, 249252.

Hopwood, N.D., Pluck, A., Gurdon, J.B. (1989). A Xenopus mRNA related to Drosophila twist is expressed in response to induction in the mesoderm and the neural crest. Cell 59, 893-903.

lemura, S., Yamamoto, T.S., Takagi, C., Uchiyama, H., Natsume, T., Shimasaki, S., Sugino, H., Ueno, N. (1998). Direct binding of follistatin to a complex of bonemorphogenetic protein and its receptor inhibits ventral and epidermal cell fates in early Xenopus embryo. Proc Natl Acad Sci U S A. 95, 9337-9342. 
Imai, T., Tokunaga, A., Yoshida, T., Hashimoto, M., Mikoshiba, K., Weinmaster, G., Nakafuku, M., Okano, H. (2001). The neural RNA-binding protein Musashi1 translationally regulates mammalian numb gene expression by interacting with its mRNA. Mol Cell Biol 21, 3888-3900.

Jarman, A.P., Grau, Y., Jan, L.Y., Jan, Y.N. (1993). atonal is a proneural gene that directs chordotonal organ formation in the Drosophila peripheral nervous system. Cell 73, 1307-1321.

Jarriault, S., Le Bail, O., Hirsinger, E., Pourquié, O., Logeat, F., Strong, C.F., Brou, C., Seidah, N.G., Isra, I.A. (1998). Delta-1 activation of notch-1 signaling results in HES-1 transactivation. Mol Cell Biol. 18, 7423-7431.

Jen, W.C., Wettstein, D., Turner, D., Chitnis, A., Kintner, C. (1997). The Notch ligand, X-Delta-2, mediates segmentation of the paraxial mesoderm in Xenopus embryos. Development 124, 1169-1178.

Jen, W.C., Gawantka, V., Pollet, N., Niehrs, C., Kintner, C. (1999). Periodic repression of Notch pathway genes governs the segmentation of Xenopus embryos. Genes Dev. 13, 1486-1499.

Jonas, E., Sargent, T.D., Dawid, I.B. (1985). Epidermal keratin gene expressed in embryos of Xenopus laevis. Proc Natl Acad Sci U S A. 82, 5413-5417.

Kageyama, R., Ohtsuka, T., Shimojo, H., Imayoshi, I. (2008). Dynamic Notch signaling in neural progenitor cells and a revised view of lateral inhibition. Nat Neurosci. 11, 1247-1251.

Kimelman, D. (2006). Mesoderm induction: from caps to chips. Nat Rev Genet. 7, 360-372.

Kintner, C.R., and Melton, D.A. (1987). Expression of Xenopus N-CAM RNA in ectoderm is an early response to neural induction. Development 99, 311-325.

Kishi, M., Mizuseki, K., Sasai, N., Yamazaki, H., Shiota, K., Nakanishi, S., Sasai, Y. (2000). Requirement of Sox2-mediated signaling for differentiation of early Xenopus neuroectoderm. Development 127, 791-800

Kiyota, T., Kinoshita, T. (2004). The intracellular domain of X-Serrate-1 is cleaved and suppresses primary neurogenesis in Xenopus laevis. Mech Dev. 121. 573-585

Klisch , T.J., Souopgui, J., Juergens, K., Rust, B., Pieler, T., and Henningfeld, K.A. (2006). Mxi1 is essential for neurogenesis in Xenopus and acts by bridging the pan-neural and proneural genes. Dev. Biol. 292, 470-485.

Kodjabachian, L., Lemaire, P. (1998). Embryonic induction: is the Nieuwkoop centre a useful concept? Curr Biol. 8, 918-921. 
Kroll, K.L., Salic, A.N., Evans, L.M., Kirschner, M.W. (1998). Geminin, a neuralizing molecule that demarcates the future neural plate at the onset of gastrulation. Development 125, 3247-3258.

Kuang, W., Tan, J., Duan, Y., Duan, J., Wang, W., Jin, F., Jin, Z., Yuan, X., Liu, Y. (2009). Cyclic stretch induced miR-146a upregulation delays C2C12 myogenic differentiation through inhibition of Numb. Biochem Biophys Res Commun. 378, 259-263.

Kuroda, H., Wessely, O., De Robertis, E.M. (2004). Neural induction in Xenopus: requirement for ectodermal and endomesodermal signals via Chordin, Noggin, beta-Catenin, and Cerberus. PLoS Biol. 2, e92.

Kuroda, H., Fuentealba, L., Ikeda, A., Reversade, B., and De Robertis, E.M. (2005). Default neural induction: neuralization of dissociated Xenopus cells is mediated by Ras/MAPK activation. Genes Dev. 19, 1022-1027

Kyriakakis, P., Tipping, M., Abed, L., Veraksa, A. (2008). Tandem affinity purification in Drosophila: the advantages of the GS-TAP system. Fly (Austin). 2, 229-235.

Kyriazis, G.A., Belal, C., Madan, M., Taylor, D.G., Wang, J., Wei, Z., Pattisapu, J.V., Chan, S.L. (2010). Stress-induced switch in Numb isoforms enhances Notchdependent expression of subtype-specific transient receptor potential channel. J Biol Chem. 285, 6811-6825.

Lamborghini, J.E. (1980). Rohon-beard cells and other large neurons in Xenopus embryos originate during gastrulation. J Comp Neurol. 189, 323-333.

Lecourtois, M., Schweisguth, F. (1995). The neurogenic suppressor of hairless DNA-binding protein mediates the transcriptional activation of the enhancer of split complex genes triggered by Notch signaling. Genes Dev. 9, 2598-2608.

Lee, J.E., Hollenberg, S.M., Snider, L., Turner, D.L., Lipnick, N., Weintraub, H. (1995). Conversion of Xenopus ectoderm into neurons by NeuroD, a basic helixloop-helix protein. Science. 268, 836-844.

Lee, K.W., Moreau, M., Néant, I., Bibonne, A., Leclerc, C. (2009). FGF-activated calcium channels control neural gene expression in Xenopus. Biochim Biophys Acta. 1793, 1033-1040.

Levine, A.J., Brivanlou, A.H. (2006). GDF3, a BMP inhibitor, regulates cell fate in stem cells and early embryos. Development. 133, 209-216.

Levine, A.J., Levine, Z.J., Brivanlou, A.H. (2009). GDF3 is a BMP inhibitor that can activate Nodal signaling only at very high doses. Dev Biol. 325, 43-48. 
Leyns, L., Bouwmeester, T., Kim, S.H., Piccolo, S., De Robertis, E.M. (1997). Frzb1 is a secreted antagonist of Wnt signaling expressed in the Spemann organizer. Cell 88, 747-756.

Li, H.S., Wang, D., Shen, Q., Schonemann, M.D., Gorski, J.A., Jones, K.R., Temple, S., Jan, L.Y., Jan, Y.N. (2003). Inactivation of Numb and Numblike in embryonic dorsal forebrain impairs neurogenesis and disrupts cortical morphogenesis. Neuron. 40, 1105-1118.

Louvi, A., Artavanis-Tsakonas, S. (2006). Notch signalling in vertebrate neural development. Nat Rev Neurosci. 7, 93-102.

Lu, B., Rothenberg, M., Jan, L.Y., Jan, Y.N. (1998). Partner of Numb colocalizes with Numb during mitosis and directs Numb asymmetric localization in Drosophila neural and muscle progenitors. Cell 95, 225-235.

Lu, C.B., Fu, W., Xu, X., Mattson, M.P. (2009). Numb-mediated neurite outgrowth is isoform-dependent, and requires activation of voltage-dependent calcium channels. Neuroscience. 161, 403-412.

Gaiano, N., Fishell, G. (2002). The role of notch in promoting glial and neural stem cell fates. Annu Rev Neurosci. 25, 471-490.

Ma, Q., Kintner, C., Anderson, D.J. (1996). Identification of neurogenin, a vertebrate neuronal determination gene. Cell. 87, 43-52.

Marchal, L., Luxardi, G., Thomé, V., Kodjabachian, L. (2009). BMP inhibition initiates neural induction via FGF signaling and Zic genes. Proc Natl Acad Sci U S A. $106,17437-17442$.

McGill, M.A., McGlade, C.J. (2003). Mammalian numb proteins promote Notch1 receptor ubiquitination and degradation of the Notch1 intracellular domain. J Biol Chem. 278, 23196-23203.

McGill, M.A., Dho, S.E., Weinmaster, G., McGlade, C.J. (2009). Numb regulates post-endocytic trafficking and degradation of Notch1. J Biol Chem. 284, 2642726438.

Meno, C., Saijoh, Y., Fujii, H., Ikeda, M., Yokoyama, T., Yokoyama, M., Toyoda, Y., Hamada, H. (1996). Left-right asymmetric expression of the TGF beta-family member lefty in mouse embryos.

Nature 381, 151-155.

Mitchell, T.S., Sheets, M.D. (2001). The FGFR pathway is required for the trunkinducing functions of Spemann's organizer. Dev Biol. 237, 295-305. 
Mizuseki, K., Kishi, M., Shiota, K., Nakanishi, S., Sasai, Y. (1998)a. SoxD: an essential mediator of induction of anterior neural tissues in Xenopus embryos. Neuron. 21, 77-85.

Mizuseki, K., Kishi, M., Matsui, M., Nakanishi, S., Sasai, Y. (1998)b. Xenopus Zicrelated-1 and Sox-2, two factors induced by chordin, have distinct activities in the initiation of neural induction. Development 125, 579-587.

Moody, S.A., Je, H.S. (2002). Neural induction, neural fate stabilization, and neural stem cells. Scientific World Journal 2, 1147-1166.

Moreau, M., Néant, I., Webb, S.E., Miller, A.L., Leclerc, C. (2008). Calcium signalling during neural induction in Xenopus laevis embryos. Philos Trans R Soc Lond B Biol Sci. 363, 1371-1375.

Moriyoshi, K., Richards, L.J., Akazawa, C., O'Leary, D.D., Nakanishi, S. (1996). Labeling neural cells using adenoviral gene transfer of membrane-targeted GFP. Neuron. 16, 255-260.

Nakata, K., Nagai, T., Aruga, J., Mikoshiba, K. (1997). Xenopus Zic3, a primary regulator both in neural and neural crest development. Proc Natl Acad Sci U S A. 94, 11980-11985.

Nieber, F. (2007). Diploma thesis: Function analysis of Xenopus Numb and NumbL.

Nieber, F., Pieler, T., Henningfeld, K.A. (2009). Comparative Expression Analysis of the Neurogenins in Xenopus tropicalis and Xenopus laevis. Dev Dyn. 238, 451458.

Nieuwkoop, P.D. (1952). Activation and organization of the central nervous system in amphibians. Part III. Synthesis of a new working hypothesis. J. Exp. Zool. 120, 83-108.

Nieuwkoop, P.D. (1969). The formation of mesoderm in urodelean amphibians. II. The origin of the dorso-ventral polarity of the mesoderm. W. Roux' Arch. Entwicklungsmech. Org. 163, 298-315.

Niikura, Y., Tabata, Y., Tajima, A., Inoue, I., Arai, K., Watanabe, S. (2006). Zebrafish Numb homologue: phylogenetic evolution and involvement in regulation of left-right asymmetry. Mech Dev. 123, 407-414.

Nishimura, T., Kaibuchi, K. (2007). Numb controls integrin endocytosis for directional cell migration with aPKC and PAR-3. Dev Cell. 13, 15-28.

Okano, H., Imai, T., Okabe, M. (2002). Musashi: a translational regulator of cell fate. J Cell Sci. 115, 1355-1359

Ornitz, D. M., Itoh, N. (2001). Fibroblast growth factors. Genome Biol. 2, 1-12 
Oschwald, R., Richter, K., Grunz, H. (1991). Localization of a nervous systemspecific class II beta-tubulin gene in Xenopus laevis embryos by whole-mount in situ hybridization. Int J Dev Biol. 35, 399-405.

Ostrakhovitch, E.A. (2009). Interplay between Numb and Notch in epithelial cancers: role for dual oxidase maturation factor. Eur J Cancer. 45, 2071-2076.

Papalopulu, N., Kintner, C. (1996). A posteriorising factor, retinoic acid, reveals that anteroposterior patterning controls the timing of neuronal differentiation in Xenopus neuroectoderm. Development 122, 3409-3418.

Pedersen, W.A., Chan, S.L., Zhu, H., Abdur-Rahman, L.A., Verdi, J.M., Mattson, M.P. (2002). Numb isoforms containing a short PTB domain promote neurotrophic factor-induced differentiation and neurotrophic factor withdrawalinduced death of PC12 Cells. J Neurochem. 82, 976-986.

Penzel, R., Oschwald, R., Chen, Y., Tacke, L., Grunz, H. (1997). Characterization and early embryonic expression of a neural specific transcription factor XSOX3 in Xenopus laevis. Int J Dev Biol. 41, 667-677.

Pera, E.M., De Robertis, E.M. (2000). A direct screen for secreted proteins in Xenopus embryos identifies distinct activities for the Wnt antagonists Crescent and Frzb-1. Mech Dev. 96, 183-195.

Pera, E.M., Ikeda, A., Eivers, E., De Robertis, E.M. (2003). Integration of IGF, FGF, and anti-BMP signals via Smad1 phosphorylation in neural induction. Genes Dev. $17,3023-3028$

Peres, J.N., Durston, A.J. (2006). Role of X-Delta-2 in the early neural development of Xenopus laevis. Dev Dyn. 235, 802-810.

Petersen, P.H., Zou, K., Hwang, J.K., Jan, Y.N., Zhong, W. (2002). Progenitor cell maintenance requires numb and numblike during mouse neurogenesis. Nature. 419(6910):929-34.

Petersen, P.H., Zou, K., Krauss, S., Zhong, W. (2004). Continuing role for mouse Numb and Numbl in maintaining progenitor cells during cortical neurogenesis. Nat Neurosci. 7, 803-811.

Piccolo, S., Agius, E., Leyns, L., Bhattacharyya, S., Grunz, H., Bouwmeester, T., De Robertis, E.M. (1999). The head inducer Cerberus is a multifunctional antagonist of Nodal, BMP and Wnt signals. Nature 397, 707-710.

Pozzoli, O., Bosetti, A., Croci, L., Gonzales, G.G., Vetter, M.L. (2001). Xebf3 is a regulator of neuronal differentiation during primary neurogenesis in Xenopus. Dev Biol. 233, 495-512. 
Rennstam, K., McMichael, N., Berglund, P., Honeth, G., Hegardt, C., Rydén, L., Luts, L., Bendahl, P.O., Hedenfalk, I. (2010). Numb protein expression correlates with a basal-like phenotype and cancer stem cell markers in primary breast cancer. Breast Cancer Res Treat. 122, 315-324.

Reugels, A.M., Boggetti, B., Scheer, N., Campos-Ortega, J.A. (2006). Asymmetric localization of Numb:EGFP in dividing neuroepithelial cells during neurulation in Danio rerio. Dev Dyn. 235, 934-948.

Rhyu, M.S., Jan, L.Y., Jan, Y.N. (1994). Asymmetric distribution of numb protein during division of the sensory organ precursor cell confers distinct fates to daughter cells. Cell 76, 477-491.

Sambrook and Russell (2001). Molecular Cloning: A Laboratory Manual (3rd ed.). Cold Spring Harbor Laboratory Press

Santolini, E., Puri, C., Salcini, A.E., Gagliani, M.C., Pelicci, P.G., Tacchetti, C., Di Fiore, P.P. (2000). Numb is an endocytic protein. J Cell Biol. 151, 1345-1352.

Sasai, Y., Lu, B., Steinbeisser, H., De Robertis, E.M. (1995). Regulation of neural induction by the Chd and BMP-4 antagonistic patterning signals in Xenopus. Nature 377, 757-759

Sasai, Y., Lu, B., Piccolo, S., De Robertis, E.M. (1996). Endoderm induction by the organizer-secreted factors chordin and noggin in Xenopus animal caps. EMBO J. $15,4547-4555$.

Saxen, L. and Toivonen, S. (1962). Primary Embryonic Induction. Logos Press, Academic Press (Lond.)

Schlosser, G. (2006). Induction and specification of cranial placodes. Dev Biol 294, 303-351.

Schneider, M.L., Turner, D.L., Vetter, M.L. (2001). Notch signaling can inhibit Xath5 function in the neural plate and developing retina. Mol Cell Neurosci. 5, 458-472.

Seo, S., Richardson, G.A. and Kroll, K.L. (2005). The SWI/SNF chromatin remodeling protein Brg1 is required for vertebrate neurogenesis and mediates transactivation of Ngn and NeuroD. Development 132, 105-115.

Seo, S., Lim, J.W., Yellajoshyula, D., Chang, L.W., Kroll, K.L. (2007). Neurogenin and NeuroD direct transcriptional targets and their regulatory enhancers. EMBO J. 26, 5093-5108.

Shibita, K., Ishimura, A., Maeno, M. (1998). GATA-1 inhibits the formation of notochord and neural tissue in Xenopus. Biochem Biophys Res Commun. 252, 241-248. 
Shivdasani, R.A. (2002). Molecular regulation of vertebrate early endoderm development. Dev Biol. 249, 191-203.

Smith, W.C., Knecht, A.K., Wu, M., Harland, R.M. (1993). Secreted noggin protein mimics the Spemann organizer in dorsalizing Xenopus mesoderm. Nature 361, 547-549.

Spemann, H., Mangold, H. (1924). Über Induktion von Embryonalanlagen durch Implantation artfremder Organisatoren. Arch. mikr. Anat. und Entw. mech. 100, 599-638

Spemann, H. (1931). Das Verhalten von Organisatoren nach Zerstörung ihrer Struktur. Verh. d. D. Zool. Ges. 129-132.

Sölter, M., Köster, M., Hollemann, T., Brey, A., Pieler, T., Knöchel, W. (1999). Characterization of a subfamily of related winged helix genes, XFD-12/12'/12" (XFLIP), during Xenopus embryogenesis. Mech Dev. 89, 161-165.

Sommer, L., Ma, Q., Anderson, D.J. (1996). neurogenins, a novel family of atonalrelated bHLH transcription factors, are putative mammalian neuronal determination genes that reveal progenitor cell heterogeneity in the developing CNS and PNS. Mol Cell Neurosci., 8, 221-241

Sorensen, E.B., Conner, S.D. (2008). AAK1 regulates Numb function at an early step in clathrin-mediated endocytosis. Traffic. 9, 1791-1800.

Souopgui, J., Sölter, M., Pieler, T. (2002). XPak3 promotes cell cycle withdrawal during primary neurogenesis in Xenopus laevis. EMBO J. 21, 6429-39.

Takahashi, S., Yokota, C., Takano, K., Tanegashima, K., Onuma, Y., Goto, J., Asashima, M. (2000). Two novel nodal-related genes initiate early inductive events in Xenopus Nieuwkoop center. Development 127, 5319-5329.

Thisse, C., Thisse, B. (1999). Antivin, a novel and divergent member of the TGFbeta superfamily, negatively regulates mesoderm induction. Development 126, 229-240.

Tokumitsu, H., Hatano, N., Yokokura, S., Sueyoshi, Y., Nozaki, N., Kobayashi, R. (2006). Phosphorylation of Numb regulates its interaction with the clathrinassociated adaptor AP-2. FEBS Lett. 580, 5797-5801.

Tonissen, K.F., Krieg, P.A. (1993). Two neural-cell adhesion molecule (NCAM)encoding genes in Xenopus laevis are expressed during development and in adult tissues. Gene. 127, 243-247. 
Toriya, M., Tokunaga, A., Sawamoto, K., Nakao, K., Okano, H. (2006). Distinct functions of human numb isoforms revealed by misexpression in the neural stem cell lineage in the Drosophila larval brain. Dev Neurosci. 28, 142-155.

Uemura, T., Shepherd, S., Ackerman, L., Jan, L.Y., Jan, Y.N. (1989). numb, a gene required in determination of cell fate during sensory organ formation in Drosophila embryos. Cell 58, 349-360.

Uwanogho, D., Rex, M., Cartwright, E.J., Pearl, G., Healy, C., Scotting, P.J., Sharpe, P.T. (1995). Embryonic expression of the chicken Sox2, Sox3 and Sox11 genes suggests an interactive role in neuronal development. Mech Dev. 49, 23-36.

Van Doren, M., Powell, P.A., Pasternak, D., Singson, A., Posakony, J.W. (1992). Spatial regulation of proneural gene activity: auto- and cross-activation of achaete is antagonized by extramacrochaetae. Genes Dev. 6, 2592-2605.

Verdi, J.M., Schmandt, R., Bashirullah, A., Jacob, S., Salvino, R., Craig, C.G., Program, A.E., Lipshitz, H.D., McGlade, C.J. (1996). Mammalian NUMB is an evolutionarily conserved signaling adapter protein that specifies cell fate. Curr Biol. 6 1134-1145.

Verdi, J.M., Bashirullah, A., Goldhawk, D.E., Kubu, C.J., Jamali, M., Meakin, S.O., Lipshitz, H.D. (1999). Distinct human NUMB isoforms regulate differentiation vs. proliferation in the neuronal lineage. Proc Natl Acad Sci U S A. 96. 10472-10476.

Vernon, A.E., Devine, C., Philpott, A. (2003). The cdk inhibitor p27Xic1 is required for differentiation of primary neurones in Xenopus. Development 130, 85-92.

Vosper, J.M., McDowell, G.S., Hindley, C.J., Fiore-Heriche, C.S., Kucerova, R., Horan, I., Philpott, A. (2009). Ubiquitylation on canonical and non-canonical sites targets the transcription factor neurogenin for ubiquitin-mediated proteolysis. J Biol Chem. 284, 15458-15468.

Wakamatsu, Y., Maynard, T.M., Jones, S.U., Weston, J.A. (1999). NUMB localizes in the basal cortex of mitotic avian neuroepithelial cells and modulates neuronal differentiation by binding to NOTCH-1. Neuron. 1, 71-81.

Wang, H., Ouyang, Y., Somers, W.G., Chia, W., Lu, B. (2007). Polo inhibits progenitor self-renewal and regulates Numb asymmetry by phosphorylating Pon. Nature 449, 96-100.

Wang, S., Younger-Shepherd, S., Jan, L.Y., Jan, Y.N. (1997). Only a subset of the binary cell fate decisions mediated by Numb/Notch signaling in Drosophila sensory organ lineage requires Suppressor of Hairless. Development 124, 44354446.

Wegner, M., Stolt, C.C. (2005). From stem cells to neurons and glia: a Soxist's view of neural development. Trends Neurosci. 28, 583-588. 
Westhoff, B., Colaluca, I.N., D'Ario, G., Donzelli, M., Tosoni, D., Volorio, S., Pelosi, G., Spaggiari, L., Mazzarol, G., Viale, G., Pece, S., Di Fiore, P.P. (2009). Alterations of the Notch pathway in lung cancer. Proc Natl Acad Sci U S A. 106, 22293-22298.

Wettstein, D.A., Turner, D.L., Kintner, C. (1997). The Xenopus homolog of Drosophila Suppressor of Hairless mediates Notch signaling during primary neurogenesis. Development 124, 693-702.

Wills, A.E., Choi, V.M., Bennett, M.J., Khokha, M.K., Harland, R.M. (2010). BMP antagonists and FGF signaling contribute to different domains of the neural plate in Xenopus. Dev Biol. 337, 335-350.

Wirtz-Peitz, F., Nishimura, T., Knoblich, J.A., (2008). Linking cell cycle to asymmetric division: Aurora-A phosphorylates the Par complex to regulate Numb localization. Cell 135, 161-173.

Wullimann, M.F., Rink, E., Vernier, P., Schlosser, G. (2005). Secondary neurogenesis in the brain of the African clawed frog, Xenopus laevis, as revealed by PCNA, Delta-1, Neurogenin-related-1, and NeuroD expression. J Comp Neurol. 489, 387-402.

Yan, B., Neilson, K.M., Moody, S.A. (2009)a. Notch signaling downstream of foxD5 promotes neural ectodermal transcription factors that inhibit neural differentiation. Dev Dyn. 238, 1358-1365.

Yan, B., Neilson, K.M., Moody, S.A., (2009)b. foxD5 plays a critical upstream role in regulating neural ectodermal fate and the onset of neural differentiation. Dev Biol. 329, 80-95.

Zhong, W., Feder, J.N., Jiang, M.M., Jan, L.Y., Jan, Y.N. (1996). Asymmetric localization of a mammalian numb homolog during mouse cortical neurogenesis. Neuron. 17, 43-53.

Zhong, W., Jiang, M.M., Weinmaster, G., Jan, L.Y., Jan, Y.N. (1997). Differential expression of mammalian Numb, Numblike and Notch1 suggests distinct roles during mouse cortical neurogenesis. Development 124, 1887-1897.

Zhong, W., Jiang, M.M., Schonemann, M.D., Meneses, J.J., Pedersen, R.A., Jan, L.Y., Jan, Y.N. (2000). Mouse numb is an essential gene involved in cortical neurogenesis. Proc Natl Acad Sci U S A. 97, 6844-6849.

Zhou, Y., Atkins, J.B., Rompani, S.B., Bancescu, D.L., Petersen, P.H., Tang, H., Zou, K., Stewart, S.B., Zhong, W. (2007). The mammalian Golgi regulates numb signaling in asymmetric cell division by releasing ACBD3 during mitosis. Cell 129, 163-178. 
Zimmerman, L.B., De Jesús-Escobar, J.M., Harland, R.M. (1996). The Spemann organizer signal noggin binds and inactivates bone morphogenetic protein 4 . Cell 86, 599-606. 


\section{Appendix}

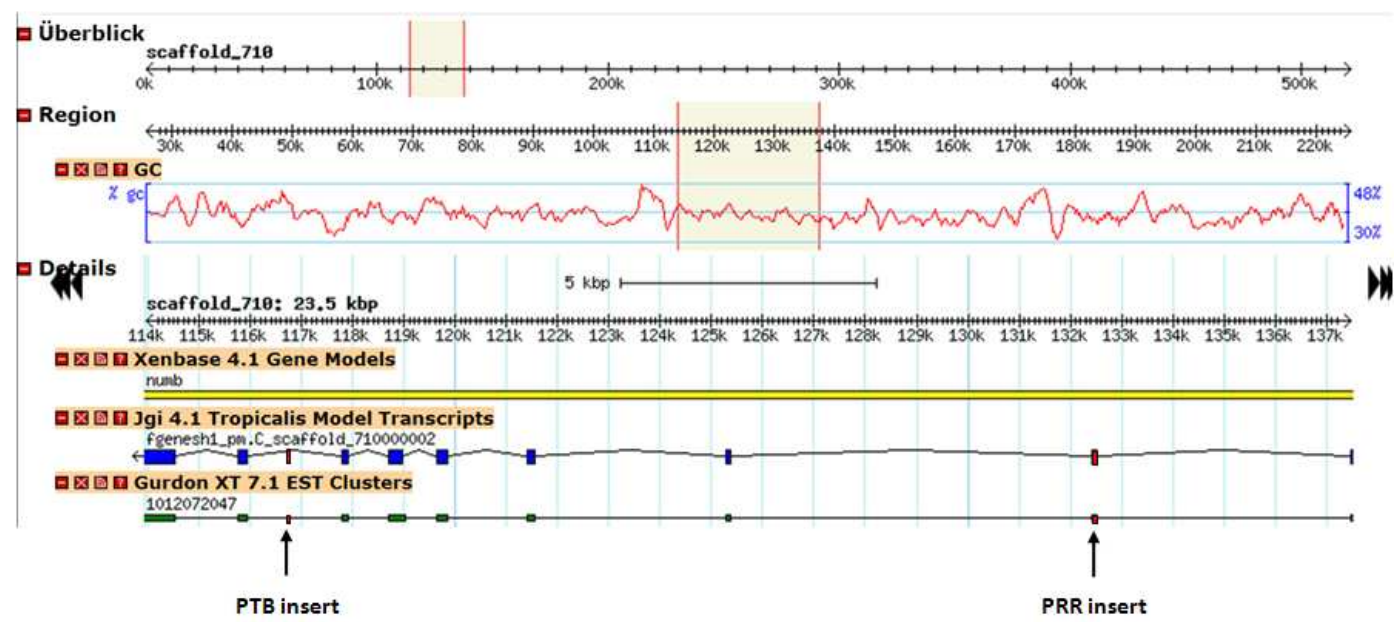

Xt Numb cDNA:

ATGAACAAACTGCGTCAGAGTTTTCGGCGGAAGAAAGATATCTATGTCCCAGAGGCAAGCCGA CCCCACCAGTGGCAAACTGACGAAGAATCGGTCAGGAATGGGAAATGTAGCTTTCAAGTTAAG TATCTCGGCCATGTGGAAGTAGAGGAATCAAGAGGGATGCACATCTGCGAAGAAGCAGTGAAA AGATTAAAATCTGAAAGGAAGTACTTCAAAGGCTTCTTTGCAAAAAGCGGCAAGAAAGCAATCA AGGCCGTCCTGTGGGTTTCAGCTGATGGACTTCGAGTTGTGGATGAAAAGACAAAGGATCTTCT GGTTGACCAGACTATTGAGAAAGTCTCCTTCTGTGCTCCAGATAGAAATTTTGACAGAGCCTTTT CTTATATCTGTCGTGATGGTACAACTAGGCGATGGATCTGTCACTGCTTCATGGCTGTTAAAGAT ACGGGCGAGAGGCTCAGCCATGCTGTTGGATGTGCATTTGCTGCTTGTCTTGAGAGGAAGCAG AAGCGGGAAAAGGAGTGTGGAGTGACTGCTACATTTGATGCCAGCAGAACTACTTTCACCCGG GAAGGCTCTTTCAGGGTCACCACAGCCACAGAGCAAGCAGAGAGAGAGGAAGTCATGAAGCA GATACAGGAATCCAGGAAAGAGCTGGAAGTGAAAGCACCAGTCGTACCAGCAGCACCTTCAAC AACTGTGTCTTCCACTCCAACCCCAGTGCTACAATCCTCTCCAACCTCTGAGGTGTTTGTGGTCCA GGACAGTAAAGATCTAAATTACCCCCATGCAATCCCTCGAAGGCATGCTCCTGTGGAACAGCTT GCCAGACAGGGCTCCTTCCGGGGTTTTCCTGCTCTCAGCCAAAAAATGTCCCCATTCAAGCGTCA GCTTTCCTTAAGGATCAATGAGCTGCCATCAACTGTTCAAAGAAAATCTGACTTTCAGGCTACAA ATCCAGTTGCAGAGATGGAAGGAGAAAACGACAGCATAAGTGCCCTGTGTTCCCAGATCACAA ACACTTTCAGCATGCCACCTGAGGATCCATTCACTTCTGCGCCCATGACTAAAGCCACCACACCA CAGTCCCCACCTTTTGGAGTAAATGGCACTGCCTCTGCATTCAGTTTGCCTGCTGCTACACCAAC ACCAATCTCTGTAACCAGCACCGCAGCAGCACCTGTGCGTGAGACCAACCCTTGGGCAAATGCT CCCGCGGCTTCTAACTTACCAGTCACTACCACTGGGACACTGTCTGTAGCCCCCTTAGTTGGTCC TGTCCCTTCATCTGGTACTCACCAGTCAAACCACAAACGAACACCCTCTGAGGCAGACCGTTGGC TTGAAGAAGTATCCAAAACAATCATGCAAAGACAGTCTCCAGTTCCTGCAGTCCCAACTCAGCCT ATGGTACAACCTGCCCTTGCCGCACCACAGCCTAACCAGCCTTACCTGGCCAATGCTTATGTGAC CTCACAGTCTATGCCTGTCTCTGTTGTCCCAGGTCTGCACCCTCCCTTCATGCCTGTGCAGCCACC ATACTCTGTAGCCAATGGAATGAGCTACCCAGCTTCCAGTGTTCCAGTTGTTGGCATAACCCCTT CTCAAATGGTAGCTAATGTTTTCGGAGTTGCAAGTCCACAGGTATTCCAGCCTAAGCCATCTCCA AATTTAGCCACACAGCAAACCTATCCAACTTATGAAGCATCCAGTGCATCCAGCAGTCCATTCTA 
TAAGCCTCCTGCCCAGCAACAGAATGGCTCTGTTGCTTTTAATGGGGTTGAAAGTAGTGGGTGG GAATTGGGCGCTAAGAGCCAGCAAGCTCCAGCTGCCCCTCCTCCTGTAGACCCATTTGAAGCTC AATGGGCAGCTCTTGAAGGCAAATCTAGACCACGTGCAAACCCATCTCCTACAAATCCTTTCTCT AGTGACCTTCAAAAGACTTTTGAAATTGAACTATAG

$X t$ Numb protein:

MNKLRQSFRRKKDIYVPEASRPHQWQTDEESVRNGKCSFQVKYLGHVEVEESRGMHICEEAVKRLK SERKYFKGFFAKSGKKAIKAVLWVSADGLRVVDEKTKDLLVDQTIEKVSFCAPDRNFDRAFSYICRDG TTRRWICHCFMAVKDTGERLSHAVGCAFAACLERKQKREKECGVTATFDASRTTFTREGSFRVTTAT EQAEREEVMKQIQESRKELEVKAPVVPAAPSTTVSSTPTPVLQSSPTSEVFVVQDSKDLNYPHAIPRR HAPVEQLARQGSFRGFPALSQKMSPFKRQLSLRINELPSTVQRKSDFQATNPVAEMEGENDSISALC SQITNTFSMPPEDPFTSAPMTKATTPQSPPFENGTASAFSLPAATPTPISVTSTAAAPVRETNPWAN APAASNLPVTTTGTLSVAPLVPVPSSGTHQSNHKRTPSEADRWLEEVSKTIMQRQSPVPAVPTQPM VQPALAAPQPNQPYLANAYVTSQSMPVSVVPGLHPPFMPVQPPYSVANGMSYPASSVPVVGITPS QMVANVFGVASPQVFQPKPSPNLATQQTYPTYEASSASSSPFYKPPAQQQNGSVAFNGVESSGW ELGAKSQQAPAAPPPVDPFEAQWAALEGKSRPRANPSPTNPFSSDLQKTFEIEL

Appendix Figure 1: Genomic structure of $X$. tropicalis Numb and identified insert sequences. Schematic representation of scaffold_710, 113,854 - 137,594 (Xenopus tropicalis genome draft 4.1), showing the $X t$ Numb gene locus. Relative positions of the PTB and the PRR exon are indicated by arrows. In the CDNA and peptide sequence of Xt Numb, the identified PTB insert is shown in blue and the PRR insert in green. (genome draft source: http://www.xenbase.org/fgb2/gbrowse/Xenopus tropicalis 4 1/?name=scaffold 710:1 $\underline{13854-137594}$, modified) 


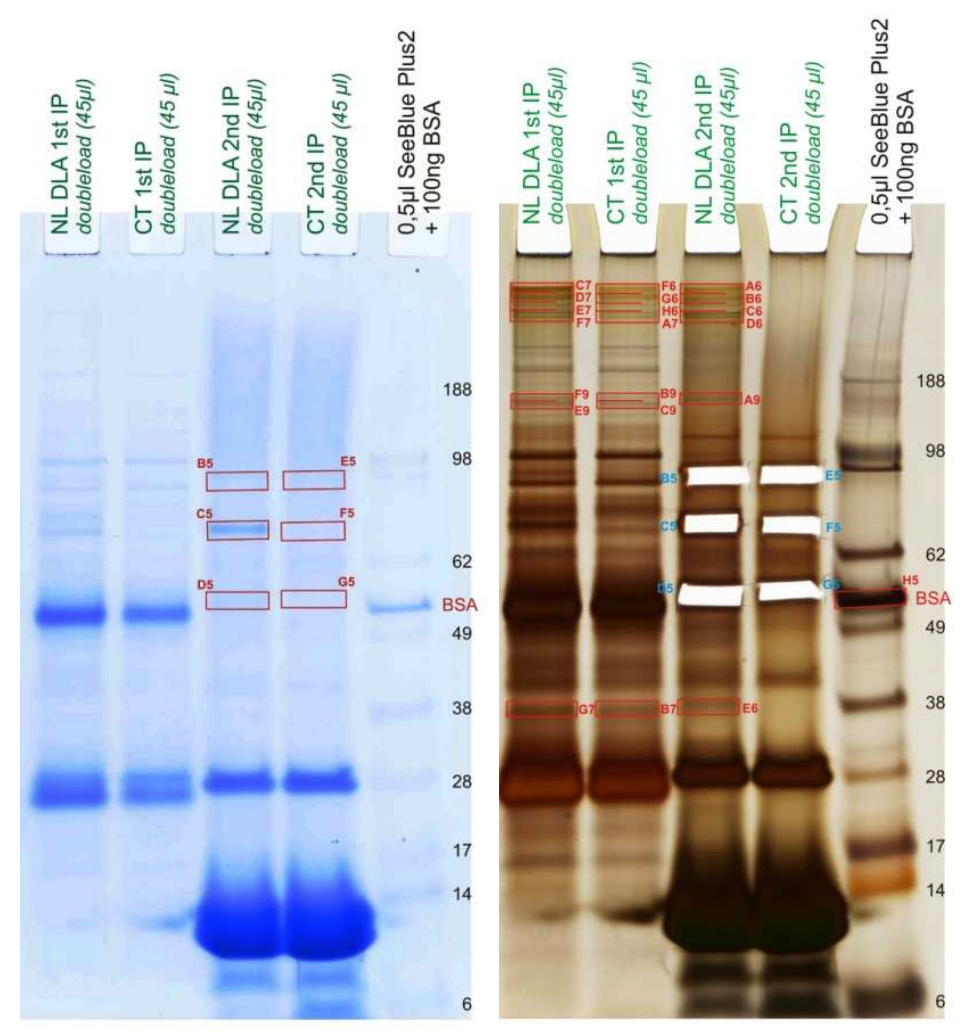

Appendix Figure 2: Tandem affinity purification of NumbL DLA-CTap. 4\%-12\% gradient gel showing the samples of subsequent pulldown steps. Left hand panel shows colloidal coomassie staining, right hand panel silver stained gel. Excised gel bands are marked by boxes. C5 was identified by mass spectrometry as NumbL DLA-CTap. Gradient gel and mass spectrometry were performed by Dr. Olaf Jahn (MPI for Experimental Medizine, Göttingen, Germany). 
Name: $\quad$ Nieber, Frank

Date of Birth: 11.01 .1982

Born in: Celle, Germany

Nationality: German

Address: $\quad$ Frank Nieber

Kaakweg 1c

37077 Göttingen, Germany

Email: Frank_Nieber@gmx.de

\section{Education:}

07.2007 - 10.2010 PhD Thesis "Function analysis of Xenopus NumbL in the context of primary neurogenesis" Department of Developmental Biochemistry, University of Göttingen

Advisor: Prof. Tomas Pieler, Supervisors: K.A. Henningfeld, PhD.

06.2006-06.2007 Diploma Thesis "Function analysis of Xenopus Numb and NumbL". Department of Developmental Biochemistry, University of Göttingen,

Advisor: Prof. Tomas Pieler, Supervisor: K.A. Henningfeld, PhD

10.2002-05.2006 Study of Biology at the University of Göttingen. Oral diploma examinations on 12.05.2006. Major subject: Biochemistry; Minor subjects: Microbiology and Organic Chemistry.

\section{Fellowships:}

09.2008-01.2011 GGNB Excellence Stipend

\section{Publications:}

Frank Nieber, Tomas Pieler, Olaf Jahn, and Kristina A. Henningfeld. NumbL is essential for Xenopus primary neurogenesis and functions independent of Notch signaling. In preparation

Frank Nieber, Tomas Pieler, and Kristine A. Henningfeld. Comparative Expression Analysis of the Neurogenins in Xenopus tropicalis and Xenopus laevis. Dev Dyn. 2009 238:451-458

Göttingen, 29.11.2010 